\title{
Evaluation of a Functional Interconnect System for SOFCs
}

\author{
Final Scientific/Technical Report \\ Start Date: July 01, 2005 \\ Project End Date: December 31, 2010
Matthew D. Bender, Ph.D. (Principal Author)
ATI Allegheny Ludlum
James M. Rakowski, Ph.D.
ATI Allegheny Ludlum
DOE Project Manager: Robin Ames
National Energy Technology Laboratory

Final Report Issued: March 31, 2011

DOE Award Number: DE-FC26-05NT42513

ATI Allegheny Ludlum

\author{
An Allegheny Technologies Company \\ 100 River Road \\ Brackenridge, PA 15014
}




\section{$\underline{\text { Disclaimer }}$}

This report was prepared as an account of work sponsored by an agency of the United States Government. Neither the United States Government nor any agency thereof, nor any of their employees, makes any warranty, express or implied, or assumes any legal liability or responsibility for the accuracy, completeness, or usefulness of any information, apparatus, product, or process disclosed, or represents that its use would not infringe privately owned rights. Reference herein to any specific commercial product, process, or service by trade name, trademark, manufacturer, or otherwise does not necessarily constitute or imply its endorsement, recommendation, or favoring by the United States Government or any agency thereof. The views and opinions of authors expressed herein do not necessarily state or reflect those of the United States Government or any agency thereof. 


\begin{abstract}
The overall objective of this project was to validate the concept and application of a functional interconnect, based on a ferritic stainless steel, for a solid oxide fuel cell through manufacturing trials, laboratory testing, and field experience. The materials of construction and their surfaces were to be optimized for the particular service conditions and include low-cost ferritic stainless steels, novel postprocess treatments, and third-party coatings. This work aimed to optimize specific aspects of substrate alloy chemistry and to study the effects of long-term exposures on resistive oxide film structure and chemistry, interaction with applied surface coatings, and effectiveness of novel surface treatments.
\end{abstract}




\section{$\underline{\text { Table of Contents }}$}

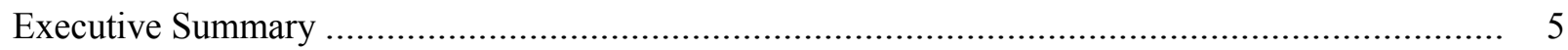

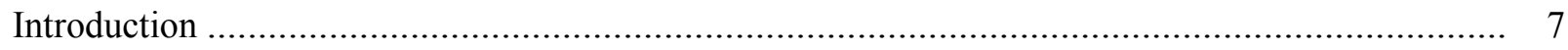

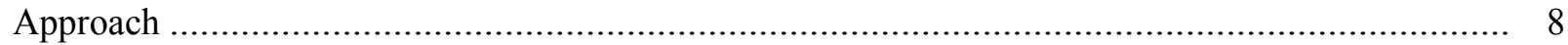

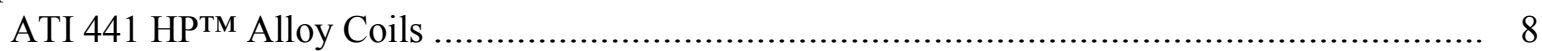

Post-Processing Surface Modification of ATI 441 HP Alloy ...................................................... 9

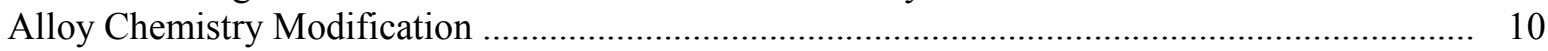

Low-Chromium Experimental Alloys .................................................................................. 11

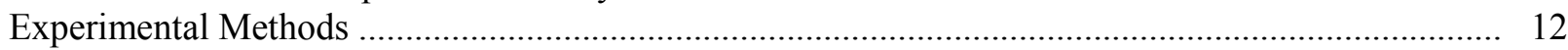

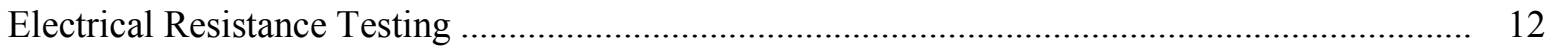

Oxidation Testing in Humidified Environment / Controlled Atmospheres ................................... 13

Oxidation Testing in Lab Atmosphere ................................................................................... 13

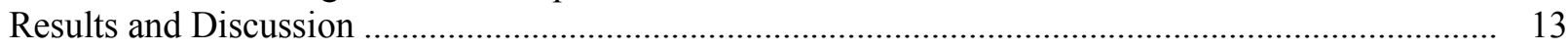

2nd-Generation Experimental Alloys: Oxidation Test Results ………………………………. 13

2nd-Generation Experimental Alloys: Electrical Resistance Test Results .................................... 14

3rd-Generation Experimental Alloys: Electrical Resistance Test Results ..................................... 15

2nd-Generation Experimental Alloys: Breakaway Event Analysis .............................................. 16

Surface-Modified ATI 441 HP Alloy: Electrical Resistance Test Results ..................................... 18

3rd-Generation Experimental Alloys: Long-Term Oxidation Testing ………............................ 18

Surface-Modified ATI 441 HP Alloy: Long-Term Oxidation Testing ......................................... 20

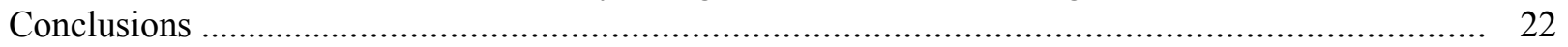

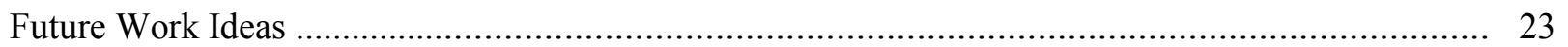

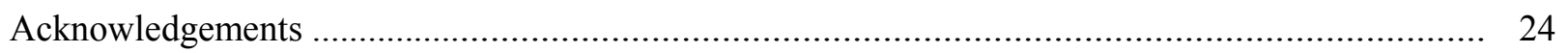

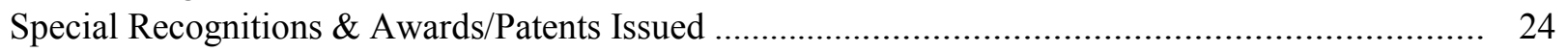

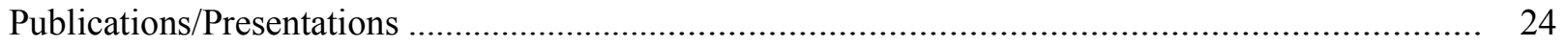

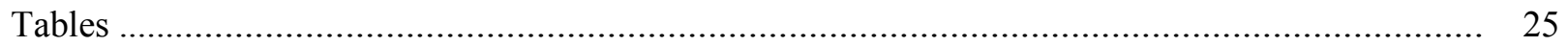

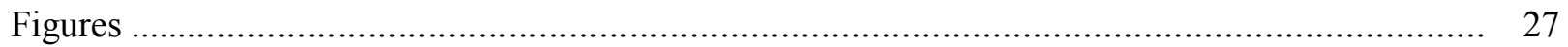

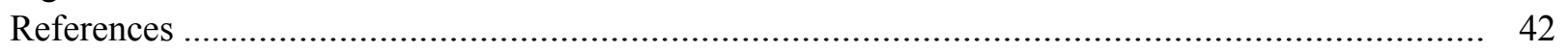

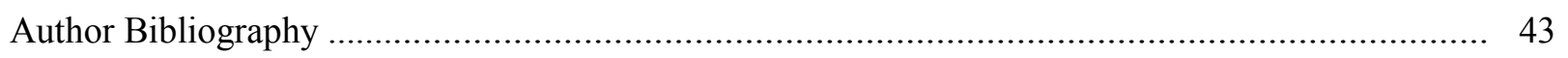

List of Acronyms and Abbreviations ................................................................................. 44

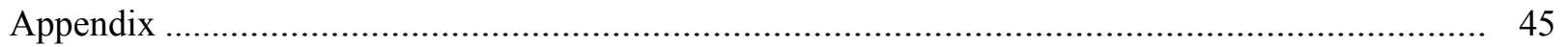




\section{$\underline{\text { Executive Summary }}$}

The maturing solid oxide fuel cell (SOFC) industry has a need for a robust and cost-effective interconnect component. SOFCs are now operating at temperatures where stainless steel can be considered for replacing ceramic for fabricating the interconnect component. Due to its knowledge and experience working with alloys for high temperature service and an interest in the fuel cell market, ATI Allegheny Ludlum embarked on a multi-year project with funding from the Department of Energy (DOE) to evaluate a functional interconnect system for planar SOFCs.

An initial survey and characterization of various commercial ferritic stainless steel alloys helped to focus this research on two compositions: a Fe-17Cr composition such as ATI 441 HPTM alloy, and a higherchromium composition such as ATI E-BRITE ${ }^{\circledR}$ alloy. At a typical SOFC operating temperature (e.g. $800^{\circ} \mathrm{C}$ ), a metallic interconnect will develop a thermally grown oxide (TGO) that becomes a part of the electrical circuit of the fuel cell stack. These electrically resistive surface oxides can be a source of degradation of stack performance. Ferritic stainless steels are a good choice for a metallic SOFC interconnect because they form chromium oxide, which is an electrically conductive TGO scale at SOFC operating temperatures, and because ferritic alloys have a good coefficient of thermal expansion match to other fuel cell stack components, have good formability, and are relatively inexpensive to manufacture. This research aimed to validate the concept and the application of a functional interconnect based on a ferritic stainless steel through laboratory testing and manufacturing trials.

Two approaches were considered for improving the functionality of a SOFC interconnect. The first approach was to optimize the materials of construction for SOFC service conditions and the second was to optimize the surface of a material for SOFC service conditions. Electrical resistance testing and oxidation testing were used to characterize the effect of each modification to the ferritic stainless steel. One disadvantage to using chromia-forming alloys for an SOFC interconnect is that they are likely to suffer from chromium volatization in the SOFC cathode environment. The Pacific Northwest National Laboratory developed a cerium-modified $(\mathrm{Mn}, \mathrm{Co})_{3} \mathrm{O}_{4}$ spinel coating for the cathode side of an interconnect to limit the chromium volatization. This coating was very effective in improving the longtime performance of tested coupons. Therefore, many of the test coupons were tested with the applied spinel coating.

A number of experimental alloys were designed to be similar to either ATI $441 \mathrm{HP}$ alloy or ATI E-BRITE alloy and a matrix analysis was carried out to look at the critical elements (i.e. $\mathrm{Cr}, \mathrm{Mn}, \mathrm{Nb}, \mathrm{Si}$ ) in these alloys. Each alloy was melted as a fifty-pound ingot and processed by hot-rolling, cold-rolling, and annealing to sheet thicknesses. Variations in chemistry were then related to high-temperature performance in either an ambient air environment or a simulated cathode gas (humidified air). Performance was characterized through oxidation weight change measurements, electrical resistance testing measuring a potential difference across metallic plates in an area specific resistance (ASR) test stand, and scanning electron microscopy. A spinel-coated ATI 441 HP alloy coupon (commercial composition) had the best long-term electrical resistance performance as measured by ASR testing. This material is expected to meet the 40,000 hour lifetime requirement of a SOFC with a rate of ASR evolution of $0.8 \mathrm{~m} \Omega \cdot \mathrm{cm}^{2} / 1,000 \mathrm{~h}$ versus the target of less than $2.5 \mathrm{~m} \Omega \cdot \mathrm{cm}^{2} / 1,000 \mathrm{~h}$. Some of the experimental alloy chemistry modifications gave similar performance, but none improved the long-term electrical resistance in air at $800^{\circ} \mathrm{C}$. Oxidation testing of $\mathrm{Fe}-17 \mathrm{Cr}$ alloys showed that concerning the potential for breakaway oxidation, there is likely an optimal silicon level that is less than that contained in the commercial AISI 441 alloy (nominally 0.40 weight percent), but not as low as possible, as demonstrated through a 0.05 weight percent silicon-containing Fe-17Cr alloy. The rates of ASR evolution of those experimental alloys with decreased silicon contents were not as favorable in the ASR testing. 
A manganese addition to the higher-chromium experimental alloys modeled after ATI E-BRITE alloy was found to be beneficial. Results indicated that manganese may have a positive role, even on spinelcoated samples where the ability to form a manganese chromite layer is not critical to reduce chromia evaporation. $\mathrm{MnCr}_{2} \mathrm{O}_{4}$ has lower resistance than $\mathrm{Cr}_{2} \mathrm{O}_{3}$. Higher-chromium alloys also exhibited relatively low rates of ASR evolution, with a trend towards decreased rates as a function of chromium content.

Four post-process surface modifications were evaluated on sample material obtained from production coils of ATI $441 \mathrm{HP}$ alloy. Three of the surface modification approaches explored methods to modify the sub-surface grain structure as a means to improve the diffusion of chromium to the surface, thus improving the oxide scale formation. Surface blasting and grinding were methods to alter the near-surface grain structure, while temper rolling (50 percent reduction) was a method to alter the through-thickness grain structure. The fourth surface modification was a desiliconization treatment, developed to selectively remove silicon from the ferritic stainless steel surface. Desiliconization aimed to minimize the formation of electrically resistive oxides (i.e. silica) in favor of promoting the formation of favorable electrically conductive oxides (i.e. chromia), in order to decrease the resistance across an interconnect. The surface modifications neither improved nor deteriorated the ASR of the ATI 441 HP coupons substantially, but some of them did result in improved spallation resistance for spinel-coated ATI 441 HP coupons compared to mill reference material. Based on the results, surface blasting appeared to be the most promising surface modification.

This project successfully demonstrated the long-term stability of various ferritic stainless steels studied in a simulated SOFC environment. Specifically, coated, commercial ATI $441 \mathrm{HP}$ alloy and coated, modified ATI E-BRITE alloy containing manganese were among the best performing alloys. This work supports the justification of fabricating intermediate-temperature SOFC interconnects from low-cost ferritic stainless steels, particularly when the interconnect is coated with a cerium-modified $(\mathrm{Mn}, \mathrm{Co})_{3} \mathrm{O}_{4}$ spinel coating on the cathode side. 


\section{Introduction}

Fuel cells are electrochemical energy conversion under consideration for both stationary applications and auxiliary power units (APUs) for mobile applications. In recent years, progress in materials and fabrication techniques have allowed for a reduction in solid oxide fuel cell (SOFC) operating temperatures to a range in which commonly used oxidation-resistant alloys, such as ferritic stainless steels, can be considered as replacement materials for the traditional ceramic interconnect materials used in high temperature SOFC stacks. The high operating temperature of a SOFC (between $650-1000^{\circ} \mathrm{C}$ ) improves energy conversion efficiency and makes on-cell or in-stack reformation of hydrocarbon fuels feasible allowing for fuel flexibility ${ }^{[1]}$, which makes it possible for a SOFC to run on hydrogen or less pure hydrogen-containing gases such as syngas. The tradeoff is that a high temperature environment can cause increased materials degradation and accelerated oxidation, so material selection becomes increasingly important.

A solid oxide fuel cell consists of a fully-dense electrolyte separating two electrodes. The electrolyte conducts oxygen ions to allow the air and fuel to react while causing the electrons to travel on an external circuit between the electrodes whereby producing electricity. Fuel is oxidized at the anode and oxygen is reduced at the cathode. A SOFC interconnect in a planar stack design separates the fuel and oxidant gases while connecting individual cells into an electrical series in a cell stack. The interconnect material is simultaneously exposed to air on the cathode side and fuel on the anode side; therefore, the material must be stable in both oxidizing and reducing environments ${ }^{[2]}$.

Although ceramic interconnects tend to be more stable, the advantages of metallic interconnects are lower cost and ease of fabrication. Interconnect alloy selection has been defined as an important issue impeding the commercialization of SOFCs, with the focus being on the use of inexpensive substrates in conjunction with special processing or coatings ${ }^{[3,4]}$. At elevated temperature, a metallic interconnect will develop a thermally grown oxide (TGO) on its surface, which becomes part of the electrical circuit of the fuel cell. Interconnects can be a source of degradation of fuel cell stack performance by the formation and growth of these electrically resistive surface oxide layers ${ }^{[5]}$, thus it is critical to control which types of oxides form and to minimize layer growth over an extended period of time. Because chromia has better electrical conductivity than alumina and silica, chromia-forming alloys are preferable to alumina- or silica-forming alloys for manufacturing an interconnect, even if chromia grows faster than the other two TGOs. The coefficient of expansion (CTE) of an interconnect material must be a good match to the other fuel cell stack components, such as the solid oxide material yttria-stabilized zirconia (YSZ), to minimize thermal stresses during thermal cycling. The CTE values of ferritic stainless steels are similar to the CTE values of other SOFC stack components, while the CTE values of austenitic stainless steels and nickel-based alloys are considerably higher.

Ferritic (Fe-Cr) stainless steels are therefore commonly used as intermediate temperature SOFC interconnects due to their electrically conductive TGO scale, good coefficient of thermal expansion match to other fuel cell components, ease of formability, and relative inexpensive manufacturing. Ferritic alloys such as AISI 430, AISI 441, and ATI E-BRITE ${ }^{\circledR}$ can be manufactured via conventional melt metallurgy, making them less expensive to manufacture than other ferritic alloys that require a high-cost vacuum processing operation.

A disadvantage to chromia-forming stainless steels in a SOFC environment is that chromia can further oxidize to vapor species and then deposit chromium-bearing compounds at the cathode, which degrades fuel cell performance (cathode poisoning). While volatization of chromium during oxidation in ambient air occurs at temperatures above the operating temperature of SOFCs, the addition of water vapor to the oxidizing gas can significantly lower the temperature where evaporation occurs to the SOFC operating 
temperature range ${ }^{[6,7]}$. The cathode side of a ferritic stainless steel interconnect will suffer from this effect.

Through choice of alloying elements, the degree of chromium volatization can be reduced. For example, an addition of manganese may cause the formation of a manganese chromium oxide spinel on the scale surface, which could lower the chromia activity. Or for example, a titanium addition may cause $\mathrm{TiO}_{2}$ to form on the scale surface to act as a barrier to chromium volatization. Although an oxide scale resulting from a designed chemistry may reduce chromium poisoning of the cathode, the long-term performance stability of the fuel cell may require something more robust to limit chromia vaporization.

One means of extending interconnect lifetime and improving performance during exposure to air (oxidant) is to apply a protective coating, such as a Ce-modified $(\mathrm{Mn}, \mathrm{Co})_{3} \mathrm{O}_{4}(\mathrm{Ce}-\mathrm{MN})$ spinel, to the cathode side of the interconnect ${ }^{[8]}$. The Pacific Northwest National Laboratory (PNNL) has been developing these types of spinel coatings for AISI 441 interconnect material. An applied interconnect coating can be effective at blocking $\mathrm{Cr}$ evaporation from the surface. Cobalt and manganese spinel oxides have shown good performance due to their good electrical conductivity and compatibility with other SOFC components. While rare earth additions to alloys is a well-established means of improving scale adherence, the cerium addition in the PNNL coating provides the benefits of the rare earth element effect without the need for them to be in the alloy composition. The coating developed by PNNL, which has a $1 \mathrm{Mn}: 1 \mathrm{Co}$ ratio, is chemically compatible with contact pastes and cathodes, reduces the oxidation rate of the steel substrate, has a good CTE match to ferritic stainless steels, and has a high electrical conductivity. The spinel coating is currently applied through an ink screen printing process using a mesh pattern, though PNNL may consider using an ultrasonic spray in the future. All coatings were supplied in the reduced state, which is a fragile decomposed spinel of manganese oxide and cobalt metal. When reoxidized during testing, many material changes occur and the spinel phase reforms at elevated temperature. During high temperature exposure, the applied coating interacts with the chromia scale forming a complex reaction layer of mixed spinel oxides ${ }^{[9]}$. A modified alloy chemistry or surface and an applied ceramic coating may work in concert to prevent chromia evaporation.

The overall objective of this project was to validate the concept and application of a functional interconnect for a SOFC through manufacturing trials, laboratory testing, and field experience. This project focused on evaluating the performance of affordable materials integrated into systems for use as SOFC interconnects. The project reference points were ferritic stainless steels such as ATI 441HPTM alloy (UNS S44100) and ATI E-BRITE ${ }^{\circledR}$ alloy (UNS S44627), which were chosen for their combination of low cost, general availability, and performance characteristics. Functionality can be added to basic interconnect materials at the cost of increased complexity. Special processing, surface treatments, and applied third-party coatings were modifications aimed at tailoring the relevant properties of the materials of construction and their surfaces to optimize them in the local fuel cell environment.

\section{$\underline{\text { Approach }}$}

\section{ATI 441 HPTM Alloy Coils}

Two full-size production coils of ATI $441 \mathrm{HP}$ were produced by ATI Allegheny Ludlum. Samples in the form of coils and cut-to-length sheets from this production coil were distributed to Core Technology and Industrial Teams (and also PNNL/NETL) for testing, analysis, prototype building, and full scale SOFC stacks. The chemistry between the coils was consistent and is listed in Table 1 along with the mechanical properties of the coils. Samples from these production coils were also used in this test program, specifically as a baseline for comparing experimental alloys or as the basis for further post-processing surface modifications. 


\section{Post-Processing Surface Modification of ATI 441 HPTM Alloy}

Perhaps the simplest approach to further improve the performance of a ferritic stainless steel interconnect is to begin with a commercially available alloy, such as ATI $441 \mathrm{HP}$ alloy, and attempt to further improve its performance as an interconnect using post-fabrication processing techniques. All material used for surface-modification testing originated from panels from coils of ATI $441 \mathrm{HP}$ alloy that were manufactured for the SECA consortium. Two unique approaches to modify the surface of ATI 441 HP alloy were evaluated. An acid pickled mill surface served as a control.

Silicon and aluminum are known to form electrically resistive oxides; therefore, the removal or sequestering of these elements may be beneficial in improving the electrical conductivity of a functional interconnect. In the first post-processing surface modification approach, a desiliconization treatment was developed to minimize the formation of silicon-oxide beneath the chromium-oxide layer by selectively removing silicon from the ferritic stainless steel surface, which should decrease the resistance across the interconnect. Sample material at $0.020^{\prime \prime}$ thick was normalizer annealed in hydrogen at $1800^{\circ} \mathrm{F}$ for 30 minutes time-at-temperature. Preliminary research showed that this treatment had value in reducing the rate of change of area specific resistance (ASR), though the effect was not studied over an extended test period. In particular, the post-processing treatment to remove silicon was shown to reduce the ASR of Type 430 ferritic stainless steel by $25-75 \%$ with respect to baseline material. ASR testing will be described later in this report. In this project, these results on T-430 were extended to include more sophisticated commercially available alloys of interest, such as AISI 441. The ATI $441 \mathrm{HP}$ alloy test samples had a slight blue tint, potentially caused by a small leak within the furnace. Earlier T-430 research demonstrated that there was no material performance difference when testing a sample with the blue tint versus testing a sample that had it chemically removed, so it was not removed in the current experiments. Auger electron spectroscopy was performed on the surface of the desiliconized coupon and compared with the surface of a mill reference coupon in Figure 1. Silicon was effectively decreased at the surface in the top twenty-five angstroms.

The second post-processing surface modification approach explored methods to modify the sub-surface grain structure as a means to improve the diffusion of chromium to the surface, whereby improving the oxide scale formation. Three different methods were studied: surface blasting, surface grinding, and temper rolling (50\% thickness reduction).

Surface blasting and grinding alter the near-surface grain structure ${ }^{[10]}$, while temper rolling alters the through-thickness grain structure. Surface grinding was performed on a 0.020 " thick sample using a belt grinder using a 60 grit belt. The imparted finish was unidirectional and uniform, with all traces of the mill finish removed. Grit blasting was performed on a 0.020 " thick sample in a blast cabinet using cast steel shot and grit, which was finer than $0.42 \mathrm{~mm}$ and was irregular in shape. Because the ATI $441 \mathrm{HP}$ sample was 0.020 " thick, it was placed on a plate of common steel to provide a strong backing and to help it hold its shape during blasting. Afterward, the sample was cleaned in dilute nitric acid to remove any embedded steel shot residue.

Delocalized through-thickness deformation was accomplished by temper rolling. A $1.00 \mathrm{~mm}(0.040$ ") thick sheet was lab cold rolled to $0.50 \mathrm{~mm}(0.020$ "), resulting in a $50 \%$ reduction in thickness. Mill rolled and annealed 0.020 " thick material served as a control for this experiment.

The application of an external oxidation-resistant and electrically conductive coating to effectively remove the stainless steel surface from direct contact with the SOFC environment was actually a third 
approach for improving the performance of an interconnect. The Ce-MC spinel $\left(\mathrm{Ce}_{0.05} \mathrm{Mn}_{1.475} \mathrm{Co}_{1.475} \mathrm{O}_{4}\right)$ coating developed by PNNL was studied in tandem with these alternative approaches.

Coated test coupons from each post-processing modification underwent long-term oxidation testing for 5,000 hours in air at $800^{\circ} \mathrm{C}$. Surface modified material was also supplied to PNNL for additional shorterterm and longer-term oxidation testing. Additional coated test coupons underwent ASR testing for 4,500 hours.

\section{Alloy Chemistry Modification}

An alternative approach to further improve the performance of a stainless steel interconnect is to incorporate minor but impactful modifications to the composition of a commercially available ferritic alloy, seeking to optimize its performance as an interconnect material. Previously published literature showed that iron-based alloys with 17 weight percent chromium may be more effective than those with more or less chromium content ${ }^{[11]}$. Higher chromium alloys were studied simultaneously in case the Fe-17Cr alloys were found to be insufficient for an SOFC interconnect. Results from an initial study, which reviewed various commercially available alloys, showed that experimental alloys should be based on either a Fe-17Cr alloy (ATI $441 \mathrm{HP}$ alloy) or a Fe-26Cr-1Mo alloy (ATI E-BRITE alloy). A matrix analysis was carried out to look at the critical elements in these alloys.

A set of six experimental alloy compositions was reduced to practice, based on current state of the art information and the results from Phase I of this project. The compositions of these alloys, identified as the " 2 nd -Generation" alloys, are listed in Table 2. (The $1^{\text {st }}$-Generation alloys are considered to be the standard compositions of the commercially available ATI 441 HP and E-BRITE alloys.) The EXP in the alloy identification designates that it was an 'experimental' heat, while the hyphenated number served as sample identification. These six experimental alloys were melted into 50 pound ingots using a vacuum induction melting (VIM) furnace and processed to 0.020 " thick sheet stock in the pilot mill at ATI Allegheny Ludlum's Technical \& Commercial Center. Samples for testing were sheared from these sheets. Samples were tested in both the coated (PNNL's Ce-MC spinel) and uncoated condition. Some of the samples were incorporated into stacks for ASR testing, while others were used for oxidation testing.

The $2^{\text {nd }}$-Generation alloys were designed to study the optimum levels of beneficial $(\mathrm{Cr}, \mathrm{Mn}$, and $\mathrm{Nb})$ and detrimental ( $\mathrm{Si}$ ) elements in a ferritic stainless steel. It is well known that higher chromium content imparts beneficial resistance to accelerated oxidation. Manganese addition promotes formation of an evaporation-resistant spinel, so increased manganese content may limit chromium volatization from chromia. The criticality of this behavior under an applied spinel coating was previously untested. The primary role of niobium in stainless steel is to stabilize the steel against sensitization (chromium carbide formation). Niobium also has a role in sequestering silicon ${ }^{[12,13]}$, which reduces an alloy's electrical performance through the formation of an electrically resistive silica layer. Silicon may preferentially partition to a $\mathrm{Fe}_{2} \mathrm{Nb}$-based intermetallic Laves phase, which is known to form in AISI 441 and ATI E-BRITE alloy. It is also postulated that oxidation resistance in chromium alloys may be impaired at very low silicon content due to the interaction of silicon and chromium in diffusion processes. Niobium and titanium additions can act to improve the high temperature strength of a material. The $2^{\text {nd }}$-Generation alloy development was the first of two design iterations focused on improving oxidation resistance and electrical conductivity through modification of alloy composition.

In the extension to Phase II, an additional set of seven alloy compositions was evaluated to further optimize specific aspects of substrate alloy chemistry, exploring the compositional space around the top two performing alloys of the initial six. These " 3 rd -Generation" experimental alloy compositions are listed in Table 3. The scope again was to study the effect of critical element concentrations, specifically 
chromium, niobium, silicon, and manganese, with an aim towards optimizing the oxidation resistance, electrical properties, and structural stability. These experimental alloys were also VIM melted and processed to sheet stock for testing. Because testing on the $2^{\text {nd }}$-Generation alloys established the advantage of the PNNL Ce-MC spinel coating, all $3^{\text {rd }}$-Generation experimental alloys were tested in the coated condition for maximum performance. ATI $441 \mathrm{HP}$ alloy again served as a baseline. Some of the coated samples were incorporated into stacks for ASR testing, while others were placed in long-term oxidation testing for 5,000 hours.

The primary focus was on ATI $441 \mathrm{HP}$ alloy variants and the secondary focus was on ATI E-BRITE alloy variants. Five of the compositions were modifications of the promising lower-chromium alloy (EXP. 580-6), while two were modifications of the promising higher-chromium alloy (EXP. 580-5). As seen in Table 3, the EXP. 580-6 composition had a silicon content modification to 0.15 weight percent, which was lower than the 0.40 weight percent typical in the ATI $441 \mathrm{HP}$ alloy. The EXP. 580-5 composition had an intentional manganese addition of 0.3 weight percent.

Early oxidation and electrical resistance results from Phase II demonstrated a notable beneficial effect of $\mathrm{Mn}$ addition for both coated and uncoated higher-chromium alloys. Two 3rd-Generation alloys, EXP. 580-5 MOD1 and MOD2, were melted to further study higher-Cr alloys with added manganese. The MOD in the alloy identification designates that it was a modification to a $2^{\text {nd }}$-Generation experimental alloy.

Early results from Phase II also demonstrated the favorable performance of 2nd-Generation alloy EXP. 580-6, containing moderate silicon content. Five 3rd-generation alloys, EXP. 580-6 MOD1 through MOD5, were melted to study further variations in $\mathrm{Nb}, \mathrm{Si}, \mathrm{Mn}$, and Ti content.

The role of niobium (columbium) and silicon content in particular was studied in the 3rd-Generation experimental alloys. A silicon content of around 0.35 weight percent more closely resembled a typical production melt composition; however, as discussed above, silicon may degrade fuel cell performance. A ferritic chromium steel with too high of a silicon content may form silicon oxide under the chromium oxide scale, which would decrease the electrical efficiency of the SOFC stack. Niobium may sequester silicon, thus reducing the electrical resistance. EXP 580-6 MOD1 through MOD3 with increased niobium content were designed to study those effects.

\section{Low-Chromium Experimental Alloys}

Uncoated ferritic stainless steels used for SOFC interconnects typically contain at least $17 \%$ chromium because a chromium content less than that can lead to instability in the protection provided by the scale. Chromium levels as high as $25-30 \%$ are possible, though above that the alloys are difficult to process. At the request of SECA management, four additional heats with alloying additions similar to AISI 441 but with chromium contents ranging from $13-18 \%$ were melted as 50-pound VIM ingots and processed to sheet stock. Table 4 lists the four alloy compositions. The Ce-MC spinel coating was applied to the material by PNNL before it was provided to Dr. Jeffrey Fergus of Auburn University for testing. These heats were melted to determine if low-chromium content ferritic stainless steels in a coated condition could be sufficient for SOFC interconnect applications. When coated, the chromia scale that develops is modified by interaction with the spinel oxide coating. The hypothesis is that the protection afforded by a low-chromium alloy substrate may be adequate for the SOFC application due improved scale stability realized with the spinel oxide coating. Results of this study evaluating whether the chromium content can be reduced without detrimental effects on the performance in SOFC conditions can be found elsewhere and are promising ${ }^{[9]}$. 
A reduction in chromium content may help lower the cost of an interconnect alloy and thus also the fuel cell stack; however, there are concerns that the results obtained from testing small samples may not scale up to be relevant to larger fuel cell stacks where there is a greater likelihood of damage occurring to the applied coating. Areas of such damage (i.e. cracks, nicks, etc.) would require a larger chromium reservoir in the alloy for sufficient oxidation resistance to extend the lifetime of a fuel cell. Research outside the scope of this study will need to be performed to find answers to these questions.

\section{Experimental Methods}

Three primary tests, listed below, were used to study the functional interconnect material.

\section{Electrical Resistance Testing}

Area specific resistance (ASR) is a critical performance factor for SOFCs. ASR testing was used to evaluate the impact of the different compositions and surface-modifications on electrical performance. ASR, a material quantity dependent on sample dimensions, is determined by passing a constant current using a DC power supply through a pair of identical samples separated by a relatively low resistance contact (e.g. platinum) and measuring the resulting voltage drop across the contact. ASR can be calculated using a modified version of Ohm's law, incorporating current density in place of current. The interface with the highest ASR generally limits the performance of the SOFC design. The electrical resistivity of a TGO is much higher than that of the other stack components; therefore, the measured increase in potential in an ASR test can be directly correlated with growth of the TGO. While the SI unit of measure for ASR is $\Omega \cdot \mathrm{m}^{2}$, it is often expressed as $\mathrm{m} \Omega \cdot \mathrm{cm}^{2}$ for SOFC work.

Initial SOFC designs used a ceramic interconnect which had an ASR of approximately $20 \mathrm{~m} \Omega \cdot \mathrm{cm}^{2}$ and did not change with time. Current designs using a ferritic stainless steel interconnect will generally suffer from increasing ASR with time due to the evolution of the TGO layer. An ASR of less than $100 \mathrm{~m} \Omega \cdot \mathrm{cm}^{2}$ after 40,000 hours is a good performance target for fuel cells with metallic interconnects. This translates to an ASR evolution rate of $2.5 \mathrm{~m} \Omega \cdot \mathrm{cm}^{2} / 1,000 \mathrm{hr}$.

ATI Allegheny Ludlum has adapted a method developed by PNNL researchers to make ASR measurements in situ while stainless steel substrates are held at temperature in an oxidizing environment. The testing simulates the cathode side of the fuel cell, specifically the cathode to interconnect interface, which is a critical region where most of the degradation in a fuel cell occurs. The setup consists of two plates of stainless steel, separated by a lanthanum strontium manganate (LSM) ceramic pellet (sourced from Praxair), which provides a current path. LSM ink is used as a contact paste for improved contact between the LSM pellet and the interconnect plates. The active area (single-sided) is $2.4 \mathrm{~cm}^{2}$ and test coupons are made slightly oversized to allow for misalignment and connection of current leads and voltage probes. ASR is monitored continuously via a set of platinum wire voltage probes welded to each stack. Test temperature is monitored via a pair of fast K-type thermocouples located in proximity to the test stack. Testing of the assembled subunit is carried out isothermally at $800^{\circ} \mathrm{C}$ using a current density of $0.5 \mathrm{~A} / \mathrm{cm}^{2}$, with a compressive load of $2 \mathrm{kPa}$ applied by a dead weight load on top of the stack. Figure 2 shows a schematic of an ASR test setup and Figure 3 shows an example of a completed test fixture. Each test stand is capable of exposing three pairs of test samples (stacks) simultaneously. Additional details of the test methodology, and previous test results for AISI 441 can be found elsewhere ${ }^{[14]}$.

As this test setup simulated only the cathode side of the fuel cell, the rate of ASR change is a more important parameter for comparing material performance than the relative position of the ASR curves to one another. The rate of ASR evolution was determined by taking the instantaneous slope at each ASR data point. The surface-modified ATI 441HP alloys were ASR tested for 4,500 hours. The $2^{\text {nd }}$-Generation alloys were ASR tested for various times. The $3^{\text {rd }}$-Generation alloys were ASR tested for 3,000 hours. 
Post-test samples from the $3^{\text {rd }}$-Generation ASR tests were sent to PNNL for characterization using standard analytical techniques (i.e. transmission electron microscopy).

\section{Oxidation Testing in Humidified Environment / Controlled Atmospheres}

Isothermal aging in tube furnaces was performed in humidified air (a simulated cathode environment), Ar- $\mathrm{H}_{2}-\mathrm{H}_{2} \mathrm{O}$ (a simulated anode gas), and $\mathrm{Ar}-\mathrm{CH}_{4}-\mathrm{H}_{2} \mathrm{O}$ (a carbon-bearing simulated anode gas) at temperatures between $750-900^{\circ} \mathrm{C}$. Results from testing in ambient air and simulated anode gas were uniform and predictable; however, testing in humidified air provided differentiation between experimental alloys with varying silicon and chromium levels.

It was learned in early testing that the reduction of silicon content in $\mathrm{Fe}-17 \mathrm{Cr}$ alloys may cause increased oxidation under conditions that may exist in an operational SOFC, notably on the air side of a dual atmosphere exposure. An additional test program was initiated to determine the risk of breakaway oxidation in EXP. 580-6 and EXP. 580-7 alloys. A comparison of those alloy compositions with ATI $441 \mathrm{HP}$ alloy is listed in Table 5. Numerous small sample coupons were tested in order to gain some statistical significance and to provide a probabilistic understanding of the risk of breakaway oxidation as a function of time, silicon content, and test atmosphere. Testing in simulated cathode gas (air $+10 \%$ water vapor) at 800,850 , and $900^{\circ} \mathrm{C}$ was performed for up to $1,000 \mathrm{hrs}$. The samples were weighed every 24 hours in order to accurately determine the onset of breakaway oxidation. The nominal ATI 441 HP silicon content of 0.40 weight percent will be referred to as nominal or standard for this discussion in comparison with EXP. 580-6 which has a moderate silicon content of 0.15 weight percent and EXP. 580-7 which has a low silicon content of 0.05 weight percent.

\section{Oxidation Testing in Lab Atmosphere}

Long-time isothermal aging in ambient air in a box furnace at $800^{\circ} \mathrm{C}$ was used to evaluate the evolution of the oxide scale and the interaction between the external regions of the oxide and PNNL's Ce-MC spinel coating. Testing on the $3^{\text {rd }}$-Generation alloys and on the surface-modified ATI 441 HP alloys was performed for 5,000 hours. (The Pacific Northwest National Laboratory ran similar testing in ambient air on the surface-modified ATI 441 HP alloys for 2000, 3000, and 6000 hours).

The test samples were $1 " \times 0.5 " \times 0.020$ " and the coating was only applied to a $0.75 " \times 0.5$ " region of one side; therefore, approximately $3 / 8$ of the coupon was coated while $5 / 8$ was uncoated. The uncoated side of each sample served as a baseline for comparison with the coated surface. The weight change for each coupon was measured at the conclusion of the testing. Microscopy analysis was performed on both the coated and uncoated sides of the coupons at the conclusion of the heat treatment.

\section{$\underline{\text { Results and Discussion }}$}

\section{$2^{\text {nd }}$-Generation Experimental Alloys: Oxidation Test Results}

The $2^{\text {nd }}$-Generation experimental alloys were tested at both 750 and $850^{\circ} \mathrm{C}$ in a humidified environment containing 10\% water vapor. Figures 4 and 5 show the measured weight change results for these experiments. The results for the $\mathrm{Fe}-17 \mathrm{Cr}$ alloys are discussed first, followed by the results for the alloys with higher chromium content between $23-26 \%$. ( $2^{\text {nd }}-$ Generation alloy compositions are listed in Table 2 .)

At $750^{\circ} \mathrm{C}$, both ATI $441 \mathrm{HP}$ alloy coupons showed a steady, stable oxide formation with small positive weight change for the full duration of the 7,500 hour test. This commercial alloy with typical silicon content did not exhibit breakaway oxidation. EXP. 580-7 alloy, a Fe-17Cr alloy containing low silicon content $(0.05 \mathrm{wt} . \%)$, oxidized very quickly and experienced rapid transition to breakaway oxidation. The 
design of EXP. 580-2 alloy was similar to EXP. 580-7, but also included the addition of cerium and lanthanum. The additions of reactive elements postponed, but did not prevent, the transition to breakaway oxidation in the low silicon chemistry. Breakaway oxidation for this alloy occurred around 2,500 hours. EXP. 580-6 alloy contained a moderate amount of silicon (0.15 wt.\%). Duplicate samples of EXP. 580-6 alloy were tested with each showing very different behavior. The first test coupon experienced rapid breakaway oxidation, while the second had performance very similar to ATI $441 \mathrm{HP}$ alloy, at least through its full test duration of approximately 4,000 hours. Summarizing the $750^{\circ} \mathrm{C}$ test results for Fe-17Cr alloys, the alloy with the highest silicon content (ATI $441 \mathrm{HP}$ alloy) performed the best, followed by the alloy with moderate silicon content, followed by the low-silicon alloy with reactive elements, and finally the low-silicon alloy which showed the worst performance.

At $850^{\circ} \mathrm{C}$, both duplicate ATI $441 \mathrm{HP}$ alloy test coupons showed steady, stable oxide formation with a slightly higher weight change than when tested at $750^{\circ} \mathrm{C}$. Similar to the $750^{\circ} \mathrm{C}$ testing, two duplicate coupons of EXP. 580-7 both experienced rapid transition to breakaway oxidation, and the EXP. 580-2 coupon with the added reactive elements postponed, but did not prevent, the breakaway oxidation. The EXP. 580-6 coupon showed an initial small positive weight change that was somewhat parabolic, but then showed irregular weight loss behavior due to spallation. After 6,000 hours of testing, this coupon had less than $1 \mathrm{mg} / \mathrm{cm}^{2}$ of weight loss.

The second category of experimental alloys had higher chromium (23-26\%). For these alloys, the addition of manganese was found to be critical. At both 750 and $850^{\circ} \mathrm{C}$, the ATI E-BRITE alloy showed a small negative weight change. This behavior could be due to evaporation of its oxide film. At $750^{\circ} \mathrm{C}$, both EXP. 580-8 and EXP. 580-9, alloys designed with an addition of manganese, had steady, stable oxide formation through the duration of the 6,000 hour test. At $850^{\circ} \mathrm{C}$, EXP. $580-9$ again had steady, stable oxide formation, though at a slightly higher rate than at the lower temperature. EXP. 580-8, though, showed an irregular weight loss behavior due to spallation at this higher temperature.

\section{$2^{\text {nd }}$-Generation Experimental Alloys: Electrical Resistance Test Results}

As mentioned above, a good target for the performance of a metallic interconnect is an ASR of less than $100 \mathrm{~m} \Omega \cdot \mathrm{cm}^{2}$ after 40,000 hours, which corresponds to an ASR evolution rate of $2.5 \mathrm{~m} \Omega \cdot \mathrm{cm}^{2} / 1,000$ hours or less. As described above, the ASR testing in this project did not test a complete fuel cell, but rather simulated the cathode subunit of the fuel cell. As such, the ASR rate of change was the important parameter for material comparison. The effect of the individual stacks 'settling in' was neglected and the response of the material behavior as a function of time was compared.

Selected results from the ASR testing of the $2^{\text {nd }}$-Generation experimental alloys are shown in Figures 6-8. The ASR and ASR evolution of an uncoated ATI E-BRITE coupon, shown in Figure 6, could be considered poor performing under these test conditions. A coated EXP. 580-9 coupon performed much better, as seen in Figure 7. Both the manganese addition in this experimental alloy and the Ce-MC spinel coating gave two orders of magnitude improvement over the uncoated ATI E-BRITE coupon. The ASR and ASR evolution of a coated EXP. 580-6 coupon is shown in Figure 8. The plotted ASR evolution curve shows an initial period where the stack configuration settled in for this ASR test setup. The data then shows a small and decreasing ASR rate of change, followed by a slightly increasing ASR rate of change. A small and decreasing ASR rate of change is the best trend as it signifies a behavior approaching an asymptote limit where the fuel cell stack performance stabilizes and no longer degrades. A flat or slightly increasing ASR rate of change is also good, though the electrical resistance continues to increase.

A compilation of the ASR rate of change results for the $2^{\text {nd }}$-Generation experimental alloys in both coated and uncoated conditions is listed in Table 6 . When samples were tested in both the coated and uncoated 
conditions, it was clearly observed that the Ce-MC spinel coating significantly decreased the ASR evolution rate for both the $\mathrm{Fe}-17 \mathrm{Cr}$ alloys and the higher-chromium alloys. Silicon reduction in $\mathrm{Fe}-17 \mathrm{Cr}$ alloys also tended to reduce the rate of ASR increase. Coated EXP. 580-6 and coated EXP. 580-7 coupons both performed better than the uncoated ATI 441 HP coupon. A coated ATI 441 HP coupon was not tested as part of this test matrix. The EXP. 580-2 alloy with rare earth additions did not show an improvement in performance. There were divergent results from identical uncoated samples of EXP. 580-7 and coated samples of EXP. 580-8. This may show instability in alloys with moderate silicon contents.

The addition of manganese was beneficial for the higher-chromium alloys. Figure 9 compares the ASR test results for both coated and uncoated coupons of ATI E-BRITE and EXP. 580-5 alloys. Performance was improved through both the manganese addition and the Ce-MC spinel coating. Also shown is the rate of ASR change of EXP. 580-5 alloy as a function of time. Figure 10 plots the ASR rate of change as a function of chromium content for coated higher-chromium alloys. The figure shows that higherchromium alloys exhibit relatively low rates of ASR evolution, with a trend towards decreased rates as a function of chromium content. The coated EXP. 580-5 coupon exhibited the best performance in this test with an ASR evolution rate of $1.4 \mathrm{~m} \Omega \cdot \mathrm{cm}^{2} / 1,000 \mathrm{~h}$.

A stainless steel interconnect ideally should have both a small rate of ASR increase and an oxide that grows at a slow predictable rate. Results from testing on the $2^{\text {nd }}$-Generation alloys showed that silicon reduction in $\mathrm{Fe}-17 \mathrm{Cr}$ alloys tended to reduce the rate of ASR increase but also tended to add instability in oxidation behavior. For this reason, additional experimental alloys were melted to further study compositions around the EXP. 580-6 alloy composition, which contained a moderate amount of silicon. EXP. 580-6 alloy had ASR evolution rates of 25.1 and $6.9 \mathrm{~m} \Omega \cdot \mathrm{cm}^{2} / 1,000 \mathrm{~h}$ for uncoated and coated samples, respectively. Results from ASR and oxidation testing also demonstrated a notable beneficial effect of manganese addition for both coated and uncoated higher-chromium alloys. This indicated that Mn may have a positive role, even on coated samples where the ability to form a manganese chromite layer is not critical to reduce chromia evaporation. For this reason, additional experimental alloys were melted to further study higher-chromium alloys with added manganese, specifically exploring compositions around the EXP. 580-5 alloy composition.

These additional experimental alloys based on EXP. 580-6 and EXP. 580-5 alloys were previously described in the Alloy Chemistry Modification subsection of the Approach section. They are referred to as $3^{\text {rd }}$-Generation experimental alloys and their compositions are listed in Table 3.

\section{$3^{\text {rd }}$-Generation Experimental Alloys: Electrical Resistance Test Results}

All testing of the $3^{\text {rd }}$-Generation experimental alloys was done on coupons in the coated condition as previous testing on $2^{\text {nd }}$-Generation alloys established the advantage of the Ce-MC spinel coating. A coated ATI $441 \mathrm{HP}$ alloy served as a baseline. The testing was conducted for 3,000 hours at $800^{\circ} \mathrm{C}$ in air. The ASR data for the $3^{\text {rd }}$-Generation experimental alloys and ATI 441 HP alloy is plotted in Figure 11. The ASR results previously determined for ATI E-BRITE ${ }^{\circledR}$ alloy, EXP. 580-6, and EXP. 580-5 are also included for comparison. Figure 12 compares the results separately for the $\mathrm{Fe}-17 \mathrm{Cr}$ alloys and the higherchromium alloys.

The ASR evolution rate results for the 3rd-Generation alloys are presented graphically in Figure 13 and are tabulated in Table 7. ATI $441 \mathrm{HP}$ alloy and a similar alloy with increased Nb (EXP. 580-6 MOD3) have the lowest ASR evolution rate of $0.8 \mathrm{~m} \Omega \cdot \mathrm{cm}^{2} / 1,000 \mathrm{hr}$, which may be extrapolated to an ASR value of $32 \mathrm{~m} \Omega \cdot \mathrm{cm}^{2}$ at the end of a 40,000 hour fuel cell lifetime. This is a very good performance for a metallic interconnect. Recall that an ASR evolution rate of $2.5 \mathrm{~m} \Omega \cdot \mathrm{cm}^{2} / 1,000 \mathrm{hr}$ or less is a good target 
for a favorable fuel cell performance. The ASR and ASR rate of change for the coated ATI 441 HP coupon through 3,000 hours of testing are shown in Figure 14. Long-term testing by PNNL of AISI 441 coated with Ce-MC spinel has indicated stable, low area-specific resistance for over 14,000 hours at $800^{\circ} \mathrm{C}$ in air ${ }^{[15]}$.

Most of the coated experimental alloys performed fairly well, with the exception of two Fe-17Cr modified alloys, one a modification with no titanium content (EXP. 580-6 MOD4) and the second having increased manganese (EXP. 580-6 MOD5). Both of these experimental alloys had a silicon content similar to ATI $441 \mathrm{HP}$ alloy. It was learned that the addition of manganese to coated $\mathrm{Fe}-17 \mathrm{Cr}$ alloys did not have the same beneficial effect as for coated, modified ATI E-BRITE alloys. In fact, the addition of manganese was detrimental to coated alloy performance after 1,500 hours of testing. Also it was learned that titanium has an important role in establishing or maintaining the TGO and that its elimination is detrimental to performance.

The coated EXP. 580-6 MOD3 coupon performed as well as a coated ATI 441 HP coupon, which showed that an increase of niobium from 0.3 to 0.7 weight percent was neither advantageous nor disadvantageous to ASR performance in an alloy with a silicon content close to that of the commercial alloy composition. For the $3{ }^{\text {rd }}$-Generation experimental $\mathrm{Fe}-17 \mathrm{Cr}$ alloys with moderate silicon content, increasing the nionium content from 0.3 to 0.5 or 0.7 led to lower ASR evolution rates as compared to the $2^{\text {nd }}$-Generation EXP. 580-6 alloy, where the alloy with highest niobium content performed the best.

Alloys EXP. 580-5 MOD1 and MOD2 outperform ATI E-BRITE alloy, however, they do not perform as well as the $2^{\text {nd }}$-generation EXP. 580-5 alloy. Commercial ATI E-BRITE alloy with addition of 0.3 weight percent manganese (EXP. 580-5 alloy) continued to have the best performance of the higher-chromium alloys. Increased niobium content did not appear to be beneficial (EXP. 580-5 MOD1). A slight drop in performance was associated with chromium content reduction (EXP. 580-5 MOD2).

This testing showed that the Ce-MC spinel coating continues to be effective in reducing the rate of ASR increase for nearly all of the alloys tested. The combined effect of the base alloy and coating may actually be obscuring the differences between the performances of the base experimental alloys. This result may be interpreted to suggest that an alloy with less than 17 percent chromium may provide the same benefits as a $\mathrm{Fe}-17 \mathrm{Cr}$ alloy in the coated condition, but it is important to temper that with the consideration of the risk of technology scale-up. In testing small coupons, it is possible to verify that a homogenous, coating is applied across the full sample; however, this care and attention may not be possible on larger sheets in a production setting. Should a nick, scratch, or other form of damage be present in the applied coating, the oxidation resistance of the underlying substrate stainless steel would be important. For this reason, an alloy with higher chromium content around 17 percent would be preferred to one with less chromium. Figure 15 is a schematic from the ASM Specialty Handbook "Stainless Steels" showing the variation of the oxidation rate and oxide scale structure with alloy chromium content ${ }^{[16]}$. A change in behavior is quite apparent around $16-17 \%$ chromium content.

At the conclusion of the electrical resistance testing, the post-test coupons were sent to PNNL for additional in-depth microscopy analysis. Selected results from this testing are included in the Appendix.

\section{$2^{\text {nd }}$-Generation Experimental Alloys: Breakaway Event Analysis}

An oxidation experiment was conducted to provide better understanding of the risk of breakaway oxidation as a function of time, alloy content (i.e. silicon), and test atmosphere in $\mathrm{Fe}-17 \mathrm{Cr}$ alloys. Recall that the reduction of silicon to lower levels reduced the rate of ASR increase, but tended to add instability in overall resistance to accelerated oxidation as noted in weight gain oxidation curves. This test program 
further characterized the breakaway oxidation in $2^{\text {nd }}-$ Generation EXP. 580-6 and EXP. 580-7 alloys in simulated cathode gas (air $+10 \%$ water vapor) at 800,850 , and $900^{\circ} \mathrm{C}$. A comparison of the alloy compositions is listed in Table 5. The samples had $0.40,0.15$, and 0.05 weight percent $\mathrm{Si}$, respectively. To gain statistical significance, this analysis had a large number of small sample coupons tested for up to 1,000 hours and weighed every 24 hours to accurately determine the onset of breakaway oxidation.

Results from testing at $800^{\circ} \mathrm{C}$, shown in Figure 16, show a shoulder in the curves around 500 hours, which was a result of a small change in furnace temperature following an unscheduled laboratory power outage. This slightly affected the oxidation rate constant, but trends between the test samples were unaffected. At $800^{\circ} \mathrm{C}$, EXP. 580-6 alloy with 0.15 weight percent silicon content performed better than EXP. 580-7 alloy with 0.05 weight percent silicon and better than ATI $441 \mathrm{HP}$ alloy with standard silicon content $(0.40$ wt.\%). The EXP. 580-7 alloy showed instability at the early test times suffering from moderate breakaway oxidation in 45 percent of samples at times less than 300 hours, whereas the alloys with higher silicon content did not. The percent of failed samples was plotted as a function of time at all three test temperatures and shown in Figure 17 . At $800^{\circ} \mathrm{C}$, neither coupons of ATI $441 \mathrm{HP}$ alloy nor of EXP. 580-6 alloy (0.15 wt.\% Si) suffered from breakaway oxidation through 1100 hours of testing. EXP. 580-6 alloy had the best performance as measured through sample weight change.

The trend in data at $850^{\circ} \mathrm{C}$ was similar to that at $800^{\circ} \mathrm{C}$, though the measured weight change was slightly higher at this higher temperature. Results from testing at $850^{\circ} \mathrm{C}$ are shown in Figure 18. Eighteen percent of EXP. 580-7 alloy samples suffered from breakaway oxidation within the first 24 hours of testing. Neither coupons of ATI 441 HP alloy nor of EXP. 580-6 alloy (0.15 wt.\% Si) suffered from breakaway oxidation for the specified 750 -hour testing at $850^{\circ} \mathrm{C}$. When extended beyond 750 hours to times longer than originally planned for this test program, one sample of ATI 441 HP alloy suffered from breakaway oxidation. Again the EXP. 580-6 samples had lower measured weight change than the other alloys and showed the best performance. Though it was unexpected that fewer EXP. 580-7 coupons had breakaway oxidation at $850^{\circ} \mathrm{C}$ than at $800^{\circ} \mathrm{C}$, the trends between alloys were still similar.

At $900^{\circ}$ C, EXP. 580-6 alloy continued to perform better than the other two alloys, as shown in Figure 19. While over 60 percent of the EXP. 580-6 alloy coupons had breakaway oxidation prior to 100 hours, the remainder did not exhibit breakaway oxidation until between 300 to 500 hours. All of the EXP. 580-7 and ATI $441 \mathrm{HP}$ alloy coupons had breakaway oxidation at very early times. ATI $441 \mathrm{HP}$ alloy slightly outperformed EXP. 580-7 alloy, as all EXP. 580-7 samples had breakaway oxidation at 24 hours into the test program. At $900^{\circ} \mathrm{C}$, the mid-level silicon content $(0.15 \mathrm{wt} . \%)$ continued to outperform the low-level Si content $(0.05 \mathrm{wt} . \%)$ and the standard silicon content $(0.40 \mathrm{wt} . \%)$ alloys. At $900^{\circ} \mathrm{C}$, the highest test temperature, breakaway oxidation rapidly occurred in the $\mathrm{Fe}-17 \mathrm{Cr}$ alloys tested. Many test samples oxidized very quickly at $900^{\circ} \mathrm{C}$ indicating that an uncoated $\mathrm{Fe}-17 \mathrm{Cr}$ alloy likely does not have sufficient oxidation resistance at this temperature. Although the $900^{\circ} \mathrm{C}$ temperature may have use for accelerated testing of SOFC interconnects, interconnects manufactured from uncoated $\mathrm{Fe}-17 \mathrm{Cr}$ alloys would likely have poor performance in a fuel cell stack operating at that temperature.

In summary, the EXP. 580-6 alloy consistently performed better than ATI $441 \mathrm{HP}$ at all temperatures tested and is, therefore, favorable for oxidation resistance in SCG conditions at 800 and $850^{\circ} \mathrm{C}$. The EXP. 580-7 alloy with too low of a silicon content did not appear to be beneficial at any temperature tested $\left(800-900^{\circ} \mathrm{C}\right)$. Low silicon content did not seem to be beneficial, but rather seemed to add instability resulting in more breakaway oxidation. These test results indicated that there may be an optimum silicon content for reducing susceptibility to breakaway oxidation that is between 0.05 and 0.40 weight percent. As demonstrated by a 0.15 weight percent silicon content alloy, there seemed to be an optimum silicon content between 0.05 and 0.40 weight percent. 
The initial intent of this experiment was to determine the breakaway oxidation probability for $\mathrm{Fe}-17 \mathrm{Cr}$ alloys, to subsequently correlate that with dual atmosphere testing, and then to generate a failure probability map. The results of the single atmosphere testing did not lend themselves to identifying further dual atmosphere testing nor to the creation of a failure probability map.

\section{Surface-Modified ATI 441 HPTM Alloy: Electrical Resistance Test Results}

ASR testing on the coated, surface-modified ATI $441 \mathrm{HP}$ alloy coupons, obtained from a full-size production coil of the alloy, was conducted for 4,500 hours at $800^{\circ} \mathrm{C}$ in air. The ASR results are shown in Figure 20. The ASR evolution results are shown in Figure 21 and compiled in Table 8.

Recall that an ASR evolution rate of $2.5 \mathrm{~m} \Omega \cdot \mathrm{cm}^{2} / 1,000 \mathrm{hr}$ is a good performance target for metallic interconnects. All of the tested conditions showed very good performance compared to this target. The ASR rate of change listed for the temper rolled material is an average from duplicate testing, while all other results are from singular testing. The ASR rate of change for the desiliconized material was 3-4 times higher than for the mill reference material, but still within an acceptable performance range. The ASR rate of change for the surface ground sample had a discrepancy occur during data collection around 2,500 hours, where it quickly increased from 0.3 to $2.9 \mathrm{~m} \Omega \cdot \mathrm{cm}^{2} / 1,000 \mathrm{hr}$. Data was not being logged during a 100 hour time period when this occurred, but the increase was related to some internal factor of the test sample rather than an external factor from outside the experiment. A second sudden increase to around $18 \mathrm{~m} \Omega \cdot \mathrm{cm}^{2} / 1000 \mathrm{~h}$ occurred around 4,200 hours. This may indicate that AISI 441 with a surface ground treatment does not have the longevity required for a 40,000 hours lifetime or it could be particular to the specific coupon tested, warranting a retest of a duplicate sample of this surface modification. It is difficult to differentiate between the surface-modifications using these ASR results because the minor differences between the samples may be within the error of experimental testing. The four surface modifications described above neither improved nor deteriorated the electrical resistance of ATI 441 HP alloy substantially. This ASR data showed that there is no significant loss of electrical resistance performance when applying a surface blasted or temper rolled post-processing surface-modification. Surface blasting and temper rolling may be most similar in performance to mill reference material. This ASR data was not as clear for the desiliconization and surface grinding treatments, but similarly those modifications did not seem to substantially impact the electrical resistance of the stainless steel substrate.

\section{$3^{\text {rd }}$-Generation Experimental Alloys: Long-Term Oxidation Testing}

Long-term oxidation testing in ambient air at $800^{\circ} \mathrm{C}$ for 5,000 hours was performed on the $3^{\text {rd }}$-Generation alloys. The weight change for these coupons, measured at the conclusion of the 5,000 hour heat treatment, is shown in Figure 22. As described in the experimental section above, part of one side of the ATI 441 HP alloy coupon was coated with the PNNL Ce-MC spinel coating, while the opposite side was left uncoated. Although the coupon will oxidize at different rates in the coated and uncoated regions due to reoxidation of cobalt in the coating, a comparison of the alloys can still provide a broad indication of relative alloy performance. In general, the $\mathrm{Fe}-17 \mathrm{Cr}$ alloys performed similarly with an average weight change of approximately $1.2 \mathrm{mg} / \mathrm{cm}^{2}$, with the exception of EXP. 580-6 MOD5, which had a higher weight change. The higher chromium alloys that were ATI E-BRITE alloy modifications all had lower weight change below $1 \mathrm{mg} / \mathrm{cm}^{2}$. None of the test samples experienced a large weight change during the heat treatment.

Scanning electron microscopy (SEM) was performed using both a Hitachi S-510 and an Amray 1810. For consistency within this report, the coated side of the sample was oriented up and the uncoated side was oriented down for all of the cross-sectional micrographs shown.

The topological structure of the oxides that developed on the $3^{\text {rd }}$-Generation alloys was studied using SEM. For each of the experimental alloys, the surface structure of the coating after the 5,000 hour heat 
treatment is shown in Figure 23. The alloys all exhibited a faceted morphology. Similarly, the topological structures of the oxides which developed on the uncoated region of the ferritic stainless steel were also studied using SEM. The surface structures of the oxides after the 5,000 hour heat treatment are shown in Figure 24.

An untested, coated EXP. 580-6 MOD1 alloy coupon was also studied to characterize the non-heattreated coating. This coupon with an 'as-received' coating was studied simultaneously with the heattreated coupons (the coating was deposited in the early part of 2010 before the long-term aging experiment was started). It is not known whether the condition studied was fully representative of the coating immediately after depositing, but it provided an indication as to what the coating would look like nearly a year after application if the material were to be maintained in a stock area waiting for application. As shown in Figure 25, numerous sample defects were observed, mainly tearing of the surface or peculiar circular defects of approximately 50 microns in diameter with a center mark. The circular defects may have been a retained mesh pattern associated with the screen printing process of the coating. The cracking may have been due to long-term drying of the coating or artifacts from the processing; however, it may also have been associated with material handling or storage as the coating was received in a reduced state, where it was a fragile decomposed spinel. Material changes occur at elevated temperature forming the more robust spinel structure. Regardless, it was assumed that the 'as-received' coating was robust, before and after exposure to elevated temperature.

ATI $441 \mathrm{HP}$ alloy had a planar, adherent, two-layer oxide on the uncoated side of the coupon. Elemental analysis of the top surface oxide layer indicated that it was likely a $(\mathrm{Cr}, \mathrm{Fe}, \mathrm{Mn})_{3} \mathrm{O}_{4}$ spinel phase. Spinel phases have a $\mathrm{MgAl}_{2} \mathrm{O}_{4}$-type structure. The oxide layer underneath was a Cr-rich chromium oxide that contained a small amount of titanium. Voids, which can contribute to weaker scale adherence, were observed at both the interface between ATI $441 \mathrm{HP}$ alloy and the inner sublayer, and at the interface between the oxide layers, with a larger number occurring at the later location. Internal oxidation penetration was observed in these micrographs. In these regions, $\mathrm{Fe}, \mathrm{Ti}$, and $\mathrm{O}$ were the primary constituents. Small $\mathrm{Nb}$-rich particles, likely the $\mathrm{Fe}_{2} \mathrm{Nb}$ Laves phase, were observed within the metal. Micrographs of the uncoated ATI 441 HP alloy surface are shown in Figure 26.

The coated ATI $441 \mathrm{HP}$ alloy surface is shown in Figure 27. The semi-adherent oxide that formed underneath the Ce-MC spinel coating had some areas with a rough interface, and others that were more planar. A slightly darker phase was present within the chromium oxide on the surface. Although the size of this darker phase was close to the spatial resolution capabilities of EDS, there were indications that it is a Mn-bearing chromium oxide phase. The coating on the ATI 441HP alloy coupon was quite thick (44 microns) near the edge of the coupon as compared to regions further in the middle (5.9 microns). This was the only coupon that exhibited such large differences between middle and outside coated regions. The oxide underneath both the thick and thinner coating regions was approximately the same thickness at around 4 microns. There was no indication of iron migration into the spinel coating. Voids were observed at the interface between the alloy and the oxide. Internal oxide penetration was observed, often occurring at the same sites as the voids, and its primary constituents were iron, titanium, and oxygen.

Cross-sectional micrographs of the Fe-17Cr modified alloys - EXP. 580-6 MOD1 through MOD5 - are shown in Figures 28-32. Cross-sectional micrographs of the higher-chromium modified alloys EXP. 580-5 MOD1 and MOD2 - are shown in Figures 33 and 34. The thicknesses of the Ce-MC coating and the oxide underneath the coating are listed in Table 9 for each $3{ }^{\text {rd }}$-Generation experimental alloy.

Because EXP. 580-6 MOD1, MOD2, and MOD3 experimental alloys all performed well in ASR testing, as discussed above, the effect of long-term oxidation on these three alloys is discussed here together. The EXP. 580-6 MOD1 alloy had an oxide on the uncoated side that was mostly planar and adherent. The 
scale had some through-thickness cracks. There also was some internal oxidation that occurred within approximately 10 microns of the surface. Its coated side had a very planar, adherent oxide that showed some internal porosity near the oxide surface. The EXP. 580-6 MOD2 alloy had an oxide on the uncoated side that was mostly planar, with a few minor undulations. The oxide was adherent and two-layered. There was also some through-thickness cracking of the scale. It is possible that sample preparation caused the cracking. The oxide underneath the coated side was flat and adherent. The EXP. 580-6 MOD3 alloy had an oxide on its uncoated side that had small undulations. There was some porosity at its two-layer interface, and there was cracking through the scale thickness. These four alloys, as previously discussed, all performed well in the ASR testing. On the uncoated side, these four alloys had oxide thicknesses around 7.4 microns, with the inner oxide layer of the two-layer scale being approximately 4 microns, which was around $54 \%$ of the entire scale thickness. There were no silica layers observed in the scale of these or the other $3{ }^{\text {rd }}$-Generation alloys.

The EXP. 580-6 MOD4 and MOD5 alloys did not perform as well in ASR testing, as previously discussed. The oxides formed after long-time aging on these samples may answer why. The oxide on the uncoated side of EXP. 580-6 MOD4 was only semi-adherent. The scale had a rough interface and had many through-thickness cracks. There was also porosity between its two oxide layers. The oxide that formed underneath the Ce-MC spinel on the coated side was fully delaminated from the underlying base metal. The EXP. 580-6 MOD5 alloy had an oxide on its uncoated side that was fairly planar with some smaller undulations; though, it was mostly delaminated as well. There was porosity within the outermost layer of scale. On its coated side, the oxide and coating appeared to be disrupted and looked as if mounds had been pushed up to create hills on the surface. The oxide was adherent across approximately half of its area. The interface between oxide and coating was also porous. As shown in Table 9, the oxide thickness on the uncoated side and the ratio of inner layer to outer layer thickness for these two alloys was similar to the other alloys discussed above. The oxide underneath the Ce-MC spinel on the coated side, however, was thicker.

EXP. 580-5 MOD1 and MOD2 alloys were based on the higher-chromium design. The scale tended to be adherent and mostly planar. The oxide on the uncoated side had two layers. The oxide thickness on the uncoated side tended to be thinner than on the Fe-17Cr alloys and the inner oxide layer was a smaller percent of the overall scale thickness. The oxide formed underneath the Ce-MC spinel coating was on the thicker side for EXP. 580-5 MOD2, but on the thinner side for EXP. 580-5 MOD1, relative to the Fe-17Cr alloys. The coating on the EXP. 580-5 MOD2 alloy was observed to be much thicker than for the other alloys.

\section{Surface-Modified ATI 441 HPTM Alloy: Long-Term Oxidation Testing}

Long-term oxidation testing in ambient air at $800^{\circ} \mathrm{C}$ for 5,000 hours was performed on the surfacemodified ATI $441 \mathrm{HP}$ alloys. The weight change for these coupons, measured at the conclusion of the heat treatment, is shown in Figure 35. As described in the experimental section above, part of one side of each coupon was coated, while the opposite side was left entirely uncoated. A comparison of the surface treatments can provide an indication of relative performance.

Four surface treatments were studied in addition to a coated mill-reference (MR) coupon and a millreference non-coated (MRNC) coupon. The MR and MRNC coupons had larger weight gain than did any of the coated, surface-modified - desiliconized (DS), surface ground (SG), surface blasted (SB), or temper rolled (TR) - coupons. The DS coupon has the smallest weight gain, followed by the temper rolled, surface blasted, and then surface ground coupons. For only the TR coupon, the majority of oxide had flaked off the sample either during testing and/or cooling after the test. The reoxidation of cobalt in the spinel-coating is a presumable cause of the larger weight gain in the MR coupon compared to the uncoated MRNC coupon. 
The topological structure of the coating after the 5,000 hour heat treatment was studied using SEM. For each of the surface treatments, the resulting surfaces of the coated regions are shown in Figure 36. Similarly, the topological structures of the oxides (uncoated regions) of the surface-modified ATI 441 HP alloy coupons after the 5,000 hour heat treatment are shown in Figure 37.

A coating was not applied to the MRNC coupon in order to determine a baseline for oxidation under the test conditions. This sample coupon was run to provide an additional verification as the MR coupon had one uncoated side as well. EDX analysis confirmed that the bulk alloy had approximately 16.5 weight percent chromium. The scale formed on the MRNC coupon, which was fairly level and only slightly undulating, is shown in Figure 38. Spallation was not observed on the MRNC coupon. Analysis of the scale showed an inner and an outer oxide layer, with some porosity separating the layers. Together the oxide layers were approximately 5.7 microns thick with the inner layer being approximately $71 \%$ of the oxide thickness. The inner oxide layer was a chromium oxide, which contained small amounts of titanium and/or possibly some manganese or silicon. The outer oxide was a chromium manganese spinel oxide where the manganese content was approximately 20 weight percent. This research shows that the manganese helped to form a spinel on the outer surface, which elsewhere has been shown to be effective at reducing the evaporation of chromium from the surface of the alloy. There was also internal oxide penetration into the matrix in this sample.

The MR coupon was identical to the MRNC coupon except that it had the Ce-MC coating applied to a 0.375 square inch area of its top surface. SEM analysis revealed some debonding of the oxide scale from the matrix beneath the coating of the MR coupon, possibly due to stresses occurring during the metallographic preparation of the sample. Mostly, this sample had an adherent, planar oxide. Micrographs are shown in Figure 39. There was some internal oxide penetration into the matrix and some secondary oxidation within the oxide layer underneath the coating. The approximate thicknesses of the coating and underlying scale at the end of the test were 5.8 microns and 4.0 microns, respectively. At one end of the cross-sectioned coupon, the oxide thickness was much thicker than across the remainder of the coupon with a thickness of 48 microns. The oxide underneath this coating was still around 4 microns thick.

Cross-sectional micrographs of the SB, SG, TR, and DS coupons are shown in Figures 40-43. A comparison of the coating and oxide thicknesses between the MRNC, MR, and surface-modified material is listed in Table 10. The coated side of the DS coupon appeared similar to the MR coupon with a mostly adherent, planar scale. The non-coated side of the DS coupon was similar to the MRNC coupon, but with slightly less porosity between the inner and outer oxide layers. The inner chromium oxide layer was approximately 5.4 microns thick, or $59 \%$ of the entire scale thickness. The outer oxide layer contained a significant amount of manganese with a weight percent content in the mid-20s. The SG coupon had an adherent, but rough interface on the coated side between the oxide and metal substrate. There was porosity at the oxide-matrix interface and at the oxide-coating interface. The oxide on the uncoated side was also turbulent, but not as well adherent. The SB coupon also had a rough interface on the coated side. The scale was somewhat non-adherent and had some cracking. On the uncoated side, the oxide was adherent, but rough. SEM microscopy showed that almost all of the oxide and coating on the coated side of the TR coupon had spalled off. When it was present, it was fairly planar with the substrate, but there was very little still adhered to the surface. The uncoated side showed completely non-adherent oxide with cracking throughout. The oxide-metal interface showed some small undulations, neither turbulent nor flat like the interfaces of the other samples. It is possible that debonding, and in some instances cracking, of the oxide scale in these samples occurred during the metallographic preparation of the samples. The thickness of the oxide beneath the coating in the SG, SB, and TR coupons was similar to that of the mill reference coupon, though larger. The DS coupon was the only surface modification with a thinner oxide on the coated side. All four surface modifications had a thicker TGO at the end of the 5,000-hour testing than the MRNC coupon. In the MR, SB, and TR coupons, the outer layer containing manganese of the 
dual-layer scale was about $30 \%$ of the thickness of the scale. It was slightly thicker for the DS and SB coupons.

For comparison, Table 10 lists the thickness of the oxide underneath the coating for samples tested by PNNL at $800^{\circ} \mathrm{C}$ for 6,000 hours. While the MR oxide had spalled by 6,000 hours in the PNNL testing, it was approximately 4.0 microns thick after 5,000 hours. The DS and SG coupons had slightly thinner oxides at 5,000 hours than at 6,000 hours, as expected. The SB and TR coupons, however, had slightly thicker oxides at the earlier test time. This discrepancy could be explained by the low number of samples tested and the sample-to-sample variation that can occur in oxidation testing.

\section{Conclusions}

Chromia-forming ferritic stainless steels are commonly used as intermediate temperature SOFC interconnects due to their electrically conductive TGO scale, good coefficient of thermal expansion match to other fuel cell components, ease of formability, and relative inexpensive manufacturing. This research project identified two promising commercial compositions, ATI 441 HP and ATI E-BRITE alloys, and explored the effect of minor chemistry variations around these compositions on both the TGO and the resulting electrical resistance across an interconnect. Composition effects were explored in $2^{\text {nd }}$-Generation, and later $3^{\text {rd }}$-Generation, experimental alloy designs.

The experimental ATI E-BRITE alloys, modified with manganese addition, exhibited relatively low rates of ASR evolution, with a trend towards decreasing rates as a function of increasing chromium content. The addition of manganese was beneficial for higher-chromium alloys. A coated EXP. 580-5 coupon, which contained 0.3 weight percent chromium, exhibited the best performance among the higherchromium alloys in the test with an ASR evolution rate of $1.4 \mathrm{~m} \Omega \cdot \mathrm{cm}^{2} / 1,000 \mathrm{~h}$.

Testing of the experimental Fe-17Cr alloys showed that reducing silicon to low levels tended to add instability in both ASR and oxidation behavior. This result warranted additional oxidation testing in a simulated cathode environment (humidified air) to study systematic trends in breakaway oxidation. An experimental $\mathrm{Fe}-17 \mathrm{Cr}$ type alloy with $0.15 \mathrm{wt} . \%$ silicon was less prone to breakaway oxidation than either one with 0.05 wt.\% silicon or commercial ATI $441 \mathrm{HP}$ alloy with $0.40 \mathrm{wt} . \%$ silicon, which suggested an optimal silicon content for oxidation resistance that is not as low as possible. The experimental heat with the low silicon level tended to experience rapid transition to breakaway oxidation. The rate of ASR increase of spinel-coated ATI $441 \mathrm{HP}$ alloy was $0.8 \mathrm{~m} \Omega \cdot \mathrm{cm}^{2} / 1,000 \mathrm{hr}$, measured after the test system reached steady-state conditions. In the coated condition, this commercial alloy outperformed all of the experimental $\mathrm{Fe}-17 \mathrm{Cr}$ type alloys tested. It also outperformed the higher-chromium alloys tested. This testing showed that coated, commercial ATI $441 \mathrm{HP}$ alloy is a robust material for fabricating a functional interconnect. Its long-term oxidation resistance and electrical resistivity at intermediate temperatures met the goals of the project by achieving an ASR evolution rate of less than $2.5 \mathrm{~m} \Omega \cdot \mathrm{cm}^{2} / 1,000 \mathrm{hr}$. While many of the coated, experimental alloys tested meet the goal of the project, which corresponds to a 40,000 hours lifetime of a fuel cell stack, the current ATI 441HP alloy chemistry gave the best performance.

A cerium-modified $(\mathrm{Mn}, \mathrm{Co})_{3} \mathrm{O}_{4}$ spinel coating, applied by PNNL, was effective in reducing the rate of ASR increase for nearly all of the samples tested. The combined effect of a modified alloy composition and the applied Ce-MC spinel coating may have obscured the differences between the performances of the experimental alloys; however, as a coating is intended to be used in the metallic interconnect manufacturing process, it helped the ferritic stainless steels studied in this test program to meet the SECA goal.

Post-processing surface modifications - surface blasting, surface grinding, temper rolling (50\% reduction), and desiliconization - were performed on flat-rolled ATI $441 \mathrm{HP}^{\mathrm{TM}}$ stainless steel as a means 
to improve the oxidation resistance and electrical resistance properties of the TGO. Long-term isothermal oxidation testing and electrical resistance testing were used to characterize the effects of the surface modifications. Results indicated that some post-processing surface modifications may have been effective for improving the spallation resistance compared to untreated ATI $441 \mathrm{HP}$ alloy. The surface modifications neither improved nor deteriorated the electrical resistance of ATI 441 HP alloy substantially. Surface-modified material was also supplied to PNNL for additional oxidation testing. Testing at ATI Allegheny Ludlum and PNNL agree that most of the oxide spalls off temper rolled material after long exposure to elevated temperatures. PNNL measured $100 \%$ delamination in the $50 \%$ cold rolled material. Based on additional results from PNNL, surface blasting appears to be the most promising surface modification as it had no delamination of its scale.

In addition to the above mentioned research, over 18,000 pounds of material in the form of coils and cutto-length sheets from production coils of ATI $441 \mathrm{HP}$ alloy were distributed to Core Technology and Industrial Teams (and also PNNL/NETL) for testing, analysis, prototype building, and full scale SOFC stacks. Also, four small experimental heats of lower-chromium (13-18 wt.\% Cr) alloys were designed, melted, and processed to explore the sufficiency of coated, very low-chromium stainless steel as SOFC interconnect material. This material was provided to Jeff Fergus at Auburn University to study spinelcoated alloy performance and to characterize the interaction between the TGO and coating.

\section{Future Work Ideas}

While the Ce-MC spinel coating was effective at improving the properties of a functional interconnect, it would be interesting to repeat electrical resistance testing on the $3^{\text {rd }}$-Generation alloys in the uncoated condition to better understand the effects of minor chemistry modifications in the $\mathrm{Fe}-17 \mathrm{Cr}$ and higherchromium alloys. Other more highly alloyed ferritic stainless steels with very good performance exist, but the cost of those alloys is prohibitive to SOFCs. The addition of a coating processing step to a lowerchromium alloy such as ATI $441 \mathrm{HP}$ is preferred to meet the lifetime and cost requirements of a SOFC. Small compositional modifications may still be able to improve a lower-chromium alloy to the point that a coating is no longer necessary. This could lead to future cost reductions and also decrease the lead time of manufacturing an interconnect component. With a goal of $2.5 \mathrm{~m} \Omega \cdot \mathrm{cm}^{2} / 1,000 \mathrm{hr}$ or less, the lowest ASR value of uncoated $2^{\text {nd }}$-Generation alloy in this study approached that with a value of $8 \mathrm{~m} \Omega \cdot \mathrm{cm}^{2} / 1,000 \mathrm{hr}$.

Although individual surface deformation techniques were studied in this project, combinations (i.e. both cold deformation and grit blasting) can also be examined. Additionally, combinations of minor compositional modifications with applied post-processing surface modifications could be studied to improve the performance of a functional interconnect in concert.

The surface blasting post-processing technique was effective when applied on a small sample of material in the laboratory. Next steps might be to perform a similar processing technique on material in a production setting to see if the process can be scaled-up and if its benefits are still realized on production material. It is expected that this processing should translate from the laboratory to a commercial production process. Finally, it is always of interest to test any of these ideas in an actual fuel cell stack as opposed to experiments that simulate the fuel cell environment. Testing of surface blasted ATI 441 HP alloy in an actual SOFC stack would increase the accuracy of these results. 


\section{Acknowledgements}

Financial support was provided by the United States Department of Energy under award number DE-FC26-05NT42513. Guidance was received from the National Energy Technology Laboratory's SolidState Energy Conversion Alliance (SECA) project management team. Dr. James Rakowski at ATI Allegheny Ludlum was the initial principal investigator on this project. Dr. Jeffry Stevenson at the Pacific Northwest National Laboratory and Dr. Jeffrey Fergus at Auburn University have been excellent collaborators. Mark Miecznikowski at ATI Allegheny Ludlum is to be thanked for many hours of experimental assistance.

\section{Special Recognitions \& Awards/Patents Issued}

1. U.S. and associated foreign patent applications have been filed on higher-chromium content alloy compositions (U.S. application numbers 20060286433, 20060286432, and 20060285993) and on the silicon removal process (U.S. application number 20080236710).

\section{Publications/Presentations}

1. Quarterly status reports for Project 42513 through January 2011.

2. Annual status reports for Project 42513 through August 2010.

3. Rakowski, J.M., "Metallic SOFC Interconnect Systems." $7^{\text {th }}$ Annual SECA Conference. Philadelphia, PA. September 12-14, 2006.

4. Rakowski, J.M., "Interconnect Alloys Metallurgy and Manufacturing." $8^{\text {th }}$ Annual SECA Workshop. San Antonio, TX. August 7-9, 2007.

5. Rakowski, J.M., "Solid Oxide Fuel Cell Metallic Interconnect Systems." $9^{\text {th }}$ Annual SECA Workshop. Pittsburgh, PA. August 5-7, 2008.

6. Bender, M.D., "Evaluation of a Functional Interconnect System of Solid Oxide Fuel Cells." $10^{\text {th }}$ Annual SECA Workshop. Pittsburgh, PA. July 13-15, 2009.

7. Status review presentation. NETL, Morgantown. March 5, 2010.

8. Bender, M.D., "Evaluation of a Functional Interconnect System of Solid Oxide Fuel Cells." $11^{\text {th }}$ Annual SECA Workshop. Pittsburgh, PA. July 27-29, 2010.

9. Bender, M.D. and J.M. Rakowski, "Investigating the Effect of Chemistry Modifications on SOFC Interconnect Alloy Performance.” Fuel Cell Seminar. San Antonio, TX. October 19, 2010. 


\section{$\underline{\text { Tables }}$}

Table 1. Composition and mechanical properties of the ATI 441 HPTM alloy production coils produced for distribution to SECA Core Technology and Industrial Teams

\begin{tabular}{|c|c|c|}
\hline $\begin{array}{c}\text { Composition I } \\
\text { Mechanical Properties }\end{array}$ & $\begin{array}{c}\text { ALC Coil 1 } \\
\text { (wt.\%) }\end{array}$ & $\begin{array}{c}\text { ALC Coil 2 } \\
\text { (wt.\%) }\end{array}$ \\
\hline $\mathrm{C}$ & 0.015 & 0.013 \\
\hline $\mathrm{Mn}$ & 0.3 & 0.3 \\
\hline $\mathrm{Si}$ & 0.38 & 0.38 \\
\hline $\mathrm{Cr}$ & 17.7 & 17.8 \\
\hline $\mathrm{Ni}$ & 0.3 & 0.3 \\
\hline $\mathrm{Al}$ & 0.04 & 0.03 \\
\hline $\mathrm{Cu}$ & 0.1 & 0.13 \\
\hline $\mathrm{Nb}$ & 0.4 & 0.5 \\
\hline $\mathrm{Ti}$ & 0.20 & 0.22 \\
\hline $\mathrm{N}$ & 0.12 & 0.14 \\
\hline \hline Yield Strength (ksi) & 67.5 & 52.3 \\
\hline Tensile Strength (ksi) & 85 & 75 \\
\hline Elongation (\%) & 22 & 30 \\
\hline ASTM Grain Size & - & 9.5 \\
\hline
\end{tabular}

Table 2. Overview of $2^{\text {nd }}$-Generation experimental alloys (weight percent)

\begin{tabular}{|c|c|c|c|c|c|}
\hline Alloy & $\mathrm{Cr}$ & $\mathbf{N b}$ & Si & Others & Comments \\
\hline ATI 441HP TM alloy & 17.5 & 0.3 & 0.4 & $0.3 \mathrm{Mn}, 0.2 \mathrm{Ti}$ & Commercial material \\
\hline EXP. 580-6 & 17 & 0.3 & 0.15 & $0.3 \mathrm{Mn}$ & Moderate Si \\
\hline EXP. 580-7 & 17 & 0.3 & 0.05 & $0.3 \mathrm{Mn}$ & Low Si \\
\hline EXP. $580-2$ & 17 & 0.3 & 0.05 & $0.1 \mathrm{Ce}+\mathrm{La}$ & Low Si; RE addition \\
\hline E-BRITE $^{\circledR}$ alloy & 26 & 0.2 & 0.3 & $1 \mathrm{Mo}$ & Commercial material \\
\hline EXP. $580-5$ & 26 & 0.2 & 0.3 & $1 \mathrm{Mo}, 0.3 \mathrm{Mn}$ & Commercial E-BRITE ${ }^{\circledR}$ comp. + 0.3 wt. $\%$ Mn \\
\hline EXP. $580-8$ & 23 & 0.3 & 0.15 & $1 \mathrm{Mo}, 0.3 \mathrm{Mn}$ & Lower Cr; Moderate Si; 0.3 wt. \% Mn \\
\hline EXP. 580-9 & 24 & 0.3 & 0.05 & $1 \mathrm{Mo}, 0.3 \mathrm{Mn}$ & Lower $\mathrm{Cr}$; Low Si; 0.3 wt. \% Mn \\
\hline
\end{tabular}

Table 3. Overview of $3^{\text {rd }}$-Generation experimental alloys (weight percent)

\begin{tabular}{|c|c|c|c|c|c|}
\hline Alloy & $\mathbf{C r}$ & $\mathbf{N b}$ & $\mathbf{S i}$ & Others & Comments \\
\hline \hline ATI 441HP ${ }^{\text {TM }}$ alloy & 17.5 & 0.3 & 0.4 & $0.3 \mathrm{Mn}, 0.2 \mathrm{Ti}$ & Commercial material \\
\hline EXP. 580-6 & 17 & 0.3 & 0.15 & $0.3 \mathrm{Mn}, 0.1 \mathrm{Ti}$ & Moderate $\mathrm{Si}$ \\
\hline EXP. 580-6 MOD1 & 17.3 & 0.5 & 0.15 & $0.3 \mathrm{Mn}, 0.2 \mathrm{Ti}$ & Increased Nb, mid Si \\
\hline EXP. 580-6 MOD2 & 17.3 & 0.7 & 0.15 & $0.3 \mathrm{Mn}, 0.2 \mathrm{Ti}$ & Increased Nb (max), mid Si \\
\hline EXP. 580-6 MOD3 & 17.3 & 0.7 & 0.35 & $0.3 \mathrm{Mn}, 0.2 \mathrm{Ti}$ & Increased Nb (max) \\
\hline EXP. 580-6 MOD4 & 17.3 & 0.3 & 0.35 & $0.3 \mathrm{Mn}, 0.0 \mathrm{Ti}$ & Increased Mn \\
\hline EXP. 580-6 MOD5 & 17.3 & 0.3 & 0.35 & $0.8 \mathrm{Mn}, 0.2 \mathrm{Ti}$ & Commercial material \\
\hline \hline E-BRITE alloy & 26 & 0.2 & 0.3 & $1 \mathrm{Mo}$ & Increased $\mathrm{Nb}$ \\
\hline EXP. 580-5 & 26 & 0.2 & 0.3 & $1 \mathrm{Mo}, 0.3 \mathrm{Mn}, 0.1 \mathrm{Ti}$ & Commercial E-BRITE ${ }^{\circledR}$ comp. $+0.3 \mathrm{wt} \% \mathrm{Mn}$ \\
\hline EXP. 580-5 MOD1 & 26 & 0.5 & 0.35 & $1 \mathrm{Mo}, 0.3 \mathrm{Mn}, 0.2 \mathrm{Ti}$ & Reduced Cr \\
\hline EXP. 580-5 MOD2 & 24 & 0.3 & 0.35 & $1 \mathrm{Mo}, 0.3 \mathrm{Mn}, 0.2 \mathrm{Ti}$ & \\
\hline
\end{tabular}


Table 4. Experimental alloys designed to contain alloying additions similar to AISI 441 (e.g. Ti, Nb) with similar (983-3, 983-4) and lower (983-1, 983-2) chromium contents.

\begin{tabular}{|c|c|c|c|c|c|c|c|}
\hline \multirow{2}{*}{ Alloy } & \multirow{2}{*}{ ID } & \multicolumn{6}{|c|}{ Concentration (wt.\%) } \\
\cline { 3 - 8 } & & $\mathbf{F e}$ & $\mathbf{C r}$ & $\mathbf{M n}$ & $\mathbf{S i}$ & $\mathbf{T i}$ & $\mathbf{N b}$ \\
\hline \hline Alloy 1 & $983-1$ & Bal. & 13 & 0.3 & 0.35 & 0.2 & 0.35 \\
\hline Alloy 2 & $983-2$ & Bal. & 15 & 0.3 & 0.35 & 0.2 & 0.35 \\
\hline Alloy 3 & $983-3$ & Bal. & 17 & 0.3 & 0.35 & 0.2 & 0.35 \\
\hline Alloy 4 & $983-4$ & Bal. & 18 & 0.3 & 0.35 & 0.2 & 0.35 \\
\hline
\end{tabular}

Table 5. Comparison of alloys tested in humidified air for breakaway oxidation study

\begin{tabular}{|c|c|c|c|c|}
\hline Alloy & $\mathbf{C r}$ & $\mathbf{N b}$ & $\mathbf{S i}$ & Others \\
\hline \hline ATI 441 HPTM alloy & 17.5 & 0.3 & 0.4 & $0.3 \mathrm{Mn}, 0.2 \mathrm{Ti}$ \\
\hline EXP. 580-6 & 17 & 0.3 & 0.15 & $0.3 \mathrm{Mn}, 0.2 \mathrm{Ti}$ \\
\hline EXP. 580-7 & 17 & 0.3 & 0.05 & $0.3 \mathrm{Mn}, 0.2 \mathrm{Ti}$ \\
\hline
\end{tabular}

Table 6. ASR rate of change of $2^{\text {nd }}$-Generation experimental alloys in both coated and uncoated conditions

\begin{tabular}{|c|c|c|c|}
\hline \multirow[t]{2}{*}{ Sample ID } & \multicolumn{2}{|c|}{$\begin{array}{l}\text { ASR Evolution Rate } \\
\left(\mathrm{m} \pi \cdot \mathrm{cm}^{2} / 1,000 \mathrm{~h}\right)\end{array}$} & \multirow[t]{2}{*}{ Comments } \\
\hline & Uncoated & Coated & \\
\hline ATI 441 HP ${ }^{\text {TM }}$ alloy & 35.4 & no test & Commercial material (0.4 wt. \% Si) \\
\hline EXP. 580-6 & 25.1 & 6.9 & Moderate Si (0.15 wt. \%) \\
\hline \multirow{2}{*}{ EXP. 580-7 } & $33.7^{\text {run1 }}$ & \multirow{2}{*}{2.2} & \multirow{2}{*}{ Low Si (0.05 wt. \%) } \\
\hline & $550.9^{\text {run2 }}$ & & \\
\hline EXP. 580-2 & 47.2 & no test & Low Si (0.05 wt. \%); RE addition \\
\hline E-BRITE $\left.^{(}\right)$alloy & 936.5 & 21.1 & Commercial material (0.3 wt. \% Si) \\
\hline EXP. $580-5$ & 38.1 & 1.4 & Standard E-BRITE ${ }^{\circledR}+0.3$ wt. $\% \mathrm{Mn}$ \\
\hline \multirow{2}{*}{ EXP. 580-8 } & \multirow{2}{*}{17.2} & 7.5 & \multirow{2}{*}{ Lower Cr; Moderate Si (0.15 wt.\%); + 0.3 wt. $\% \mathrm{Mn}$} \\
\hline & & 223.7 & \\
\hline EXP. 580-9 & 7.9 & 2.5 & Lower Cr; Low Si (0.05 wt. \%); + 0.3 wt. \% Mn \\
\hline
\end{tabular}

Table 7. ASR evolution rate of $3^{\text {rd }}$-Generation experimental alloys in the coated condition

\begin{tabular}{|c|c|c|c|}
\hline \multirow[t]{2}{*}{ Sample ID } & \multicolumn{2}{|c|}{$\begin{array}{l}\text { ASR Evolution Rate } \\
\left(\mathrm{m} \Omega \cdot \mathrm{cm}^{2} / 1,000 \mathrm{~h}\right)\end{array}$} & \multirow[t]{2}{*}{ Comments } \\
\hline & Uncoated & Coated & \\
\hline ATI 441 HP ${ }^{\text {TM }}$ alloy & 35.4 & 0.8 & Commercial material $(0.4$ wt. $\% \mathrm{Si})$ \\
\hline EXP. 580-6 & 25.1 & 6.9 & Moderate Si $(0.15$ wt. \%) \\
\hline 580-6 MOD1 & no test & 4.6 & Increased $\mathrm{Nb}, \mathrm{mid} \mathrm{Si}$ \\
\hline 580-6 MOD2 & no test & 1.6 & Increased $\mathrm{Nb}$ (max), mid Si \\
\hline 580-6 MOD3 & no test & 0.8 & Increased $\mathrm{Nb}(\max )$ \\
\hline 580-6 MOD4 & no test & 77.1 & Modified stabilization with no Ti \\
\hline 580-6 MOD5 & no test & 118.6 & Increased $\mathrm{Mn}$ \\
\hline E-BRITE ${ }^{\circledR}$ alloy & 936.5 & 21.1 & Commercial material (0.3 wt.\% Si) \\
\hline EXP. 580-5 & 38.1 & 1.4 & Commercial E-BRITE comp. +0.3 wt. $\% \mathrm{Mn}$ \\
\hline 580-5 MOD1 & no test & 4.4 & Increased $\mathrm{Nb}$ \\
\hline 580-5 MOD2 & no test & 2.4 & Reduced $\mathrm{Cr}$ \\
\hline
\end{tabular}


Table 8. ASR evolution rate results for surface-modified ATI 441 HPTM coupons

\begin{tabular}{|c|c|c|}
\hline \multirow{2}{*}{$\begin{array}{c}\text { Sample ID } \\
\left(\text { ATI } 441 \mathrm{HP}^{\text {TM }} \text { alloy) }\right.\end{array}$} & \multicolumn{2}{|c|}{$\begin{array}{c}\text { ASR Evolution Rate } \\
\left(\mathrm{m} \Omega \cdot \mathrm{cm}^{2} / 1,000 \mathrm{~h}\right)\end{array}$} \\
\cline { 2 - 3 } & Uncoated & Coated \\
\hline \hline Mill Reference & no test & 0.6 \\
\hline Surface Ground & no test & $0.3 / 2.9$ \\
\hline Surface Blasted & no test & 1.0 \\
\hline Temper Rolled & no test & 0.5 \\
\hline Desiliconized & no test & 2.2 \\
\hline
\end{tabular}

Table 9. Comparison of coating and oxide thicknesses (units: microns) for the $3^{\text {rd }}$-Generation experimental alloys after long-term oxidation testing at $800^{\circ} \mathrm{C}$

\begin{tabular}{|c|c|c|c|c|c|}
\hline Alloy & Coating & $\begin{array}{c}\text { Oxide } \\
\text { underneath } \\
\text { coating }\end{array}$ & $\begin{array}{c}\text { Oxide on } \\
\text { uncoated side }\end{array}$ & $\begin{array}{c}\text { Inner oxide layer } \\
\text { on uncoated side }\end{array}$ & $\begin{array}{c}\text { Percent of thickness } \\
\text { of inner layer on } \\
\text { uncoated side }\end{array}$ \\
\hline ATI 441HP alloy & $44.2 / 5.9$ & $3.6 / 4.3$ & 7.8 & 3.9 & $50 \%$ \\
\hline EXP. 580-6 MOD1 & 9.5 & 2.8 & 7.0 & 4.0 & $58 \%$ \\
\hline EXP. 580-6 MOD2 & 13.9 & 3.1 & 7.4 & 4.1 & $55 \%$ \\
\hline EXP. 580-6 MOD3 & 6.9 & 3.2 & 8.5 & 4.3 & $50 \%$ \\
\hline EXP. 580-6 MOD4 & 3.9 & 6.3 & 6.9 & 3.5 & $51 \%$ \\
\hline EXP. 580-6 MOD5 & 5.6 & 4.6 & 10.2 & 4.7 & $46 \%$ \\
\hline EXP. 580-5 MOD1 & 7.4 & 1.1 & 4.8 & 2.1 & $44 \%$ \\
\hline EXP. 580-5 MOD2 & 24.9 & 5.8 & 6.1 & 2.0 & $33 \%$ \\
\hline
\end{tabular}

Table 10. Comparison of coating and oxide thicknesses (units: microns) for MRNC, MR, and surface-modified ATI 441HPTM coupons

\begin{tabular}{|l|c|c|c|c|c|c|}
\hline & MRNC & MR & DS & SG & SB & TR \\
\hline Remaining coating & N/A & 5.8 & 12.3 & 8.7 & 12.9 & 4.8 \\
\hline Oxide beneath coating & N/A & 4.0 & 1.8 & 5.3 & 6.7 & 4.8 \\
\hline Entire oxide on uncoated region & 5.7 & see MRNC & 9.1 & 12.5 & 12.1 & 8.1 \\
\hline PNNL: Oxide beneath coating, 6,000 hrs & N/A & spalled & 2.4 & 5.5 & 4.1 & 1.6 \\
\hline
\end{tabular}

\section{Figures}

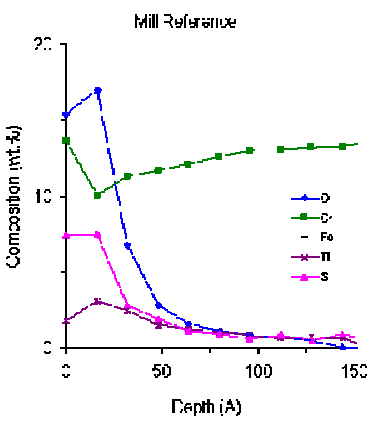

(a.)

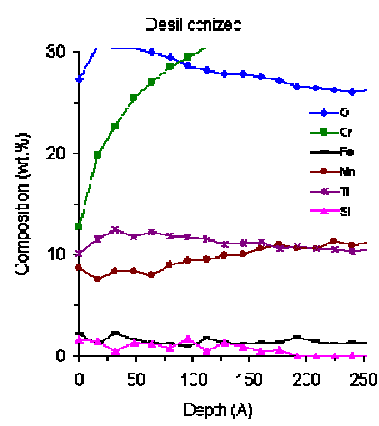

(b.)

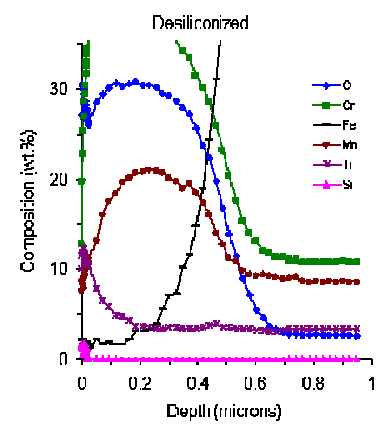

(c.)

Figure 1. Comparison of selected elements on the (a) mill reference and (b, c) desiliconized surfaces of 0.020 " thick coupons as measured with Auger electron spectroscopy. (Manganese was not selected for measuring in the mill reference coupon. Its measurement in the desiliconized coupon resulted in skewed chromium and oxygen values due to an overlap in peaks with manganese.) 


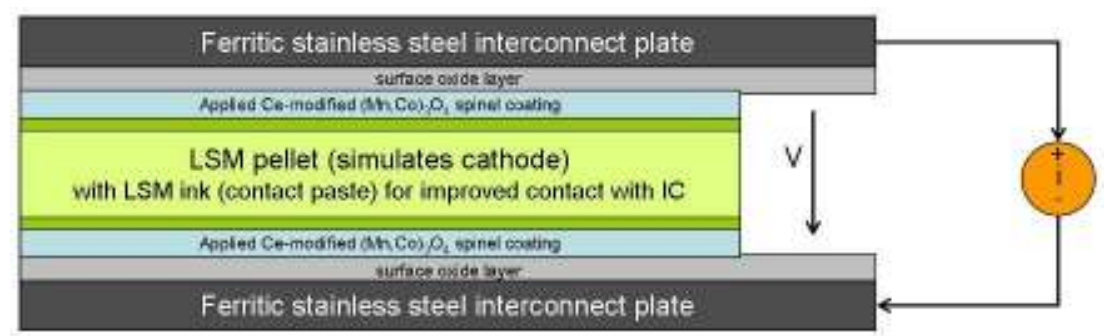

Figure 2. ASR test setup simulating the cathode to interconnect fuel cell subunit
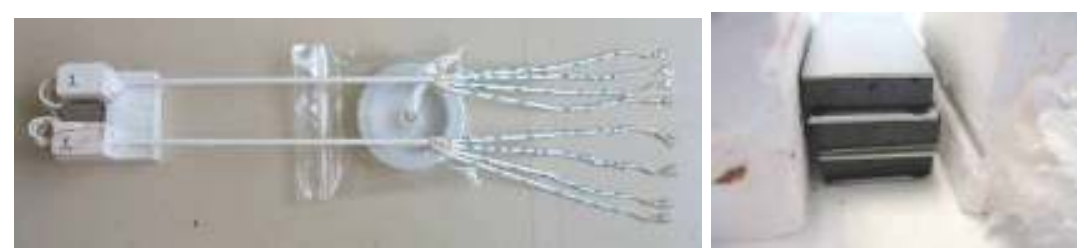

Figure 3. Overhead and front views of completed ASR test fixture

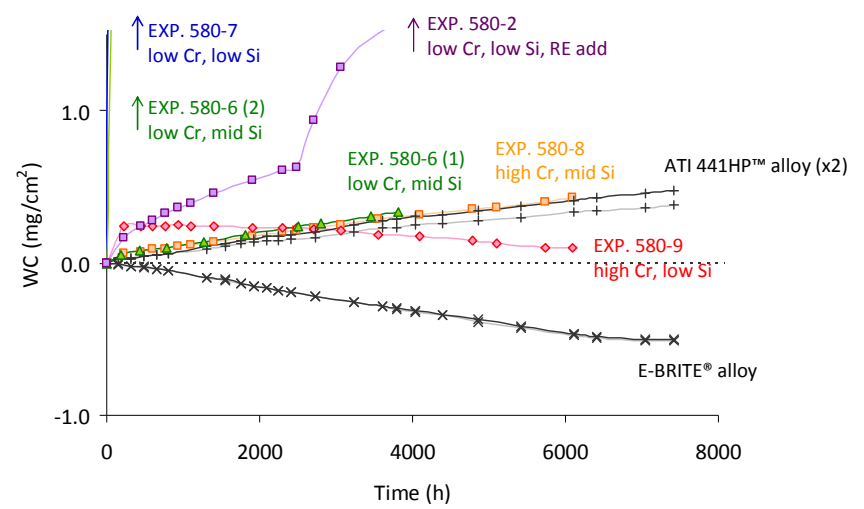

Figure 4. Oxidation test results for $2^{\text {nd }}$-Generation experimental alloys at $750^{\circ} \mathrm{C}$ in air $+10 \% \mathrm{H}_{2} \mathrm{O}$ vapor

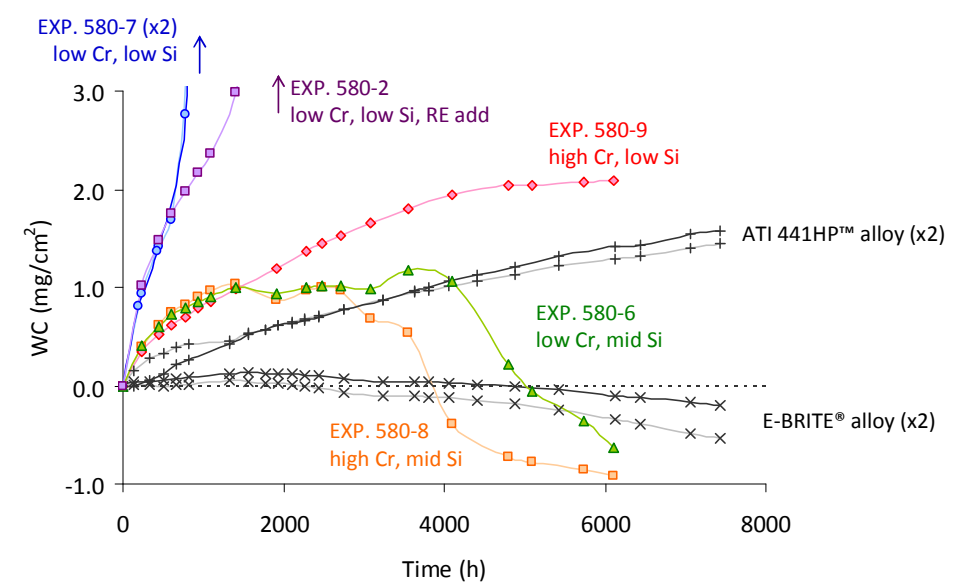

Figure 5. Oxidation test results for $2^{\text {nd }}$-Generation experimental alloys at $8500^{\circ} \mathrm{C}$ in air $+10 \% \mathrm{H}_{2} \mathrm{O}$ vapor 


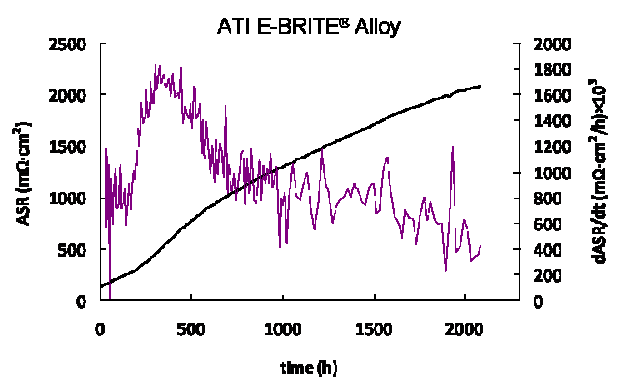

Figure 6. ASR test results of an uncoated ATI E-BRITE ${ }^{\circledR}$ coupon. The testing was conducted at $800^{\circ} \mathrm{C}$ and 0.5 ampere $/ \mathrm{cm}^{2}$.

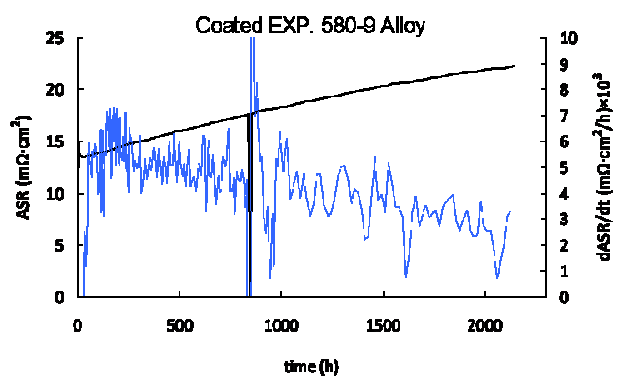

Figure 7. ASR test results of a coated EXP. 580-9 coupon. This experimental alloy modified the ATI E-BRITE ${ }^{\circledR}$ alloy composition with the addition of manganese. The testing was conducted at $800^{\circ} \mathrm{C}$ and 0.5 ampere $/ \mathrm{cm}^{2}$.

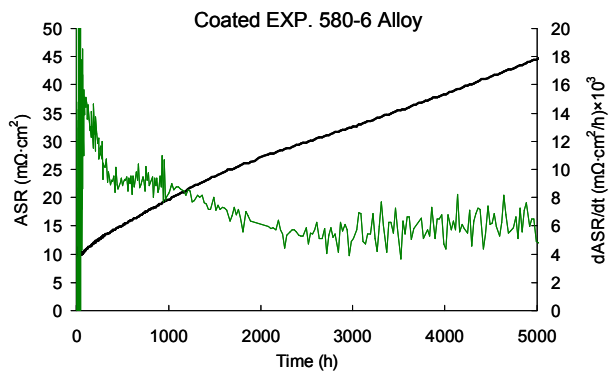

Figure 8. ASR test results of a coated EXP. 580-6 coupon. The testing was conducted at $800^{\circ} \mathrm{C}$ and 0.5 ampere $/ \mathrm{cm}^{2}$.

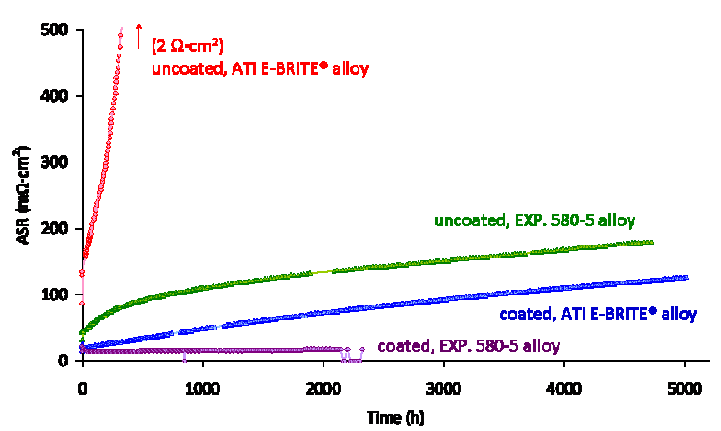

(a.)

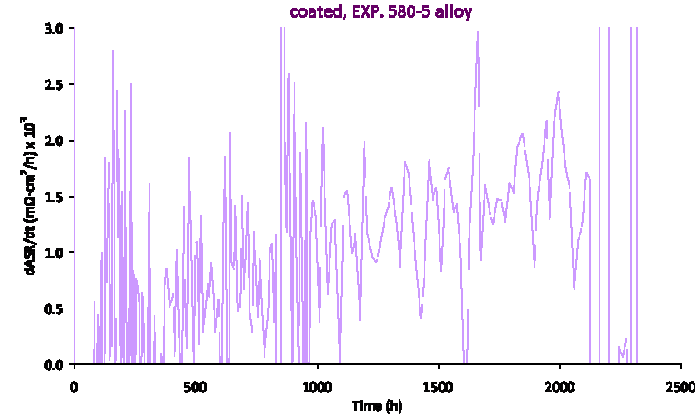

(b.)

Figure 9. (a.) ASR test results comparing coated and uncoated coupons of commercial ATI E-BRITE ${ }^{\circledR}$ and EXP. 580-5 alloys, and (b.) the rate of ASR change for the coated EXP. 580-5 coupon. EXP. 580-5 alloy is similar in composition to ATI E-BRITE alloy, but has an addition of manganese. 


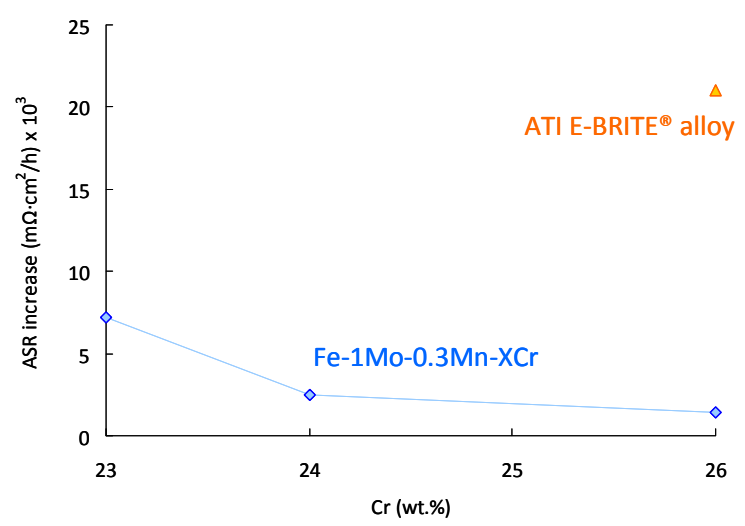

Figure 10. Effect of manganese on coated, high-chromium alloys

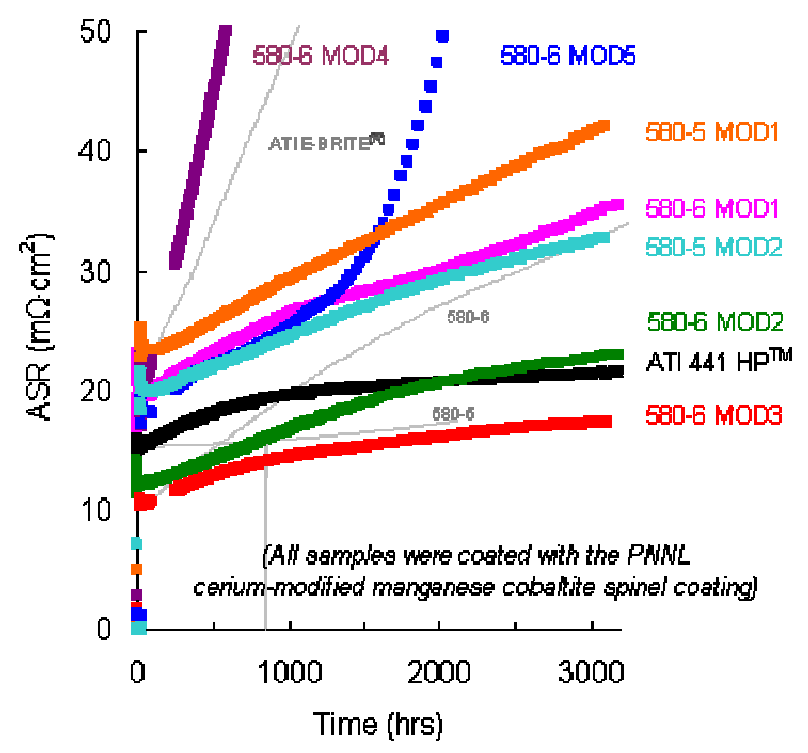

Figure 11. ASR compilation of all $3^{\text {rd }}$-Generation alloys with ATI $441 \mathrm{HP}^{\mathrm{TM}}$, ATI E-BRITE ${ }^{\circledR}$, EXP. 580-6, and EXP. 580-5 alloys for comparison.

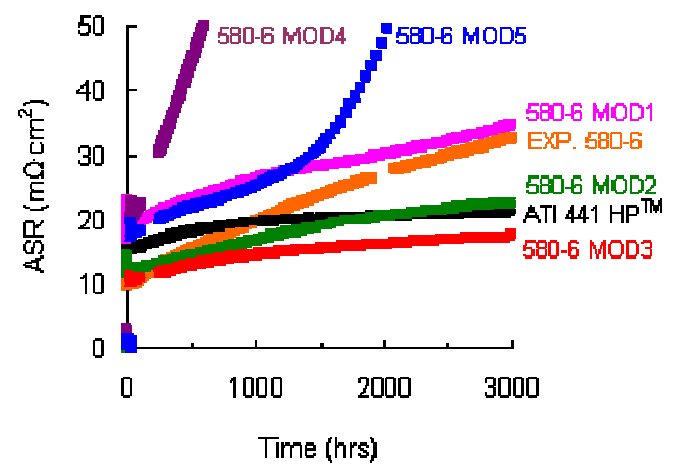

(a.)

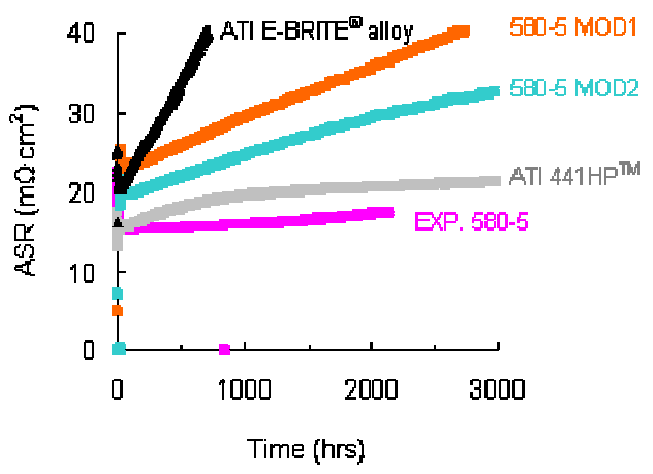

(b.)

Figure 12. ASR comparison of the experimental (a) Fe-17Cr alloys and (b) higher-chromium alloys. 


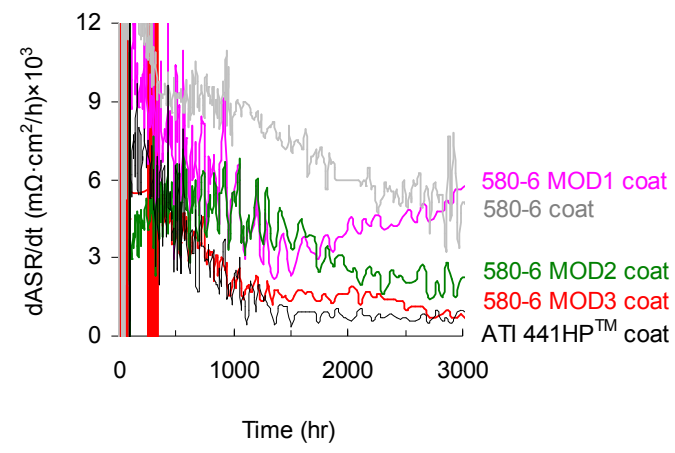

(a.)

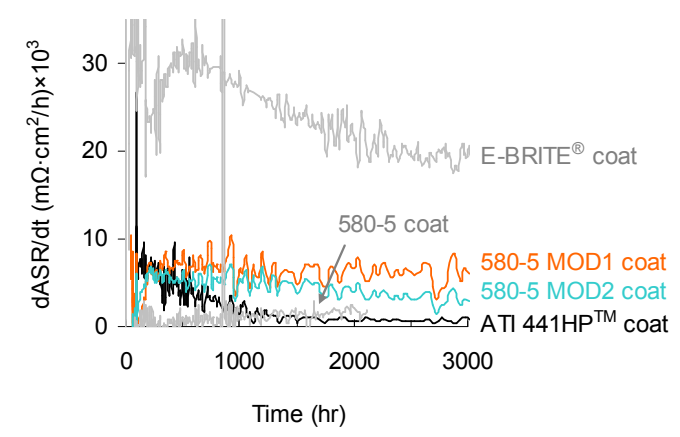

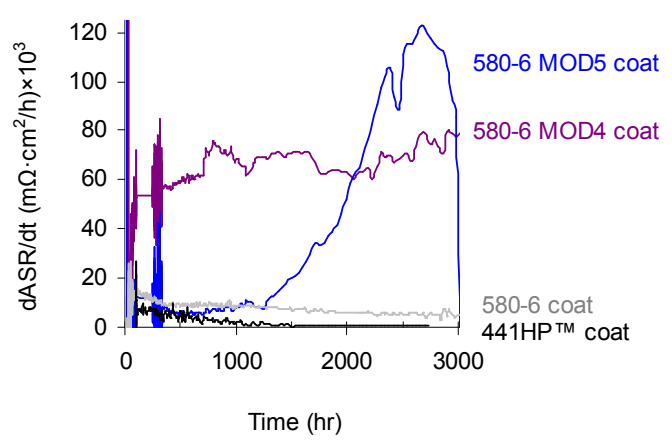

(b.)

(c.)

Figure 13. ASR rate of change comparison of the experimental (a, b) Fe-17Cr alloys and (c) higher Cr alloys.

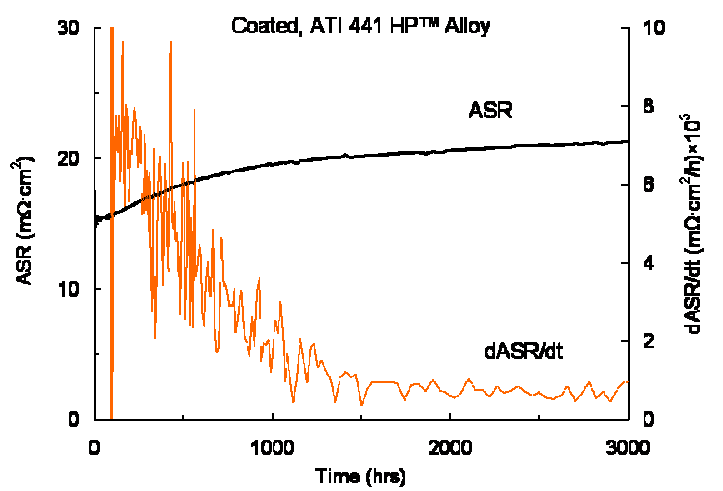

Figure 14. ASR and ASR rate of change for the ATI 441 HPTM alloy test coupon coated with the PNNL ceriummodified manganese cobaltite spinel coating. 


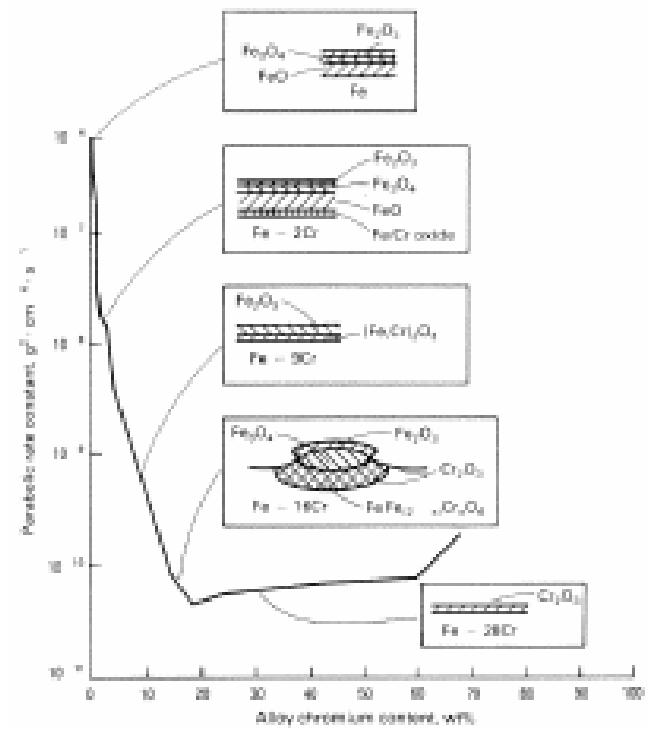

Figure 15. Schematic of the variation of the oxidation rate and oxide scale structure with alloy chromium content (based on isothermal studies at $1000^{\circ} \mathrm{C}$ in 0.13 atm oxygen) ${ }^{[16]}$.

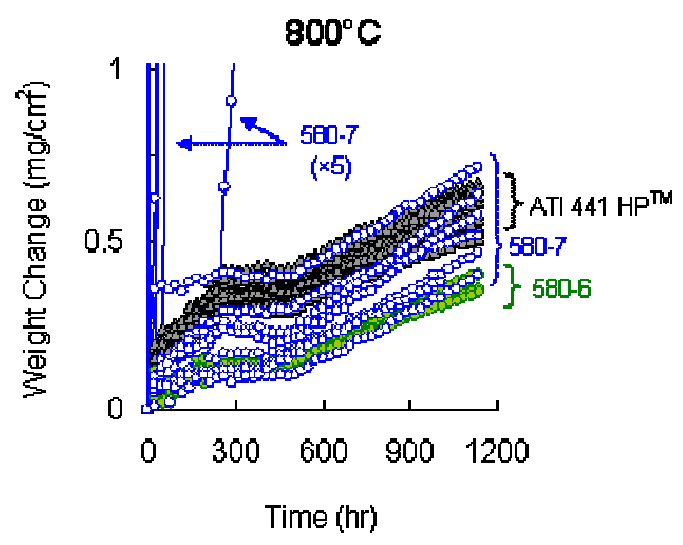

Figure 16. Isothermal oxidation weight change measurements at $800^{\circ} \mathrm{C}$ for ATI 441 HPTM, EXP. 580-6, and EXP. $580-7$ alloys.

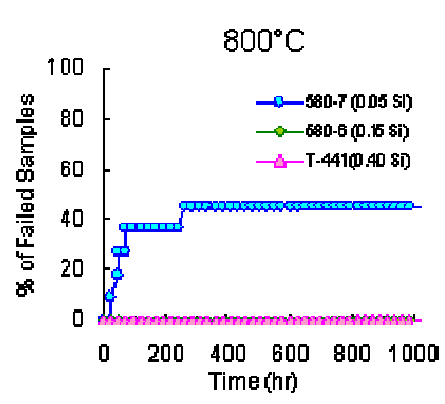

(a.)

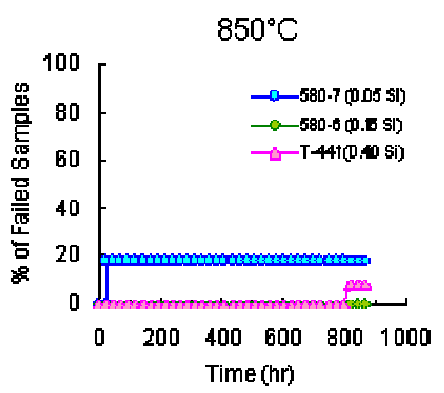

(b.)

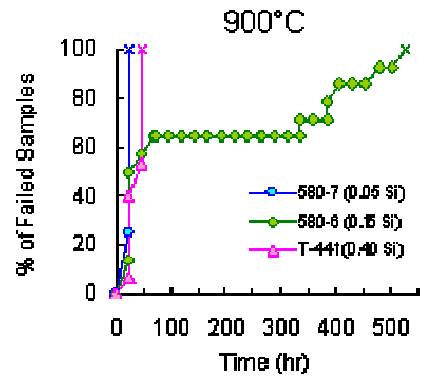

(c.)

Figure 17. Percent of failed samples as a function of time at (a.) $800^{\circ} \mathrm{C}$, (b.) $850^{\circ} \mathrm{C}$, and (c.) $900^{\circ} \mathrm{C}$ in a breakaway oxidation study of Fe-17Cr alloys. 


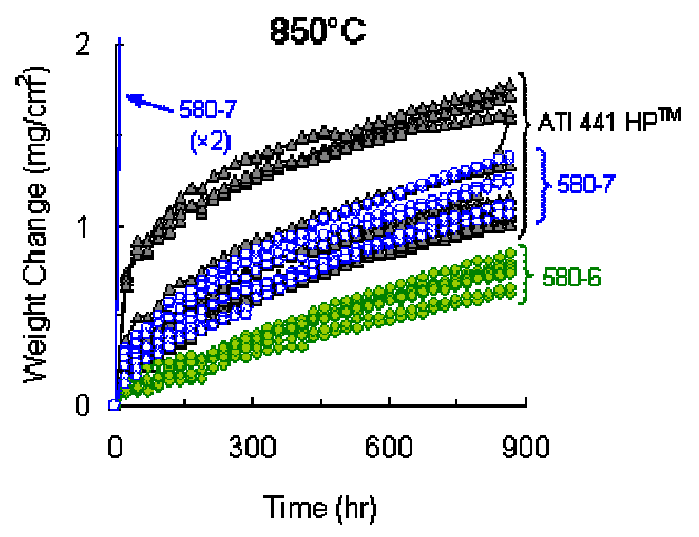

Figure 18. Isothermal oxidation weight change measurements at $850^{\circ} \mathrm{C}$ for ATI 441 HPTM, EXP. 580-6, and EXP. 580-7 alloys.

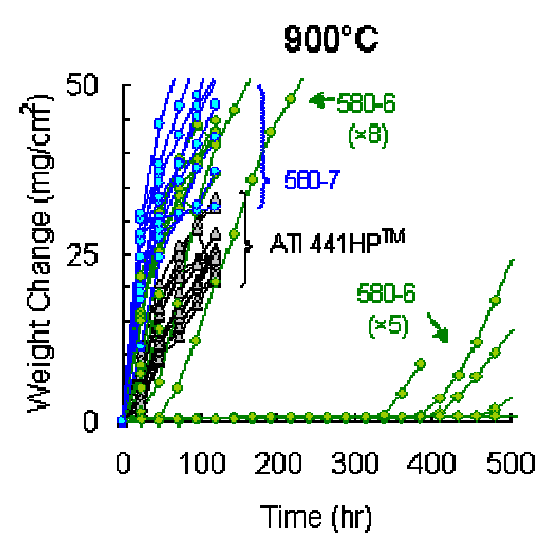

Figure 19. Isothermal oxidation weight change measurements at $900^{\circ} \mathrm{C}$ for ATI 441 HPTM, EXP. 580-6, and EXP. 580-7 alloys.

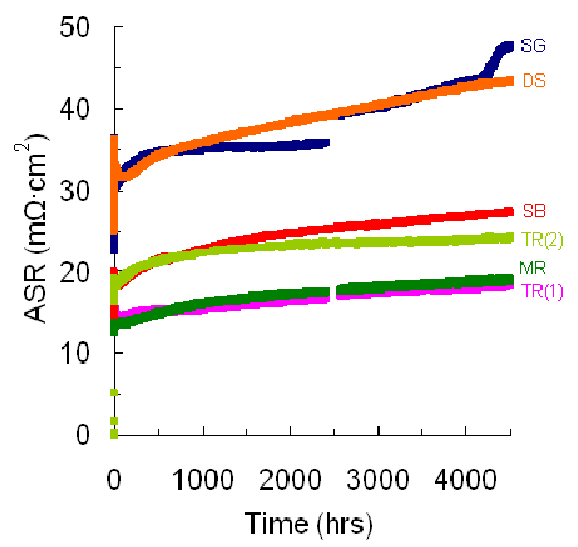

Figure 20. Compilation of ASR test results versus time of all surface-modified ATI 441 HPTM alloy coupons for comparison $(\mathrm{DS}=$ desiliconized, $\mathrm{SG}=$ surface ground, $\mathrm{SB}=$ surface blasted, $\mathrm{TR}=$ temper rolled, $\mathrm{MR}=$ pickle annealed mill reference) 


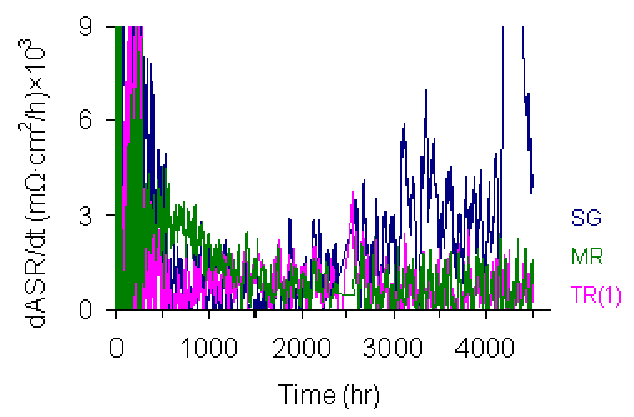

(a.)

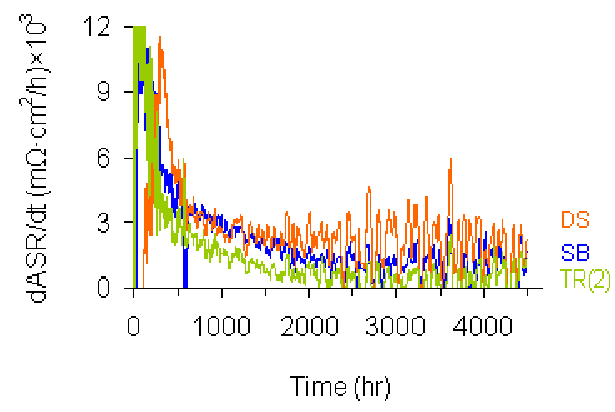

(b.)

Figure 21. Plots of ASR rate of change measurement versus time to better understand long-term material behavior as test coupons settle into a steady state behavior $(\mathrm{DS}=$ desiliconized, $\mathrm{SG}=$ surface ground, $\mathrm{SB}=$ surface blasted, TR $=$ temper rolled, $\mathrm{MR}=$ pickle annealed mill reference)

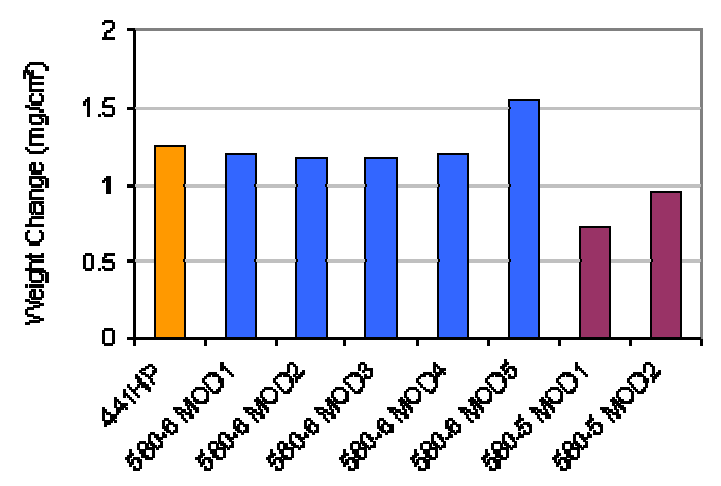

Figure 22. Weight change of $3^{\text {rd }}$-Generation alloy coupons following $800^{\circ} \mathrm{C}$ isothermal exposure for 5,000 hours

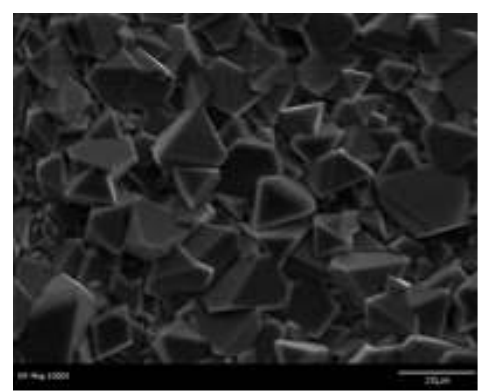

a. ATI $441 \mathrm{HP}$ alloy

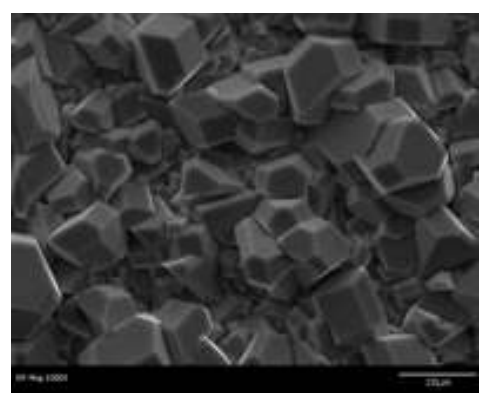

d. EXP. 580-6 MOD3

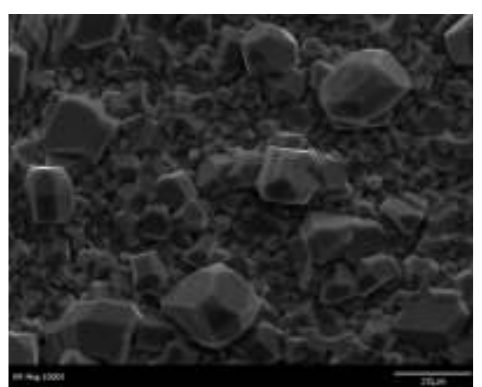

b. EXP. 580-6 MOD1

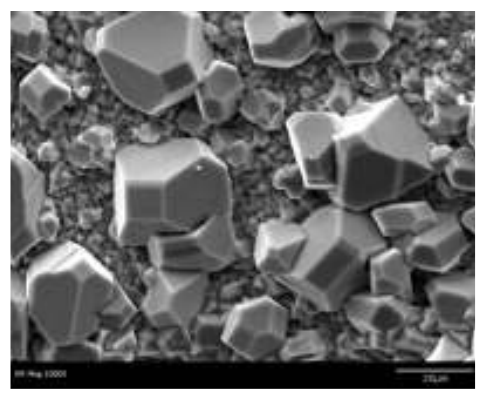

e. EXP. 580-6 MOD4

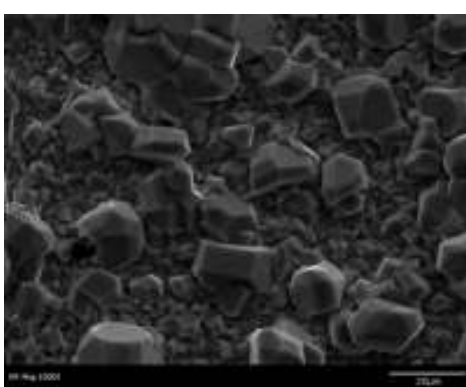

c. EXP. 580-6 MOD2

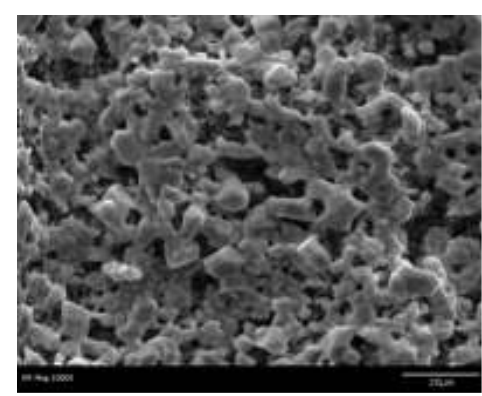

f. EXP. 580-6 MOD5 


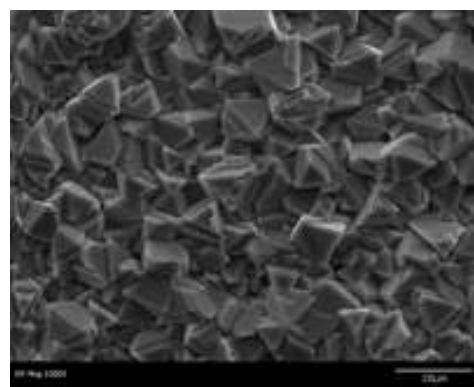

g. EXP. 580-5 MOD1

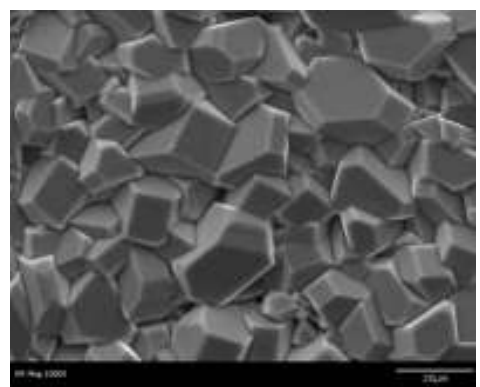

h. EXP. 580-5 MOD2

Figure 23 . The topological structures of the coated regions of $3^{\text {rd }}$-Generation alloys after 5,000 hours at $800^{\circ} \mathrm{C}$

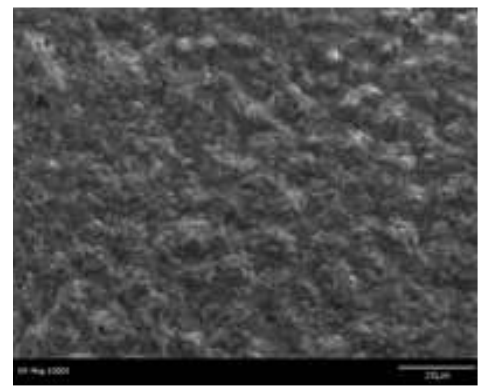

a. ATI 441 HP alloy

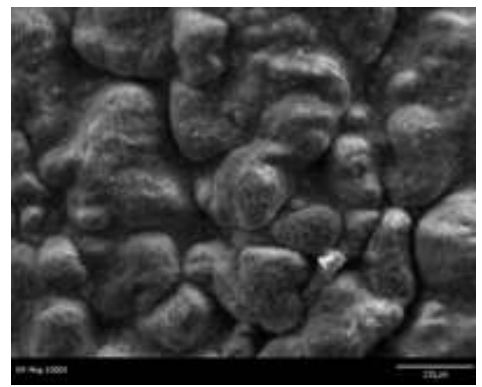

d. EXP. 580-6 MOD3

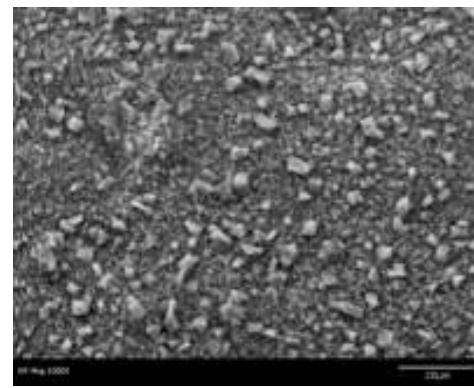

g. EXP. 580-5 MOD1

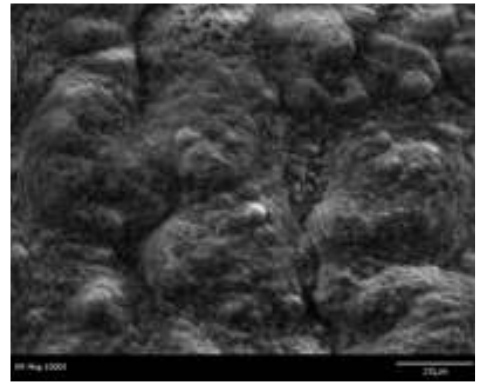

b. EXP. 580-6 MOD1

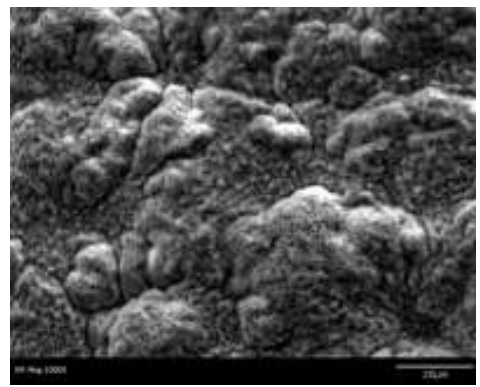

e. EXP. 580-6 MOD4

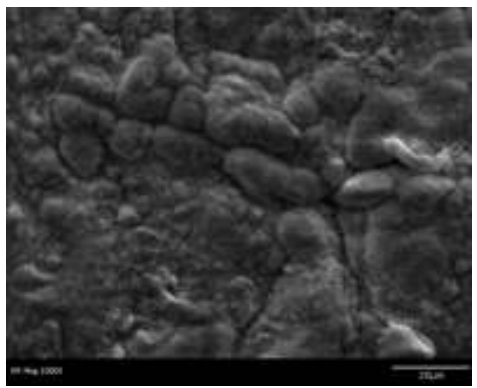

h. EXP. 580-5 MOD2

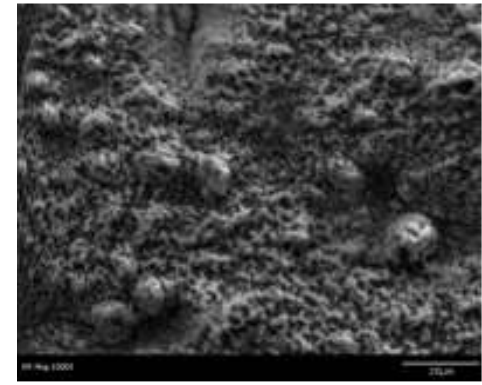

c. EXP. 580-6 MOD2

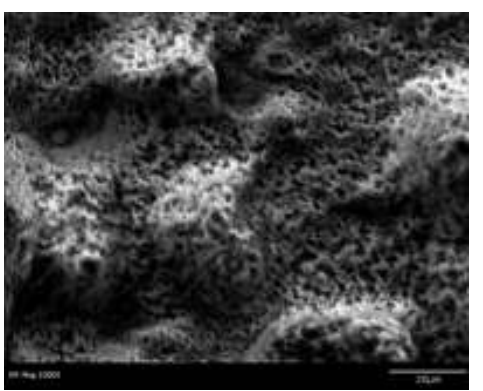

f. EXP. 580-6 MOD5

Figure 24. The topological structures of the uncoated regions (oxides) of $3^{\text {rd }}$-Generation alloys after 5,000 hours at $800^{\circ} \mathrm{C}$ 


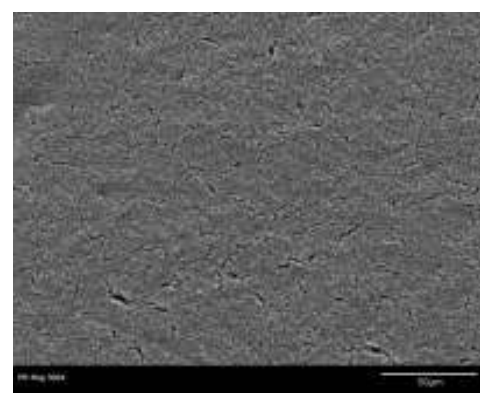

(a.)

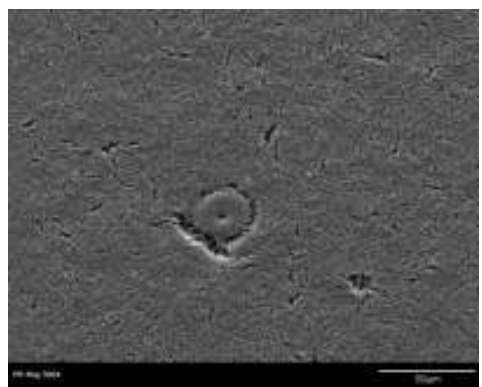

(b.)

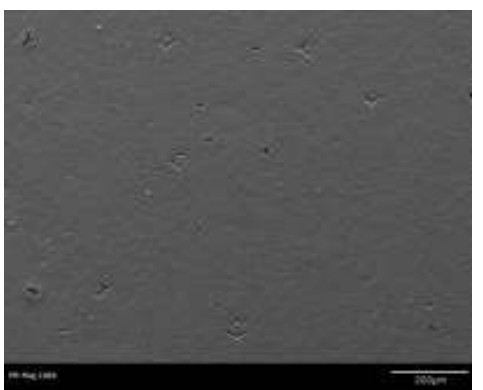

(c.)

Figure 25. The topological structure of the coating on an untested, coated EXP. 580-6 MOD1 coupon showing (a.) surface tearing and $(b, c$.) the retained mesh pattern associated with screen printing.

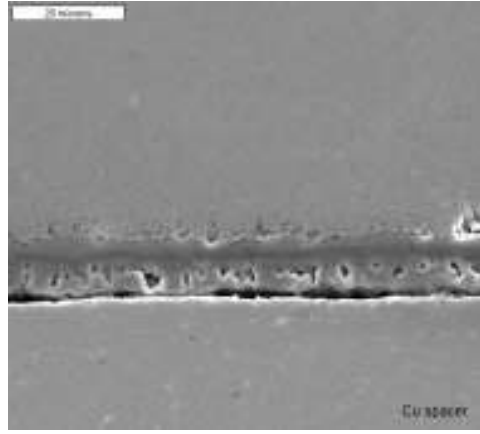

(a.)

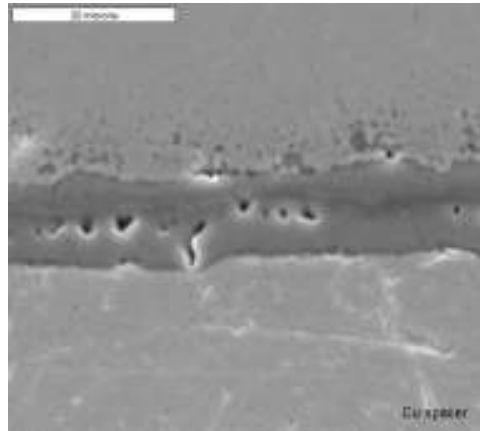

(c.)

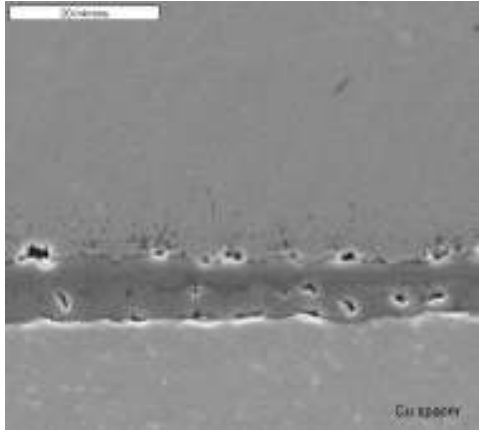

(b.)

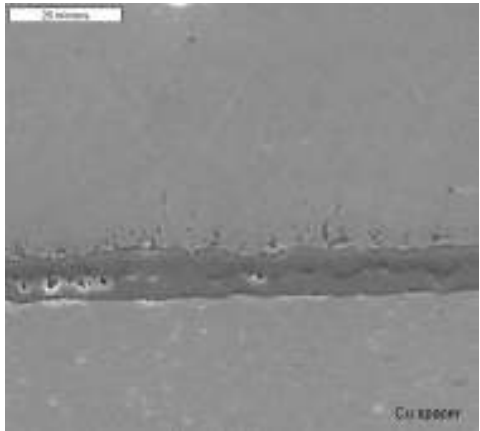

(d.)

Figure 26. Duplex oxide structure on the uncoated region of the ATI $441 \mathrm{HP}^{\mathrm{TM}}$ coupon after 5,000 hours at $800^{\circ} \mathrm{C}$

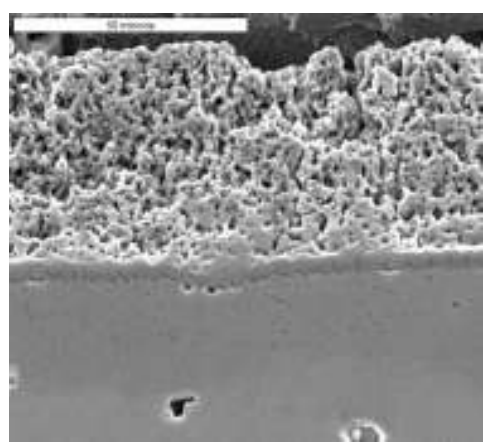

(a.)

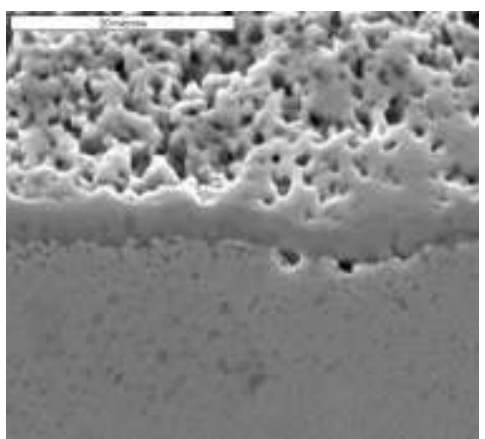

(b.)

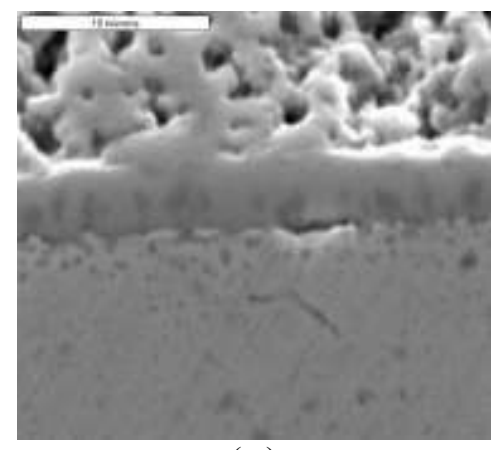

(c.) 


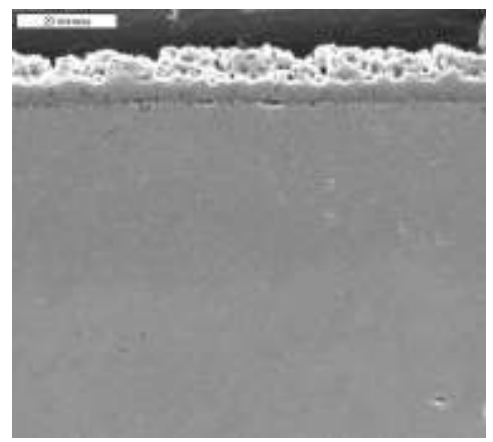

(d.)

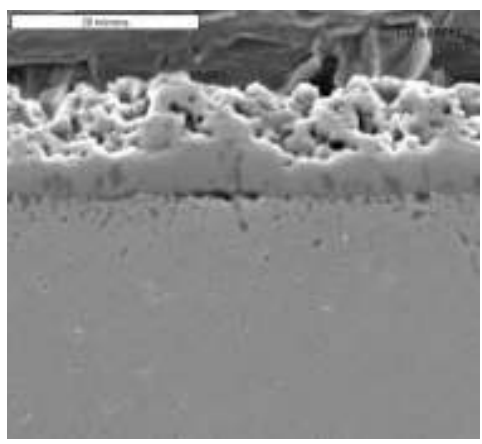

(e.)

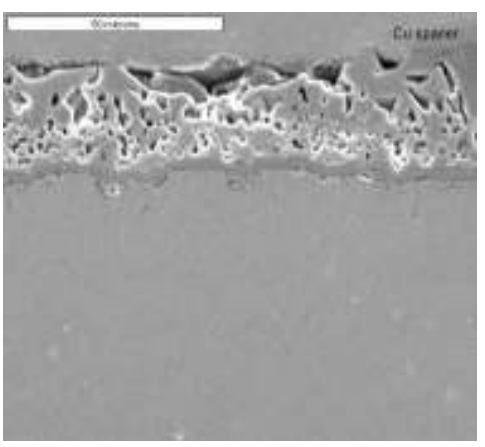

(f.)

Figure 27. Cross-section of the spinel-coated region of the ATI $441 \mathrm{HP}^{\mathrm{TM}}$ coupon after 5,000 hours at $800^{\circ} \mathrm{C}$

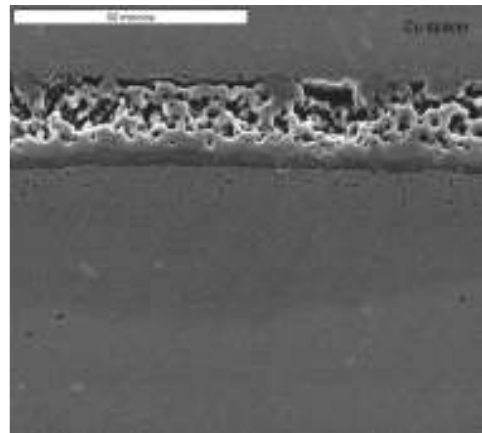

(a.)

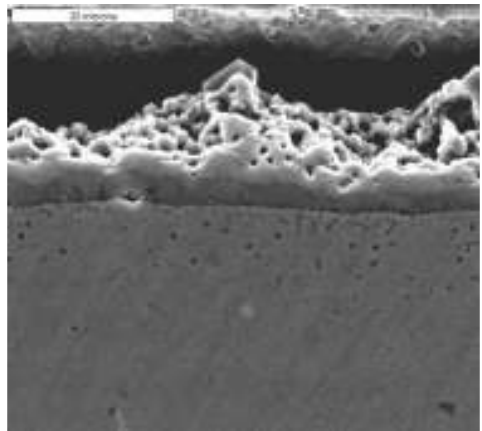

(b.)

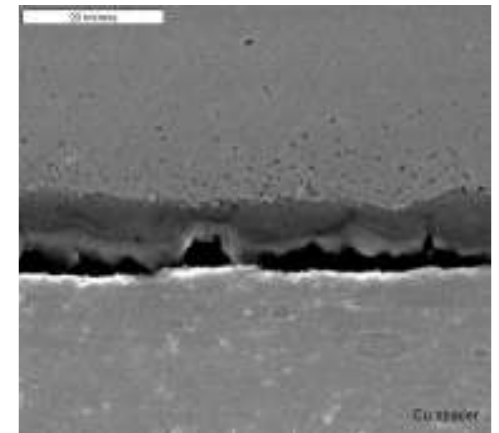

(c.)

Figure 28. Cross-section of the coated (a, b) and uncoated (c) sides of the EXP. 580-6 MOD1 experimental alloy coupon after 5,000 hours at $800^{\circ} \mathrm{C}$

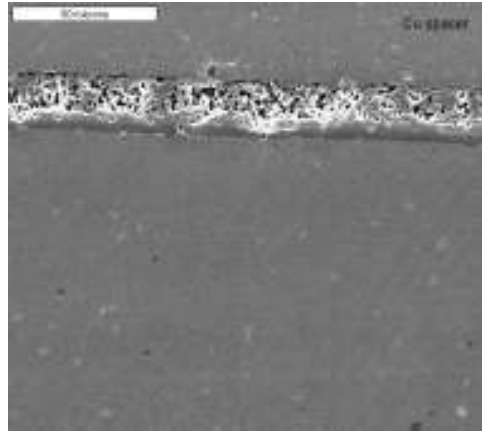

(a.)

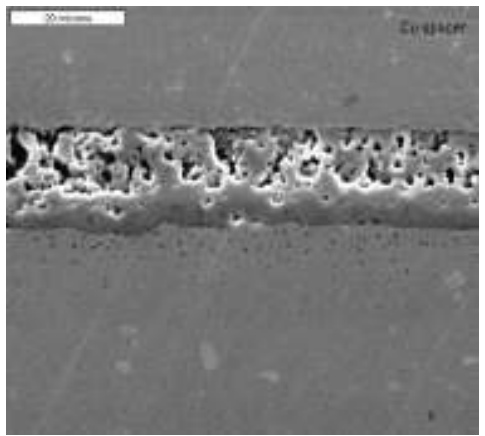

(b.)

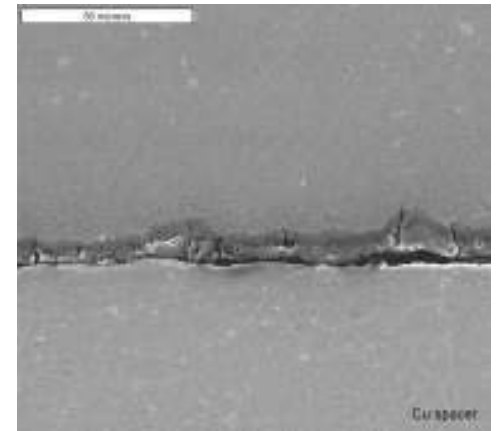

(c.)

Figure 29. Cross-section of the coated (a, b) and uncoated (c) sides of the EXP. 580-6 MOD2 experimental alloy coupon after 5,000 hours at $800^{\circ} \mathrm{C}$

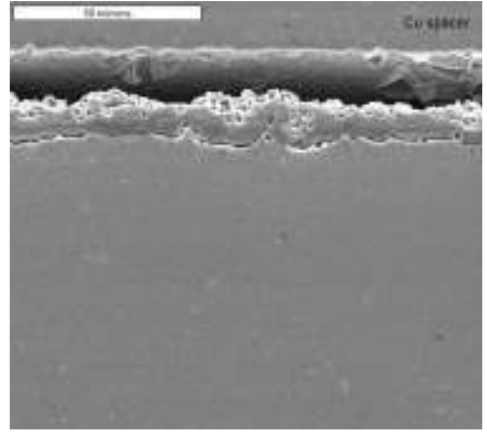

(a.)

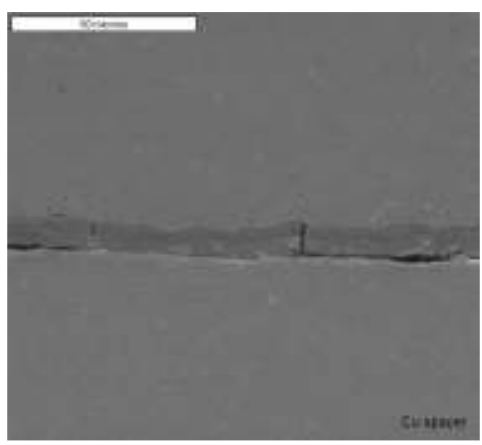

(b.)

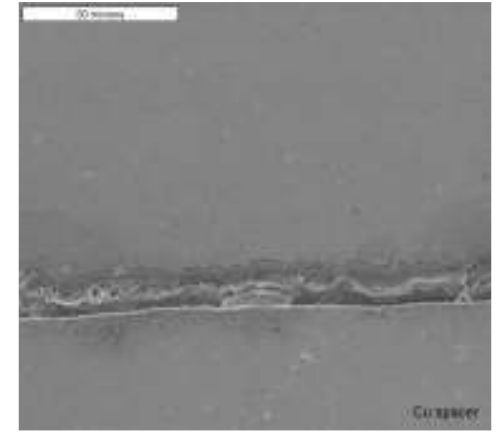

(c.) 
Figure 30. Cross-section of the coated (a) and uncoated (b, c) sides of the EXP. 580-6 MOD3 experimental alloy coupon after 5,000 hours at $800^{\circ} \mathrm{C}$

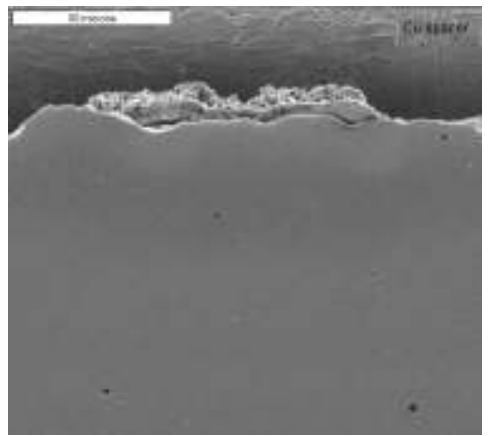

(a.)

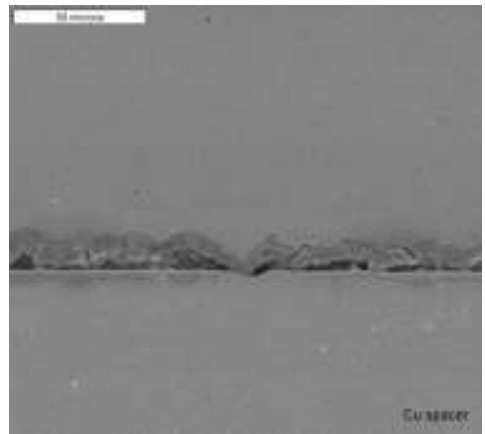

(b.)

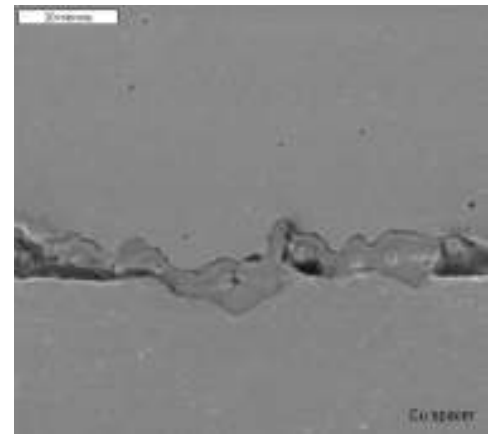

(c.)

Figure 31. Cross-section of the coated (a) and uncoated (b, c) sides of the EXP. 580-6 MOD4 experimental alloy coupon after 5,000 hours at $800^{\circ} \mathrm{C}$

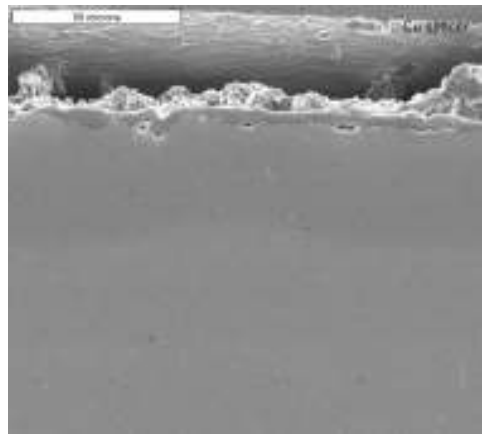

(a.)

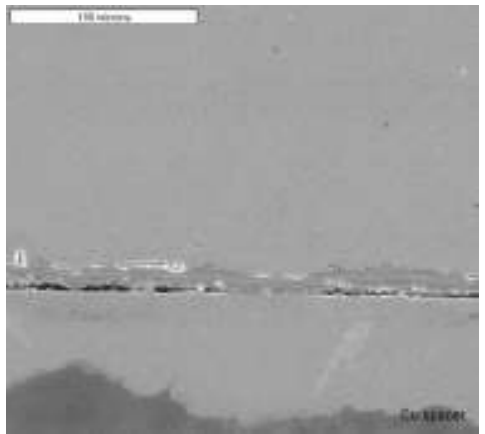

(b.)

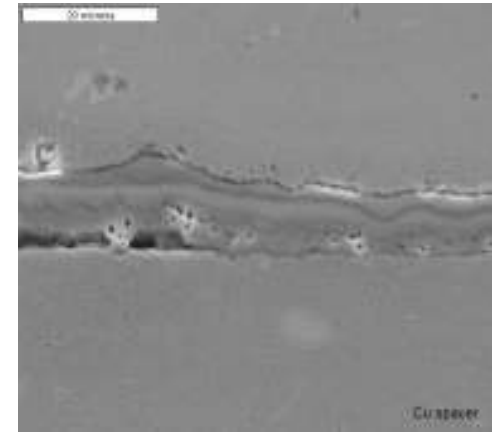

(c.)

Figure 32. Cross-section of the coated (a) and uncoated (b, c) sides of the EXP. 580-6 MOD5 experimental alloy coupon after 5,000 hours at $800^{\circ} \mathrm{C}$

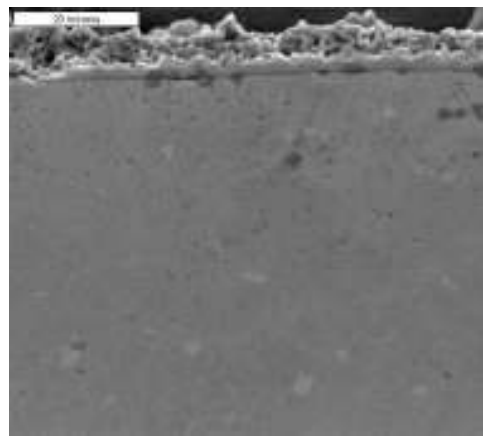

(a.)

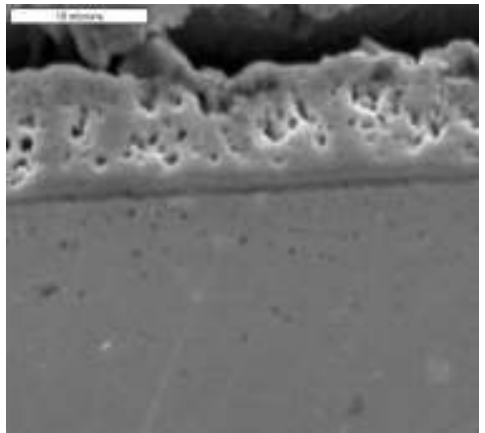

(b.)

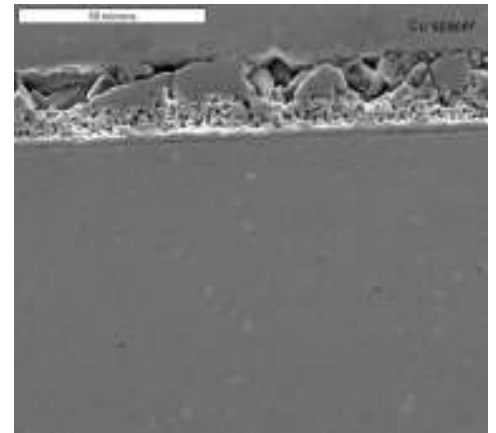

(c.) 


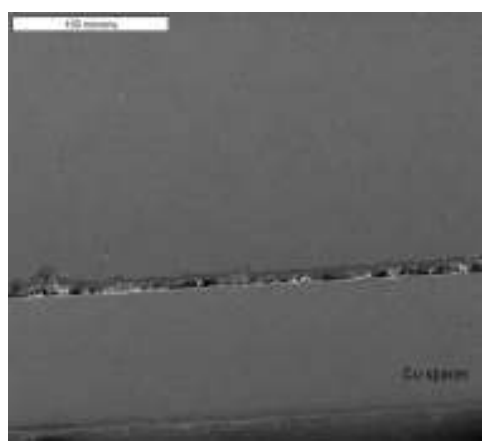

(d.)

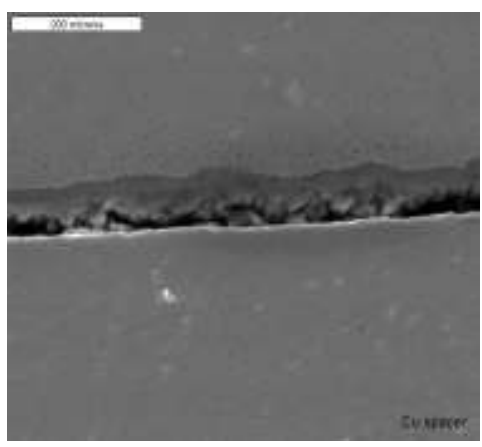

(e.)

Figure 33. Cross-section of the coated (a, b, c) and uncoated (d, e) sides of the EXP. 580-5 MOD1 experimental alloy coupon after 5,000 hours at $800^{\circ} \mathrm{C}$

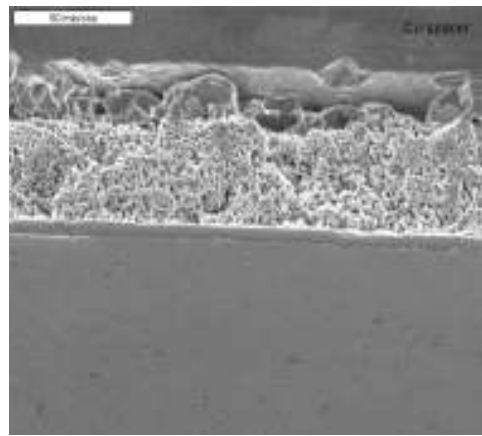

(a.)

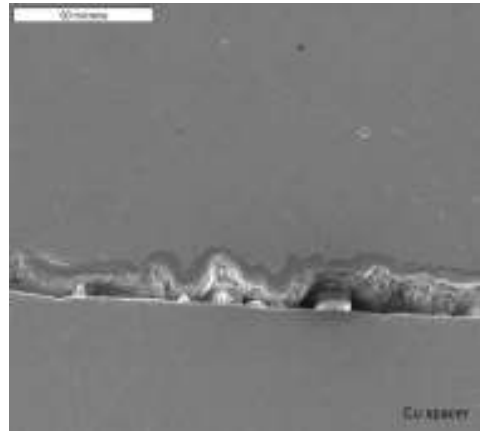

(b.)

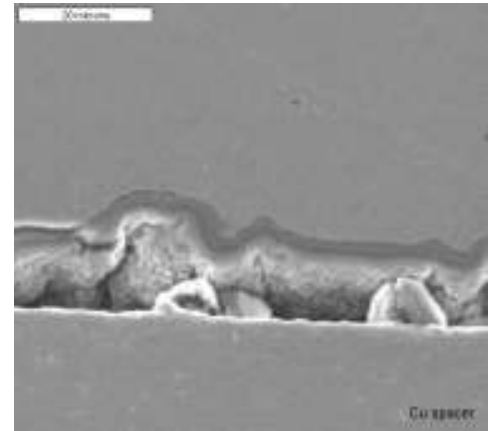

(c.)

Figure 34. Cross-section of the coated (a) and uncoated (b, c) sides of the EXP. 580-5 MOD2 experimental alloy coupon after 5,000 hours at $800^{\circ} \mathrm{C}$

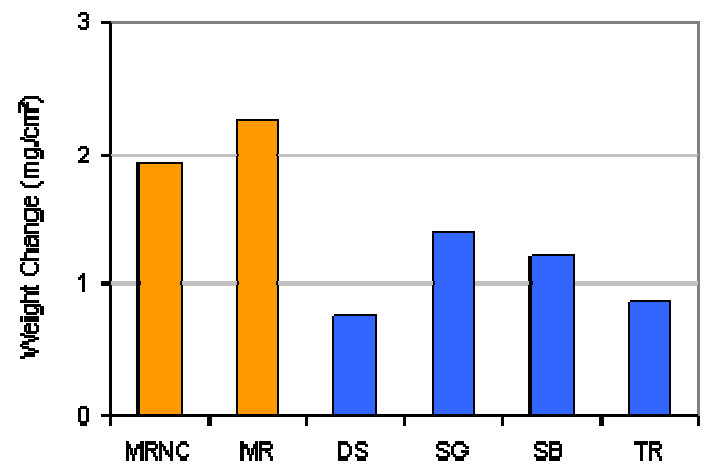

Figure 35. Weight change of surface-modified ATI $441 \mathrm{HP}^{\mathrm{TM}}$ alloy coupons following $800^{\circ} \mathrm{C}$ exposure for 5,000 hours
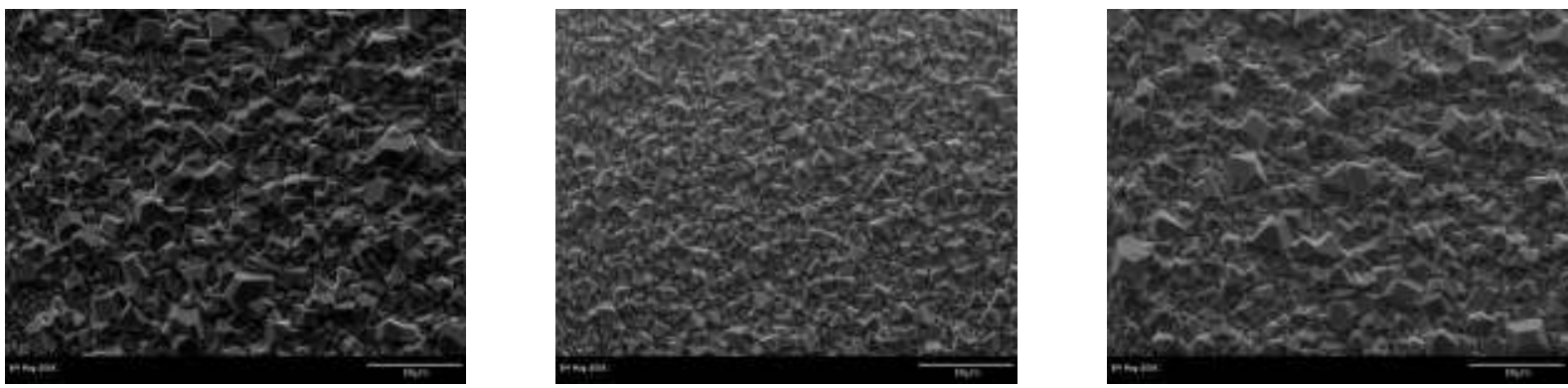
a. MR (mill reference)

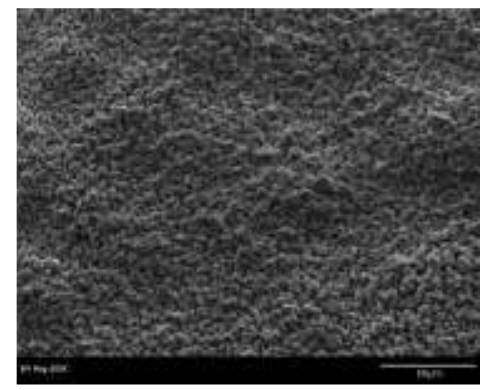

d. SB (surface blasted) b. DS (desiliconized)

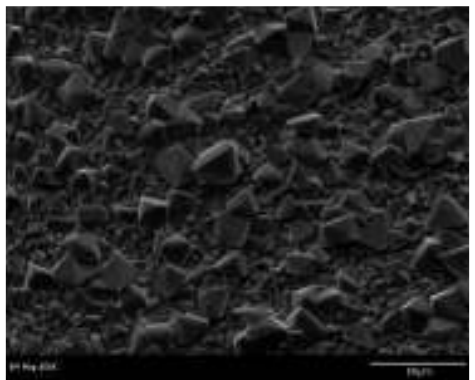

e. TR (temper rolled; $50 \%$ reduction)

c. SG (surface ground)

Figure 36. The topological structure of the coated region after 5,000 hours at $800^{\circ} \mathrm{C}$

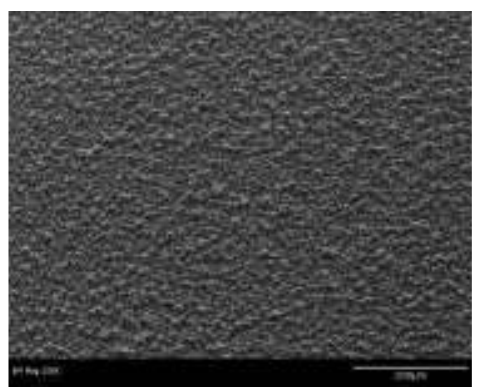

a. MRNC (mill reference, no coating)

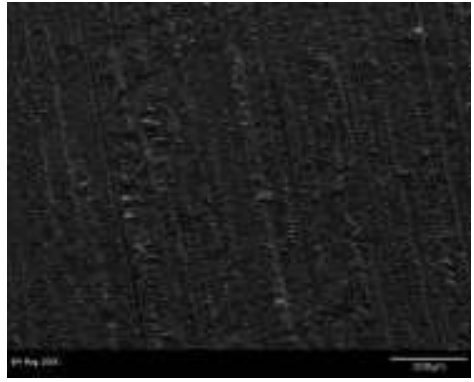

d. SG (surface ground)

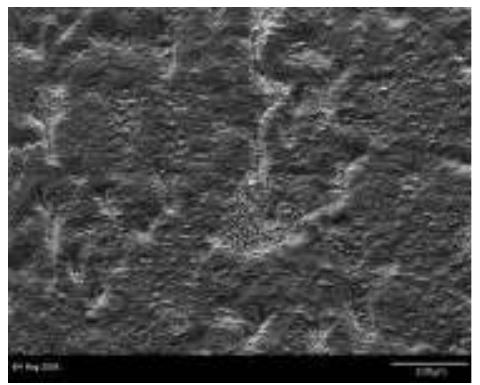

b. MR (mill reference)

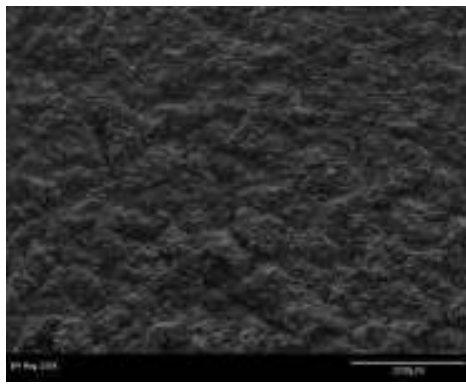

e. SB (surface blasted)

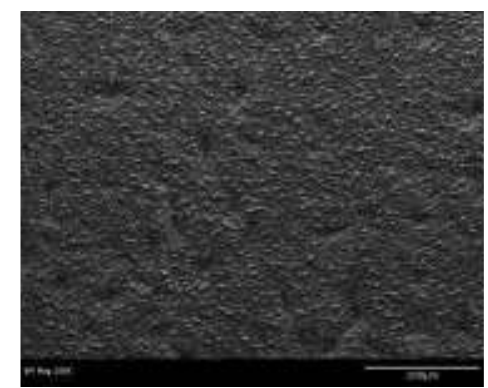

c. DS (desiliconized)

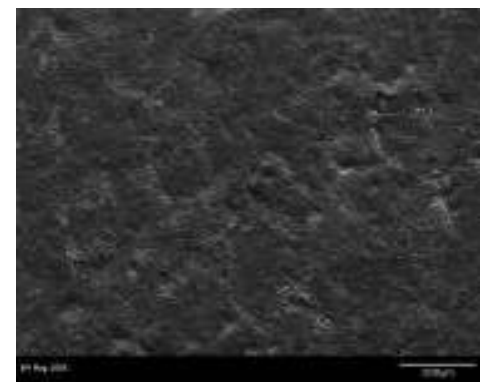

f. TR (temper rolled; $50 \%$ reduction)

Figure 37 . The topological structure of the uncoated region after 5,000 hours at $800^{\circ} \mathrm{C}$

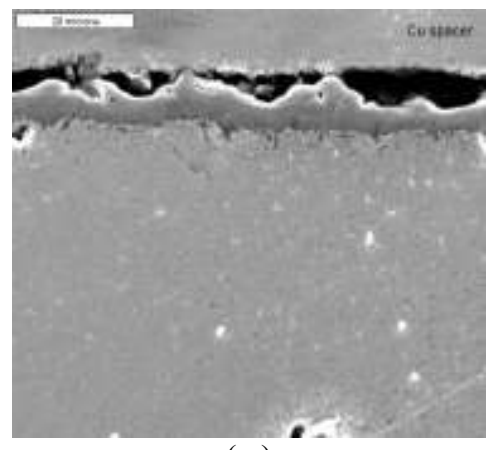

(a.)

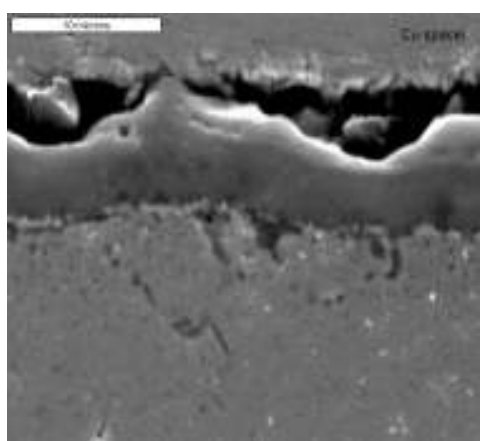

(b.)

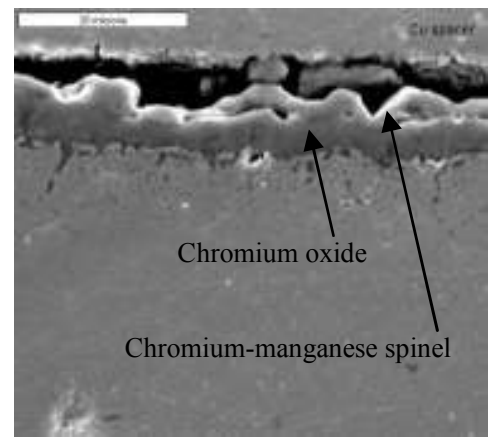

(c.) 


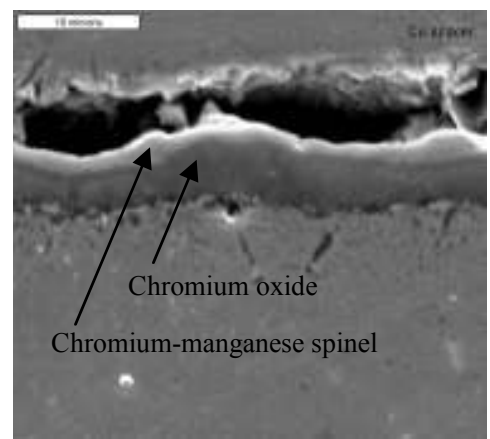

(d.)

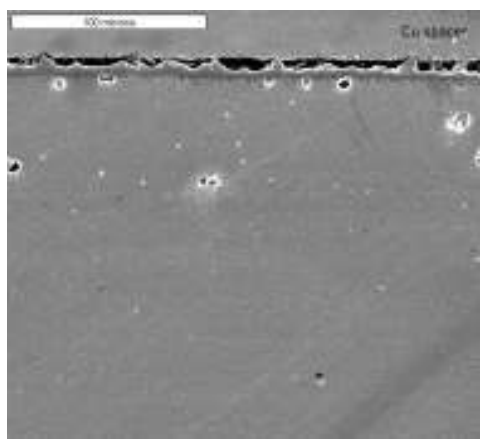

(e.)

Figure 38. Cross-section of the scale formed on an MRNC (mill-reference, non-coated) coupon after 5,000 hours at $800^{\circ} \mathrm{C}$

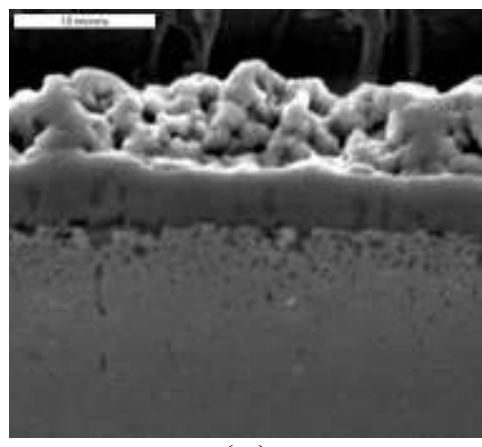

(a.)

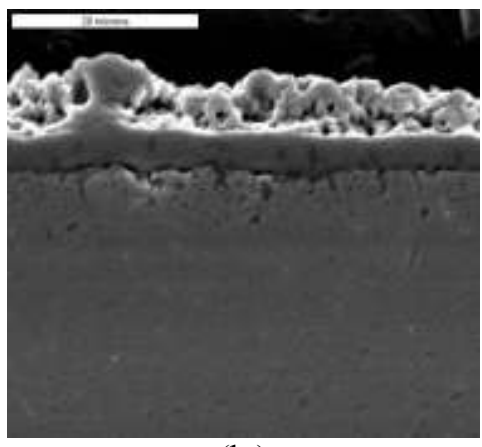

(b.)

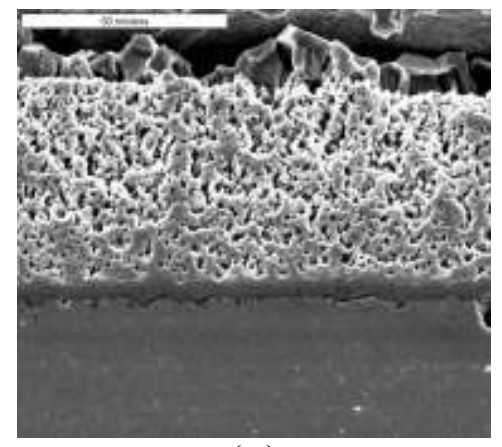

(c.)

Figure 39. Cross-section of the coated side of the MR (mill-reference) coupon after 5,000 hours at $800^{\circ} \mathrm{C}$

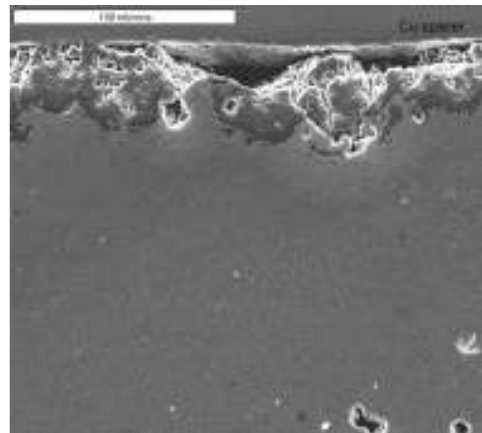

(a.)

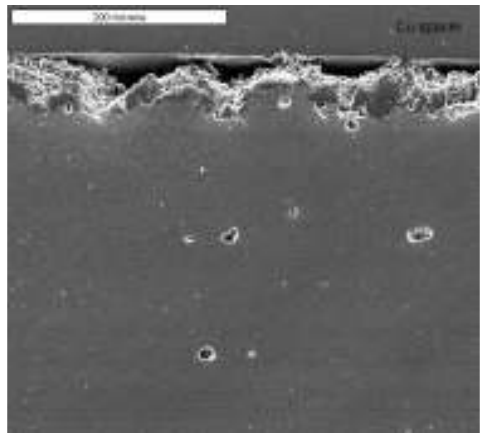

(b.)

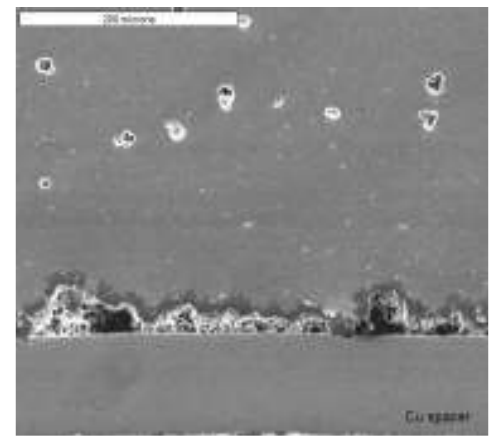

(c.)

Figure 40. Cross-section of the coated (a, b) and uncoated (c) sides of the SB (surface blasted) coupon after 5,000 hours at $800^{\circ} \mathrm{C}$

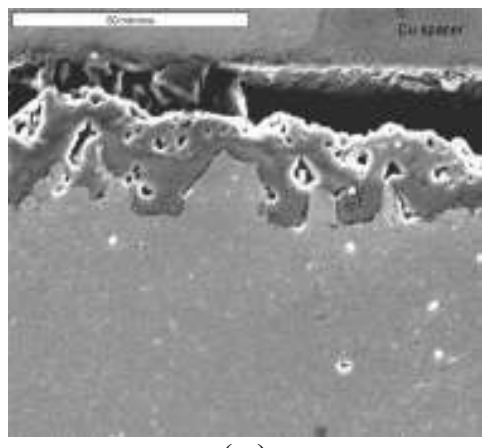

(a.)

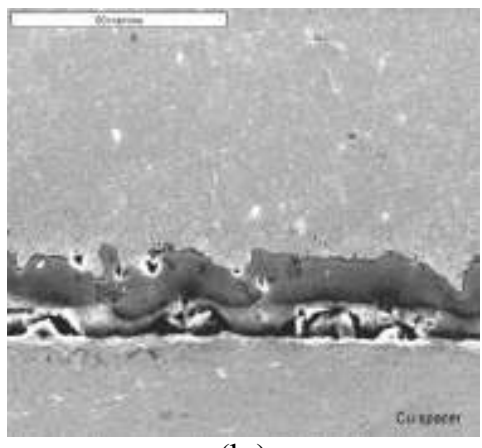

(b.)

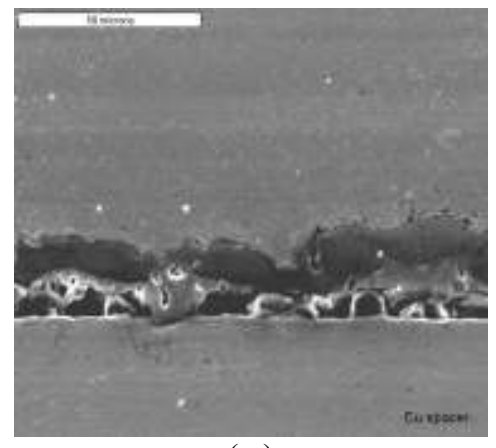

(c.) 
Figure 41. Cross-section of the coated (a) and uncoated (b, c) sides of the SG (surface ground) coupon after 5,000 hours at $800^{\circ} \mathrm{C}$

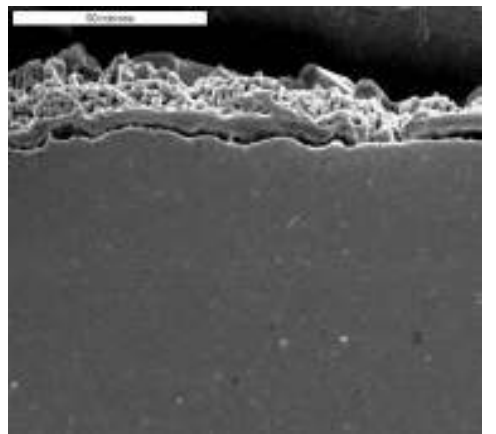

(a.)

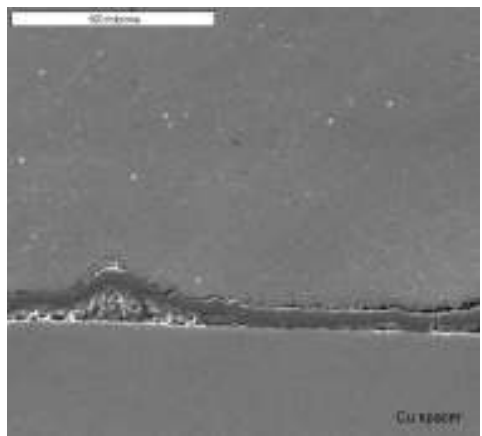

(b.)

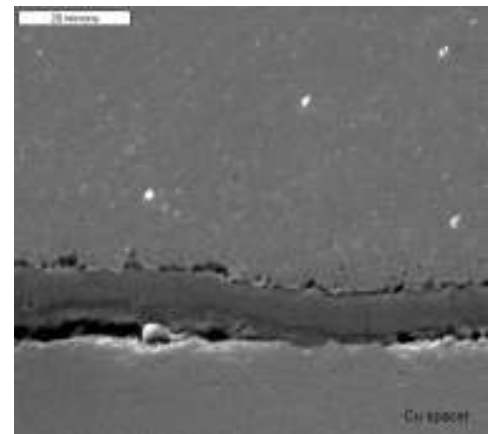

(c.)

Figure 42. Cross-section of the coated (a) and uncoated (b, c) sides of the TR (temper rolled) coupon after 5,000 hours at $800^{\circ} \mathrm{C}$

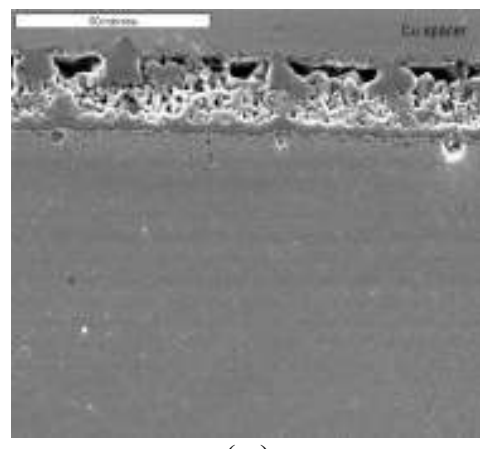

(a.)

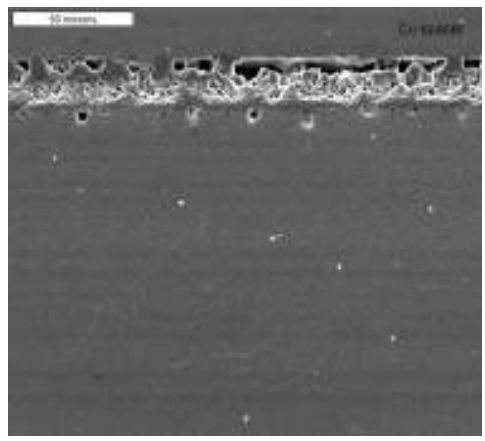

(d.)

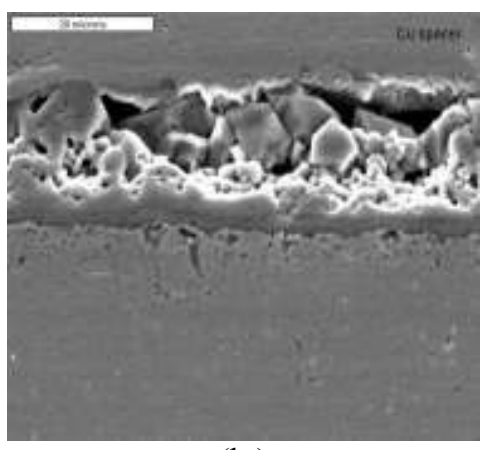

(b.)

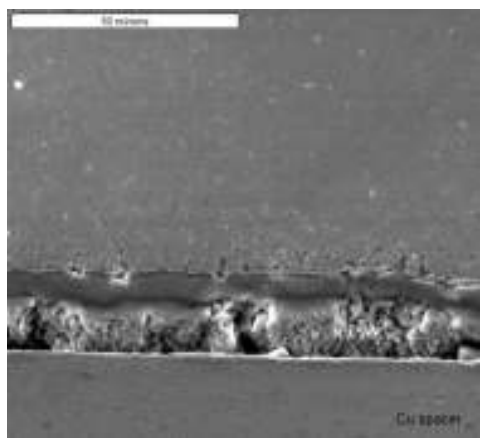

(e.)

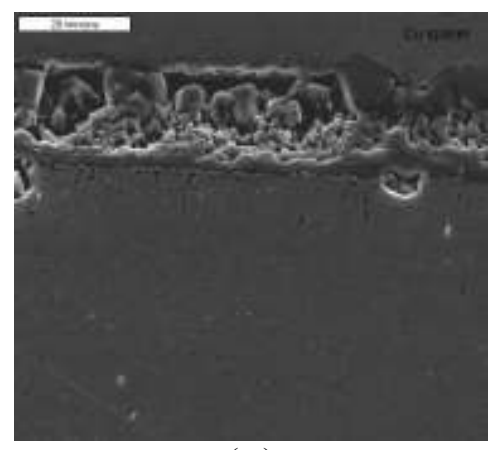

(c.)

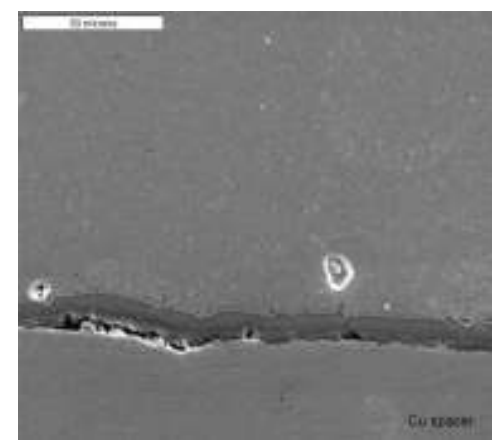

(f.)

Figure 43. Cross-section of the coated (a, b, c, d) and uncoated (e, f) sides of the DS (desiliconized) coupon after 5,000 hours at $800^{\circ} \mathrm{C}$

\section{References}

1. Wachsman, E.D. and S.C. Singhal, "Solid Oxide Fuel Cell Commercialization, Research, and Challenges." ECS Interface, 18[3], 38 (2009).

2. Rufner, J., et. al. "Oxidation behavior of stainless steel 430 and 441 at $800^{\circ} \mathrm{C}$ in single (air/air) and dual atmosphere (air/hydrogen) exposures.” Intl. J. of Hydrogen Energy, Vol. 33, 2008, pp. 13921398 
3. U.S. DOE Fossil Energy Fuel Cell Program, W. Surdoval, presented at the $7^{\text {th }}$ Annual SECA Workshop and Peer Review, Philadelphia, PA, September 12-14, 2006.

4. Fergus, J. "Materials Challenges for Solid-Oxide Fuel Cells.” JOM., December 2007, pp. 56-62

5. Fuel Cell Handbook, 7th Edition, EG\&G Technical Services, Inc. p. 7-6

6. Visco, S.J. et. al. "Development of Novel Electrode Structures and Stabilization of Metal Components for Cost-competitive SOFCs." Unpublished paper presented at the Sixth Annual SECA Workshop, Asilomar CA, April 17-21, 2005.

7. Rakowski, J. "High Temperature Oxidation of Heat-Resistant Alloys in Combustion Environments." CORROSION 2008, March 16-20, 2008, New Orleans, LA. (Paper 08446)

8. Yang, Z., et. al. "Ce-Modified $(\mathrm{Mn}, \mathrm{Co})_{3} \mathrm{O}_{4}$ Spinel Coatings on Ferritic Stainless Steels for SOFC Interconnect Applications.” Electrochem. Solid-State Lett., Vol. 11, Issue 8, 2008: B140-B143.

9. Fergus, J.W. and Y. Zhao. "Low-Chromium Alloys for Solid Oxide Fuel Cell Interconnects." Paper submitted for presentation at SOFC XII, Montreal Canada, May 1-6 2011

10. Giggins, C.S. and F.S. Pettit, "Oxidation of Ni-Cr Alloys Between $800^{\circ} \mathrm{C}$ and $1200^{\circ} \mathrm{C} . "$ Trans. Met. Soc. AIME 245, 2509 (1969)

11. Dulieu, D., et. al. "Development of Interconnect Materials for Intermediate Temperature SOFC's." Ed. Philippe Stevens. Proceedings from Third European Solid Oxide Fuel Cell Forum. Nantes, France. June 2-5, 1998.

12. Jablonski, P.D. et. al. "Exploration of alloy 441 chemistry for solid oxide fuel cell interconnect application.” J Power Sources, Vol. 195, Issue 3, 1 February 2010, pp. 813-820

13. Schuisky, M. "The Effect of Minor Alloying Elements in Ferritic Steels for Interconnects in SOFCs." Fuel Cell Seminar, 2006 (P0804-Schuisky).

14. Yang, Z.G., et. al. " $\mathrm{Mn}_{1.5} \mathrm{Co}_{1.5} \mathrm{O}_{4}$ Spinel Protection Layers on Ferritic Stainless Steels for SOFC Interconnect Applications." Electrochem. Solid-State Lett., Vol. 8, Issue 3, 2005: A168-170.

15. Stevenson, J.W., et. al. "Effect of Surface Treatments on Properties of Spinel-coated AISI 441." Topical Report submitted to NETL in February 2011.

16. Davis, J.R. ASM Specialty Handbook “Stainless Steels.” ASM International, 1994, p. 207

\section{Author Bibliography}

Dr. Matthew Bender is a Metallurgical Specialist in the Market \& Product Development Group at ATI Allegheny Ludlum's Technical \& Commercial Center where he is the supervisor of the High Temperature Oxidation Laboratory. He manages various high temperature alloy development projects and is interested in material applications in alternative energy markets. 


\section{List of Acronyms and Abbreviations}

ASR - area specific resistance

ATI - Allegheny Technologies

$\mathrm{Ce}-\mathrm{MC}$ - cerium-modified $(\mathrm{Mn}, \mathrm{Co})_{3} \mathrm{O}_{4}$ spinel

$\mathrm{CTE}$ - coefficient of thermal expansion

DOE - Department of Energy

LSM - lanthanum strontium manganate ceramic

PNNL - Pacific Northwest National Laboratory

SEM - scanning electron microscopy

SOFC - solid oxide fuel cell

TGO - thermally grown oxide

${ }^{\circledR}$ Registered Trademark of ATI Properties, Inc. ${ }^{\mathrm{TM}}$ Trademark of ATI Properties, Inc. 


\section{$\underline{\text { Appendix }}$}

Post-test ASR coupons from the $3^{\text {rd }}$-Generation experimental alloys were sent to the Pacific Northwest National Laboratory for characterization. Micrographs were on a JEOL 7600F and measurements of the scale thickness were taken using Bersoft Image Measurement version 7.01. The average chromia scale thickness beneath the Ce-MC spinel coating on each of the coupons after 3,000 hours of testing is listed in Table A1. The ATI 441HP alloy coupon had the thickest oxide at 3.2 microns, while the EXP. 580-5 MOD1 alloy coupon had the thinnest oxide measured at 0.7 microns. Figure A1 shows selected micrographs used in this analysis.

A compositional analysis of the post-test ATI 441HP alloy test coupon was also conducted by PNNL. The results are shown in Figure A2. The micrograph shows LSM on the upper surface, Ce-MC spinel coating, chromia scale that formed during thermal exposure, and the underlying ATI 441HP alloy. It appears that some manganese chromium spinel formed in the chromia scale on the bottom side adjacent to the base alloy. Figures A3(a) and A3(b) shows this more clearly. Silicon, likely in the form of silica, is present at the interface between the chromia and manganese chromium spinel as shown in Figure A3(c). It is possible that some of this could be contamination from the colloidal silica used in the final polish of the sample. The interface is shown to be fairly porous and there does not seem to be much titanium ingress into the chromia scale. Compositions as measured by EDS are listed in Table A2. A line scan across the oxide and coating regions is shown in Figure A4.

\section{$\underline{\text { Appendix Tables }}$}

Table A1. Average chromia scale thickness on $3^{\text {rd }}$-Generation alloy coupons after ASR testing at $800^{\circ} \mathrm{C}$ for 3,000 hours

\begin{tabular}{|c|c|}
\hline Alloy & Average chromia scale thickness (microns) \\
\hline ATI 441HPTM alloy & 3.2 \\
\hline EXP. 580-6 MOD1 & 1.8 \\
\hline EXP. 580-6 MOD2 & 1.5 \\
\hline EXP. 580-6 MOD3 & 1.7 \\
\hline EXP. 580-6 MOD4 & 2.7 \\
\hline EXP. 580-6 MOD5 & 1.6 \\
\hline EXP. 580-5 MOD1 & 0.7 \\
\hline EXP. 580-5 MOD2 & 1.0 \\
\hline
\end{tabular}

Table A2. Compositions (atomic percent) of selected regions from the ATI 441HPTM alloy coupon

\begin{tabular}{|c|c|c|c|c|c|c|c|c|c|c|c|}
\hline Spectrum & $\mathbf{O}$ & $\mathbf{A l}$ & $\mathbf{S i}$ & $\mathbf{T i}$ & $\mathbf{C r}$ & $\mathbf{M n}$ & $\mathbf{F e}$ & $\mathbf{C o}$ & $\mathbf{N i}$ & $\mathbf{N b}$ & $\mathbf{C e}$ \\
\hline$\# \mathbf{1}$ & 4.9 & 0 & 0.9 & 0 & 18 & 0.2 & 76 & 0.3 & 0.4 & 0 & 0 \\
\hline$\# \mathbf{2}$ & 13 & 1.5 & 0.9 & 4.5 & 16 & 0.4 & 63 & 0.4 & 0.3 & 0.2 & 0 \\
\hline$\# \mathbf{3}$ & 69 & 0 & 0.2 & 0.4 & 28 & 1 & 0.3 & 0.5 & 0 & 0.1 & 0 \\
\hline$\# \mathbf{4}$ & 57 & 0 & 0 & 0.2 & 0.3 & 22 & 0.6 & 20 & 0 & 0 & 0.2 \\
\hline$\# \mathbf{5}$ & 44 & 0 & 0.4 & 0.3 & 1.1 & 28 & 1.1 & 24 & 0 & 0 & 0.4 \\
\hline$\# \mathbf{6}$ & 28 & 4.6 & 0 & 16 & 11 & 0 & 41 & 0 & 0 & 0 & 0 \\
\hline$\# \mathbf{7}$ & 0 & 0 & 0 & 13 & 18 & 0 & 66 & 0 & 0 & 2.9 & 0 \\
\hline$\# \mathbf{8}$ & 50 & 0 & 0.9 & 0.4 & 0.5 & 25 & 0 & 23 & 0 & 0 & 0 \\
\hline$\# \mathbf{9}$ & 65 & 0 & 0 & 0 & 0 & 18 & 0 & 17 & 0 & 0 & 0 \\
\hline$\# \mathbf{1 0}$ & 0 & 0 & 4.5 & 0 & 14 & 0 & 67 & 0 & 0 & 14.3 & 0 \\
\hline$\# \mathbf{1 1}$ & 58 & 0 & 4 & 0.4 & 4 & 17 & 0.4 & 16 & 0 & 0 & 0.3 \\
\hline
\end{tabular}




\section{Appendix Figures}

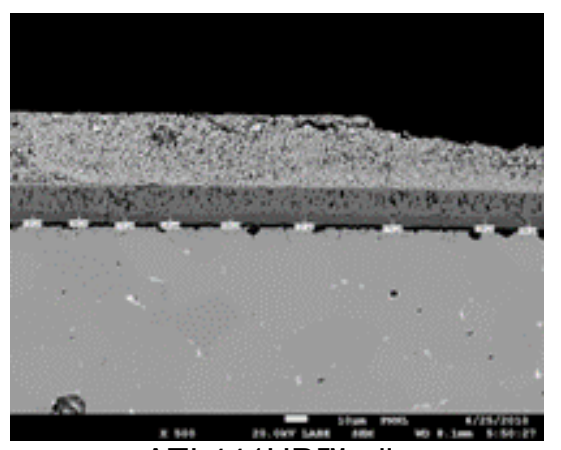

a. ATI 441HP ${ }^{\mathrm{TM}}$ alloy

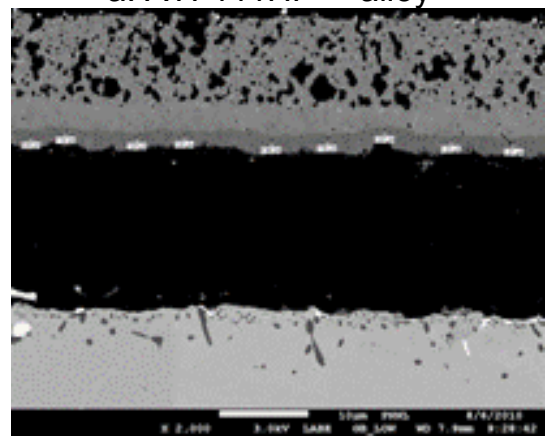

d. EXP. 580-6 MOD3

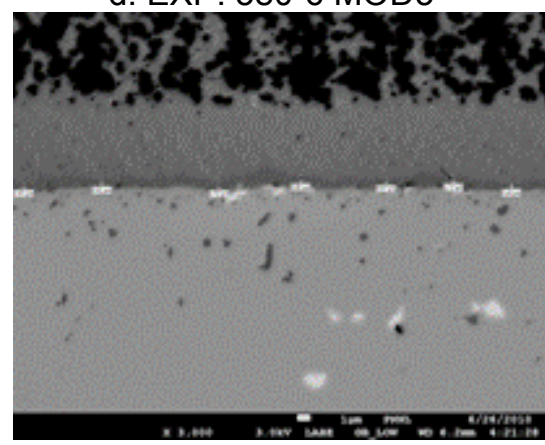

g. EXP. 580-5 MOD1

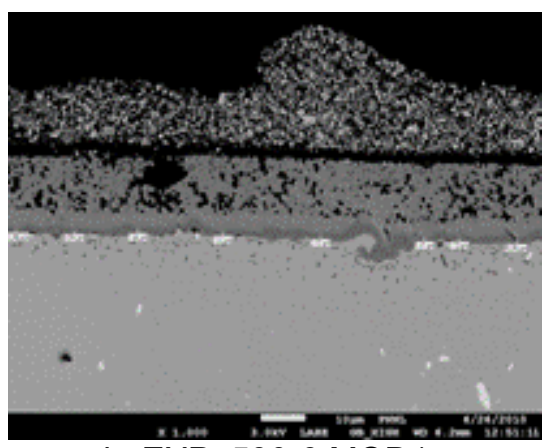

b. EXP. 580-6 MOD1

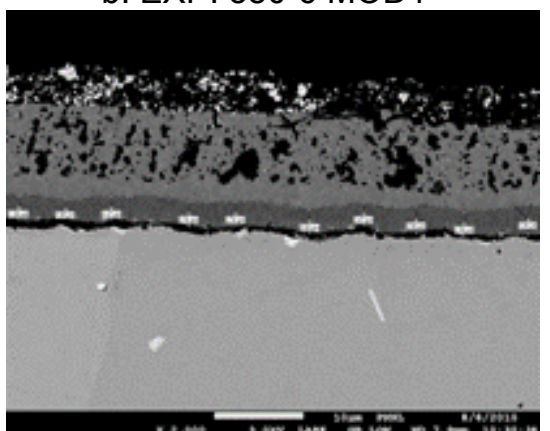

e. EXP. 580-6 MOD4

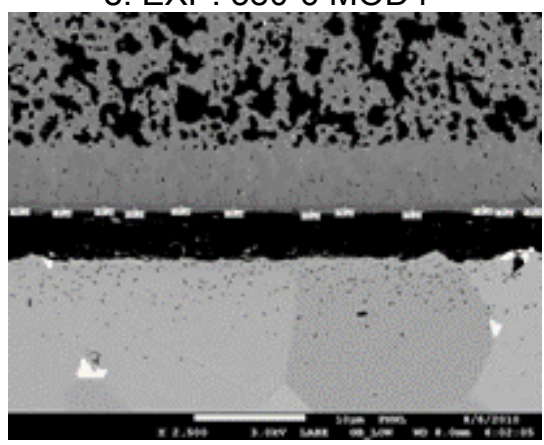

h. EXP. 580-6 MOD2

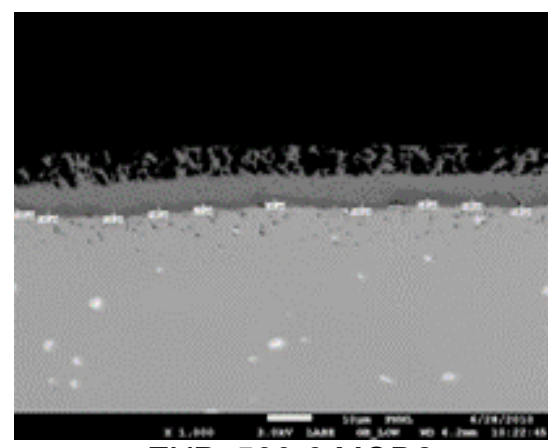

c. EXP. 580-6 MOD2

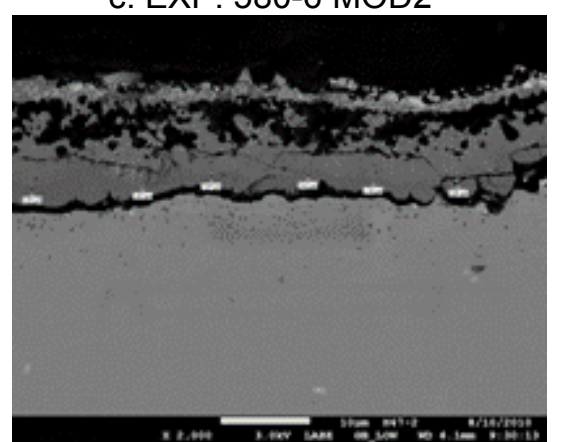

f. EXP. 580-6 MOD5

Figure A1. Selected micrographs of $3^{\text {rd }}$-Generation experimental alloys used to measure oxide thickness
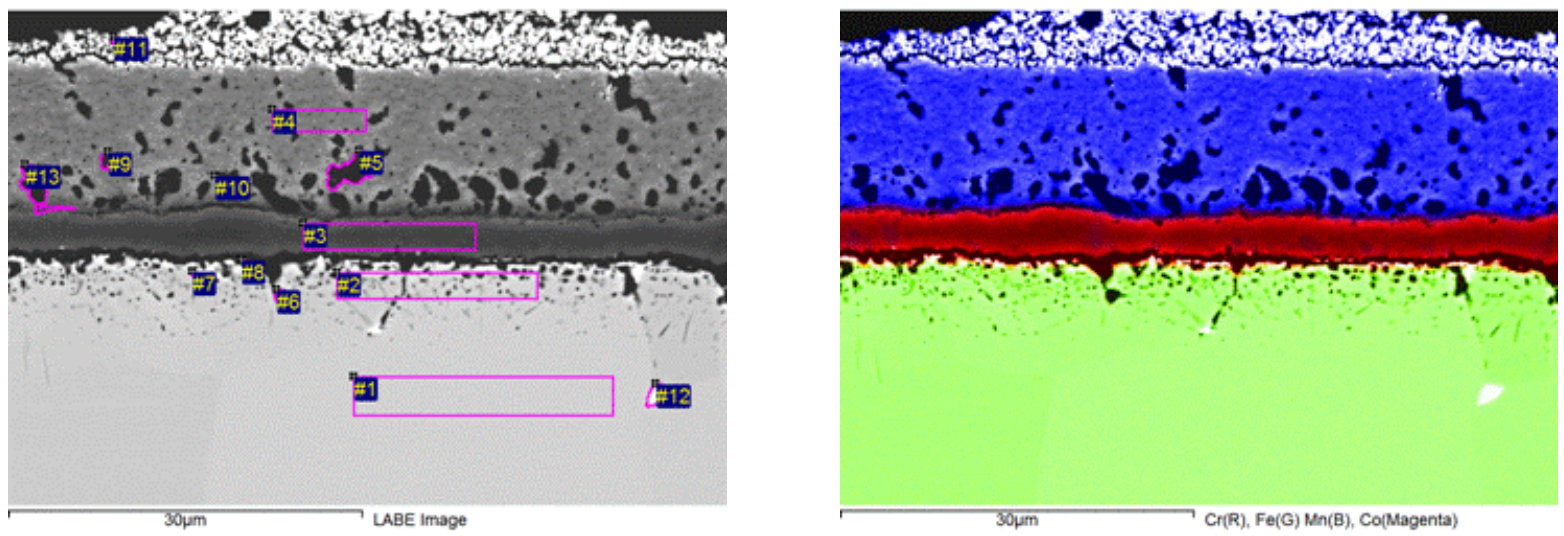

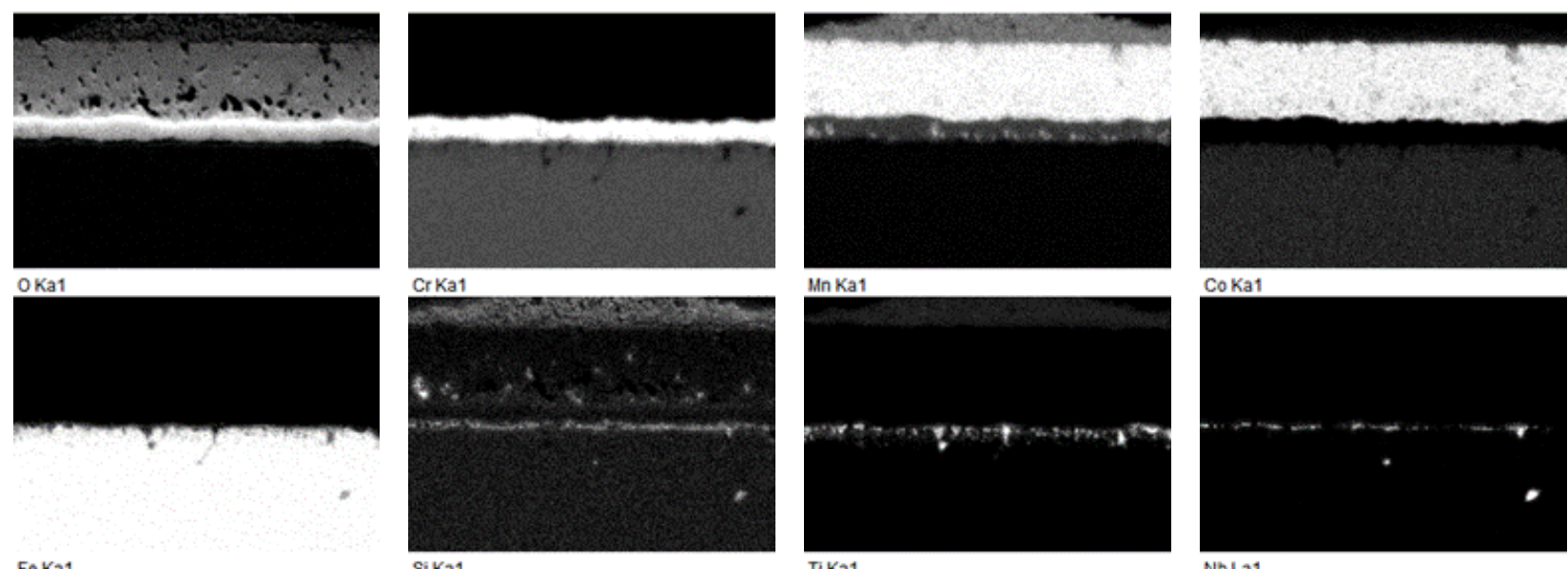

Si Ka1

TiKa1

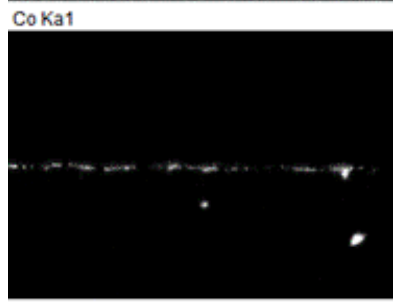

Figure A2. ATI $441 \mathrm{HP}^{\mathrm{TM}}$ alloy coupon following 3,000-hr ASR test at $800^{\circ} \mathrm{C}$

NoLa1
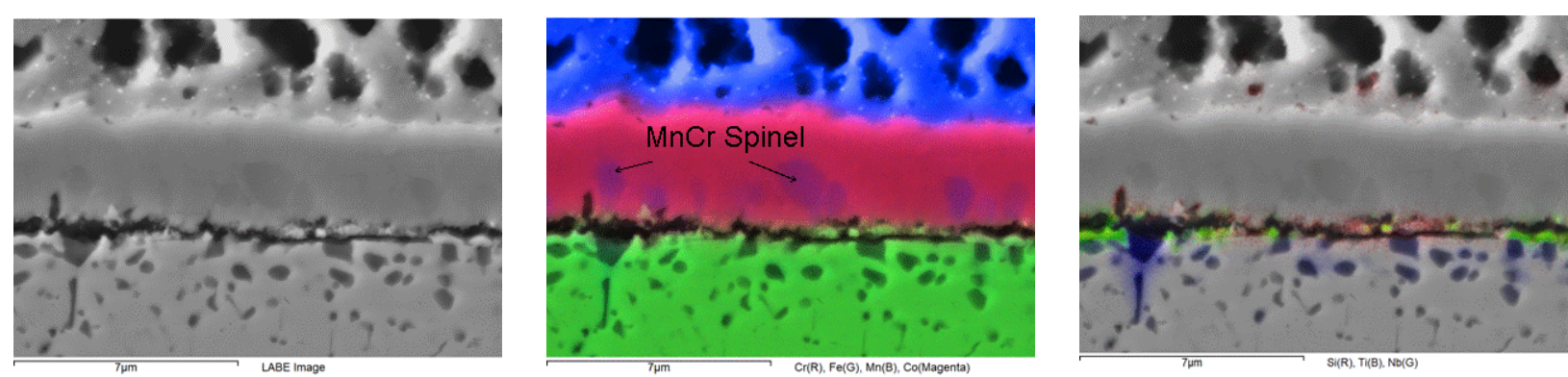

Figure A3. Manganese chromium spinel formed in the chromia scale on ATI 441HPTM alloy

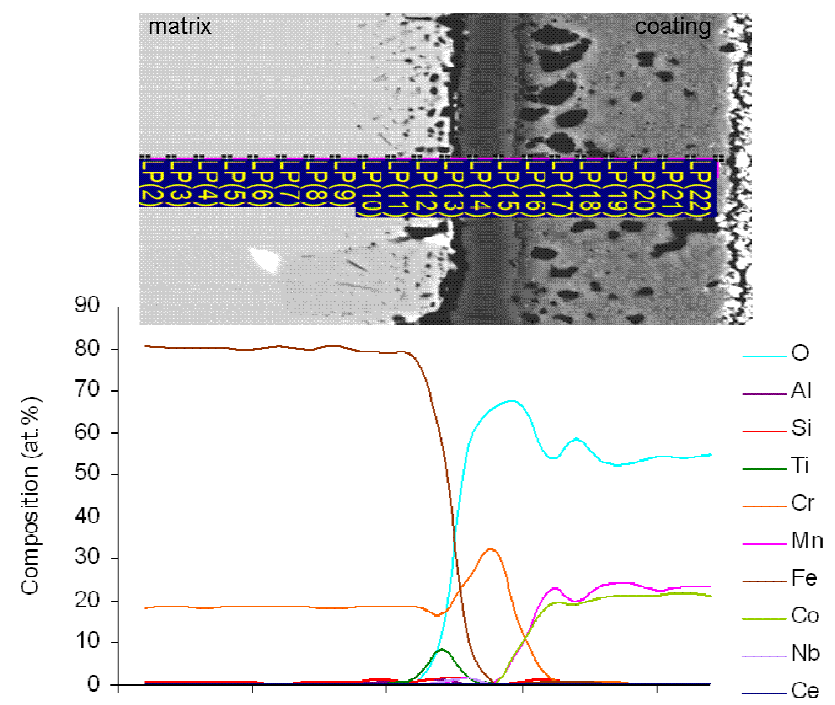

Figure A4. Line scan across the ATI 441HPTM alloy coupon crossing base metal, oxide, and coating 